This document is downloaded from DR-NTU (https://dr.ntu.edu.sg) Nanyang Technological University, Singapore.

Novel titanium dioxide nanocomposites and

nanostructures for high performance

dye-sensitized solar cells

He, Ziming

2014

https://hdl.handle.net/10356/59237

https://doi.org/10.32657/10356/59237 

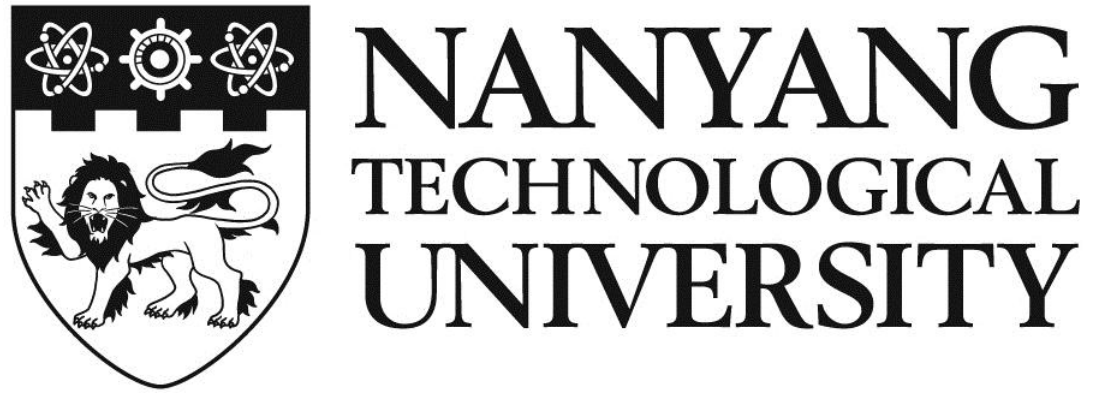

NOVEL TITANIUM DIOXIDE NANOCOMPOSITES AND NANOSTRUCTURES FOR HIGH PERFORMANCE DYE-SENSITIZED SOLAR CELLS

HE ZIMING

SCHOOL OF CHEMICAL AND BIOMEDICAL ENGINEERING 2014 


\section{Novel Titanium Dioxide Nanocomposites and Nanostructures for High Performance Dye-Sensitized Solar Cells}

School of Chemical and Biomedical Engineering

A thesis submitted to the Nanyang Technological University in fulfilment of the requirement for the degree of Doctor of Philosophy 


\section{Acknowledgement}

First, I would like to express my most sincere gratitude to my advisor, Professor Timothy Thatt Yang Tan, for his warm encouragement and patient instructions. Professor Tan has been advising, inspiring, and supporting me throughout my graduate studies. His trust and guidance have always kept me going and striving for excellence. The professional knowledge, technical writing skills and research experience learned from him are the greatest treasures to me, which will definitely benefit me in future research work and life.

Special thanks are extended to Professor Li Chang Ming and Dr Guai Guan Hong, for their valuable suggestions, inspiring discussions, kind support and enthusiastic assistance at my studies in dye-sensitized solar cell area.

I am also grateful to Professor Thuc-Quyen Nguyen, Dr Xuan-Dung Dang, $\mathrm{Mr}$ Hung Phan and all other members in Prof Nguyen's group, for their supportive collaboration, generous technique sharing and valuable suggestions during my research visiting in UCSB.

My acknowledgement will never be complete without the special mention of all the team members and friends in SCBE of NTU, especially Ms Liu Jing, for their intimate friendship and immeasurable support over the years.

Last, but not least, I would like to express my deepest gratitude to my parents for their love and dedication in raising me, supporting me, and educating me throughout my life. I consider myself the luckiest person in the world to have such a supportive family, which means the world to me. 


\section{Publications}

$\dagger$ denotes equal authorship.

1. ZM He, J Liu, JW Miao, B Liu, TTY Tan*, A one-pot solvothermal synthesis of hierarchical microspheres with radially assembled single-crystalline $\mathrm{TiO}_{2}$-nanorods for high performance dye-sensitized solar cells, Journal of Materials Chemistry C, 2014, 2, 1381. (Chapter 6)

2. ZM He ${ }^{\dagger}, \mathrm{H}$ Phan ${ }^{\dagger}$, J Liu, T-Q Nguyen*, TTY Tan*, Understanding $\mathrm{TiO}_{2}$ Size-Dependent Electron Transport Properties of a Graphene- $\mathrm{TiO}_{2}$ Photoanode in Dye-sensitized Solar Cell Using Conducting Atomic Force Microscopy, Advanced Materials, 2013, 25, 6900. (Chapter 5)

3. $\mathbf{Z M ~ H e}^{\dagger}$, J Liu${ }^{\dagger}$, Y Qiao, CM Li*, TTY Tan*, Architecture Engineering of Hierarchically Porous Chitosan/Vacuum-Stripped Graphene Scaffold as Bioanode for High Performance Microbial Fuel Cell, Nano Letters, 2012, 12, 4738.

4. ZM He, G Guai, J Liu, CX Guo, SCJ Loo, CM Li*, TTY Tan*, Nanostructure control of graphene-composited $\mathrm{TiO}_{2}$ by a one-step solvothermal approach for high performance dye-sensitized solar cells, Nanoscale, 2011, 3, 4613. (Chapter 4)

5. ZM He, QC Xu, TTY Tan*, Understanding bactericidal performance on ambient light activated $\mathrm{TiO}_{2}-\mathrm{InVO}_{4}$ nanostructured films, Nanoscale, 2011, 3, 4977.

6. J Liu, ZM He, JW Xue and TTY Tan*, “A metal-catalyst free, flexible and free-standing chitosan/vacuum-stripped graphene/polypyrrole three dimensional electrode interface for high performance dopamine sensing', Journal of Materials Chemistry B, 2014, 2, 2478. (An invited submission to 2014 Emerging Investigators Theme Issue)

7. SY Khoo, HB Yang, ZM He, JW Miao, KC Leong, CM Li, TTY Tan*, Enhanced Charge Extraction of Polymer Solar Cell by Solution-Processable Gold Nanoparticles, Journal of Materials Chemistry C, 2013, 1, 5402.

8. JD Lin, P Hu, Y Zhang, MT Fan, ZM He, CK Ngaw, JSC Loo, DW Liao, and TTY Tan*, Understanding the photoelectrochemical properties of a reduced graphene oxide- $\mathrm{WO}_{3}$ heterojunction photoanode for efficient solar-light-driven overall water splitting, $R S C$ Advances, 2013, 3, 9330.

9. QC Xu, Y Zhang, ZM He, SCJ Loo, TTY Tan*, An Efficient Visible and UV Light Activated B-N-codoped $\mathrm{TiO}_{2}$ Photocatalytic Film for Solar Depollution Prepared via a Green Method, Journal of Nanoparticle Research, 2012, 14, 1042.

10.Y Wang, KA Wang, C Guan, ZM He, ZS Lu, T Chen, J Liu, X Tan, CM Li*, TTY Tan, Surface functionalization-enhanced spillover effect on hydrogen storage of $\mathrm{Ni}-\mathrm{B}$ nanoalloy-doped activated carbon, International Journal of Hydrogen Energy, 2011, 36, 13663. 


\section{Table of contents}

Acknowledgement..........................................................................................................

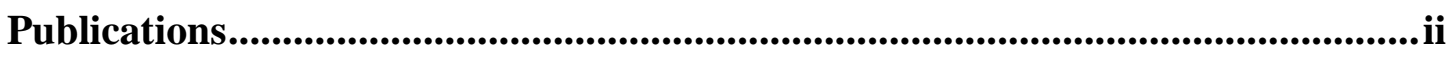

Table of contents...................................................................................................ii

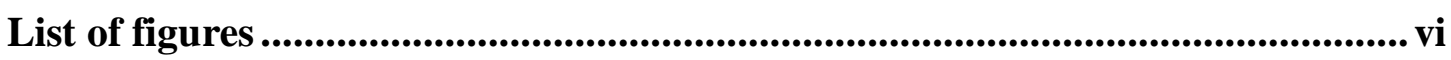

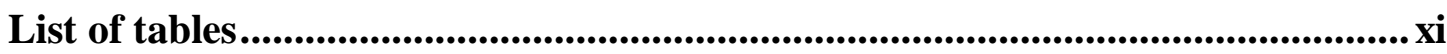

List of abbreviations .........................................................................................

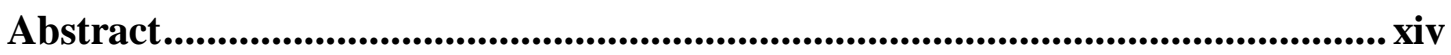

Chapter 1 Introduction .......................................................................................................... 1

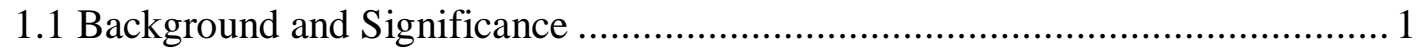

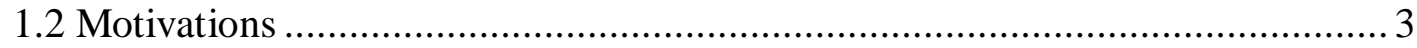

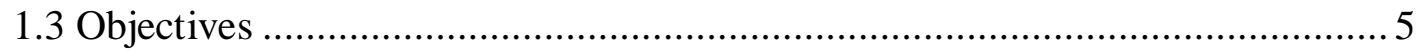

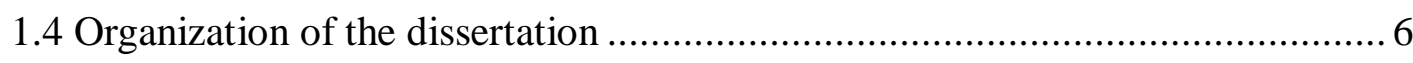

Chapter 2 Literature review ........................................................................................... 8

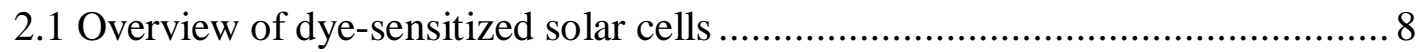

2.1.1 Configuration and working principle of the DSSCs .................................. 8

2.1.2 Electron transfer and recombination process............................................. 11

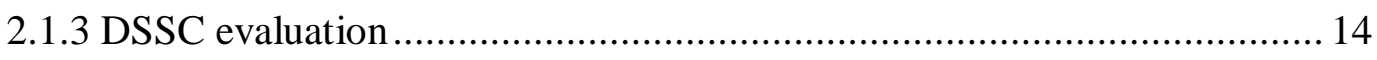

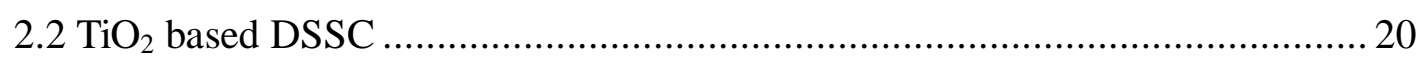

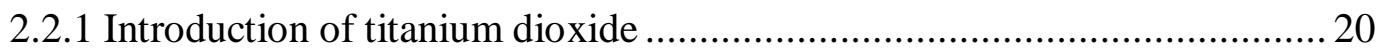

2.2.2 $\mathrm{TiO}_{2}$ and other metal oxides based electrodes ........................................... 21

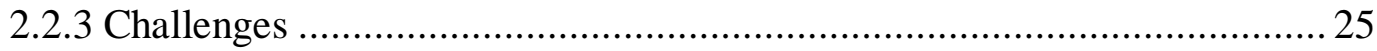

2.3 Techniques for photoanode optimization........................................................ 26

2.3.1 Incorporation of charge transport enhancer ............................................... 26

2.3.1.1 Conventional charge transport enhancer ............................................... 26

2.3.1.2 Graphene: a promising and efficient charge transport enhancer ........... 30 
2.3.2 Optimization of $\mathrm{TiO}_{2}$ nanostructures ................................................. 32

2.3.2.1 Conventional $\mathrm{TiO}_{2}$ nanostructures involved in DSSC ........................ 32

2.3.2.2 Hierarchical $\mathrm{TiO}_{2}$ microspheres: the multi-functional photoanode

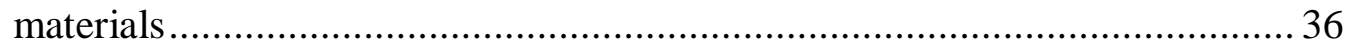

2.3.3 Surface modification of $\mathrm{TiO}_{2}$ electrodes .............................................. 39

2.3.4 Electronic structure modification of $\mathrm{TiO}_{2}$ nanocrystals ......................... 41

Chapter 3 Research Methodology ........................................................................43

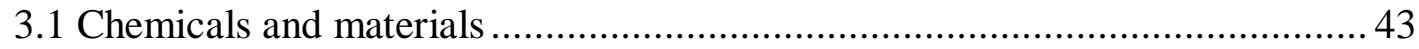

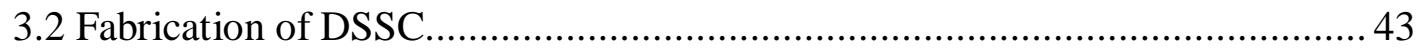

3.2.1 Preparation of screen-printing pastes ................................................... 43

3.2.2 Preparation of photoanode................................................................... 44

3.2.3 Preparation of platinized counter electrode as cathode ............................ 46

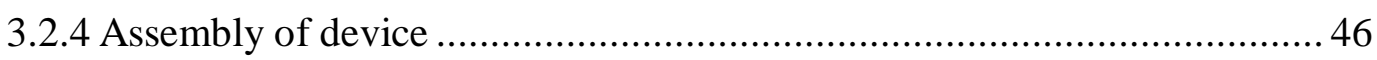

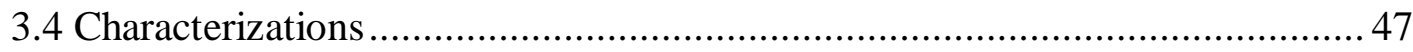

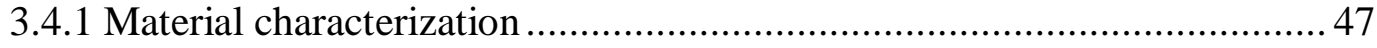

3.4.2 Conducting AFM characterization ........................................................ 48

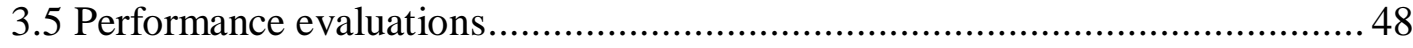

3.5.1 Photocurrent density-voltage $(\mathrm{J}-\mathrm{V})$ characteristics............................... 48

3.5.2 Incident photon-to-current conversion efficiency (IPCE) ........................ 48

3.5.3 Electrochemical impedance spectra (EIS)......................................... 49

Chapter 4 Nanostructure control of graphene-composited $\mathrm{TiO}_{2}$ by a one-step solvothermal approach for high performance dye-sensitized solar cells .............. 50

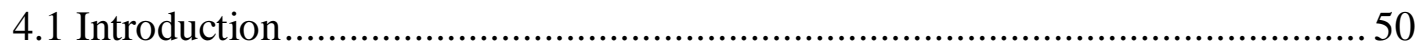

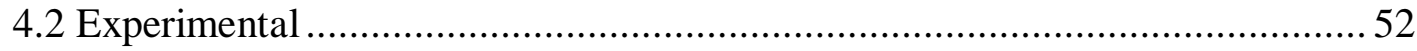

4.2.1 Synthesis of graphene oxide nanosheets ............................................... 52

4.2.2 Synthesis of graphene- $\mathrm{TiO}_{2}$ nanocomposites ........................................ 53

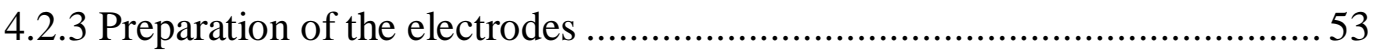

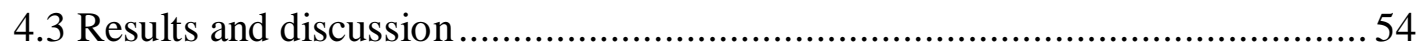

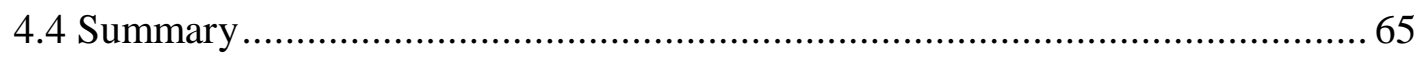

Chapter 5 Understanding $\mathrm{TiO}_{2}$ Size-Dependent Electron Transport Properties of a Graphene-TiO 2 Photoanode in Dye-sensitized Solar Cell Using Conducting 


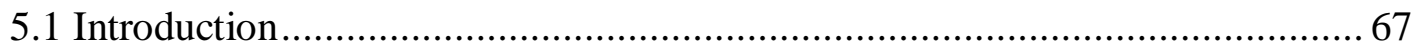

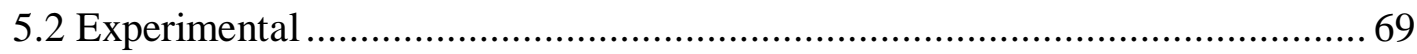

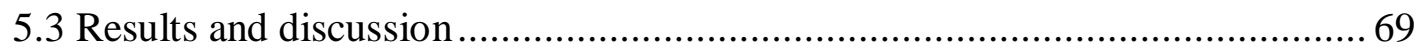

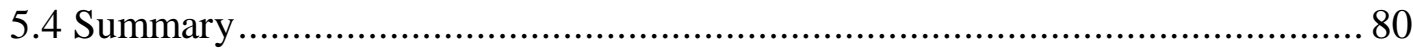

Chapter 6 A one-pot solvothermal synthetic strategy of hierarchical microspheres with radially assembled single-crystalline $\mathrm{TiO}_{2}$-nanorods as high performance photoanode materials in dye-sensitized solar cells ........................ 82

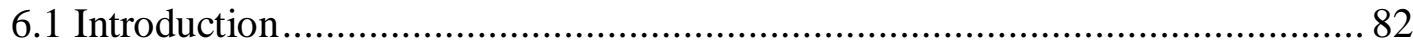

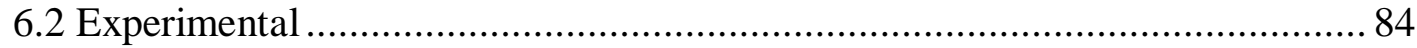

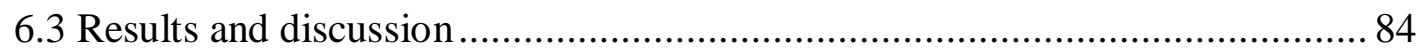

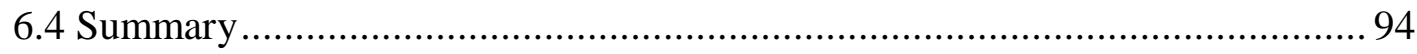

Chapter 7 General conclusions and recommendations for future research

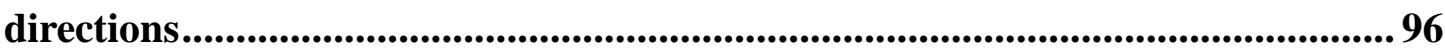

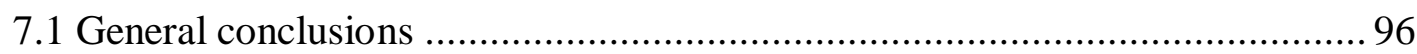

7.2 Recommendations for future research directions........................................ 98

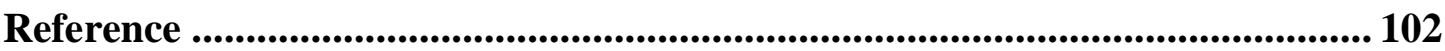




\section{List of figures}

Figure 2.1 A typical DSSC configuration. 8

Figure 2.2 Energy level of the components involved in a DSSC consisted of $\mathrm{TiO}_{2}$, N719 and iodide/triiodide redox system.

Figure 2.3 Pathways indicating favourable charge transfer (1-3) and unfavourable recombination (4-6) processes involved in the DSSCs (a), and typical time constants for the charge transfer process 1-6 (b) [44]. Copyright (2012) with permission from American Institute of Physics. 11

Figure 2.4 Photon flux of the AM 1.5 G spectrum at $1000 \mathrm{~W} \mathrm{~m}^{-2}$ (ASTM G173-03), and calculated accumulated photocurrent (dotted line) [36]. Copyright (2010) with permission from American Chemical Society. 14

Figure 2.5 A typical $J$-V curve of a solar cell under simulated sunlight (black line) and power output curve (red line) calculated based on the $J$-V curve. 15

Figure 2.6 A typical plot of IPCE as a function of the excitation wavelength for a nanocrystalline anatase film (the inset) sensitized by the surface-anchored ruthenium complex cis-RuL $2(\mathrm{SCN})_{2}$ [41]. Copyright (2001) with permission from Nature Publishing Group. 17

Figure 2.7 A typical Nyquist plot of a DSSC (bottom panel) and a corresponding equivalent circuit (top panel) [38]. Copyright (2009) with permission from John Wiley and Sons. 18

Figure 2.8 Diagrams for the photogenerated electrons transport route in plain $\mathrm{TiO}_{2}$ electrodes (a) and CNT-incorporated electrodes (b) [125]. Copyright (2012) with permission from American Chemical Society. 27

Figure 2.9 Schematic of VACNF arrays coated with anatase $\mathrm{TiO}_{2}$ nanoneedles for 
DSSCs (a), SEM image of the as-grown VACNF array (b), TEM image of an asgrown CNF (c), SEM image of the VACNF array coated with anatase $\mathrm{TiO}_{2}$ nanoneedles (d) and TEM image of a CNF coated with anatase $\mathrm{TiO}_{2}$ nanoneedles(e) [130]. Copyright (2009) with permission from American Chemical Society....

Figure 2.10 Mother of all graphitic forms [132]. Graphene is a 2D building material for carbon materials of all other dimensionalities. It can be wrapped up into 0D buckyballs, rolled into 1D nanotubes or stacked into 3D graphite. Copyright (2007) with permission from Nature Publishing Group.

Figure 2.11 Schematic illustration of the 2D graphene serving as electron bridge in a $\mathrm{TiO}_{2}$-based photoanode

Figure $2.12 \mathrm{TiO}_{2}$ nanotubes prepared with an anodization method and their application in DSCs: (a) morphology of the $\mathrm{TiO}_{2}$ nanotube array, (b) growth mechanism of the nanotubes and formation of a barrier layer under the nanotube film, (c) back-side illumination and (d) front-side illumination structures of the DSCs made of $\mathrm{TiO}_{2}$ nanotube array $[16,153]$. Copyright (2010) with permission from Elsevier and Copyright (2006) with permission from Elsevier.

Figure 2.13 FESEM images of oriented rutile $\mathrm{TiO}_{2}$ nanorod array grown on FTO substrate in $30 \mathrm{ml}$ of deionized water, $30 \mathrm{ml}$ of hydrochloric acid, and $1 \mathrm{ml}$ of titanium butoxide at $150{ }^{\circ} \mathrm{C}$ for $20 \mathrm{~h}$ : (a) top view, (b) cross-sectional view, (c) and (d) tilted cross-sectional views [152]. Copyright (2009) with permission from American Chemical Society. 35

Figure 2.14 Schematic of the DSSC with a scattering layer consisting of $\mathrm{TiO}_{2}$ particles prepared by the sol-gel method [170]. Copyright (2011) with permission from Elsevier. 37

Figure 2.15 Nanoporous $\mathrm{TiO}_{2}$ spheres for application in DSCs: (a) SEM and (b) TEM images of nanoporous $\mathrm{TiO}_{2}$ spheres, and (c) schematic diagram showing the 
electrolyte diffusion through the external (A) and internal (B) pores in the film made of nanoporous $\mathrm{TiO}_{2}$ spheres [180]. Copyright (2011) with permission from John Wiley and Sons. 38

Figure 3.1 Fabrication scheme of the screen-printing pastes. 44

Figure 3.2 Photographs of a cleaned FTO substrate (a), FTO substrate with patterned 3M tape (b), FTO substrate with the tape and loaded paste (c), FTO substrate with the tape and paste film flatten using a razor blade (d) and FTO substrate with paste film

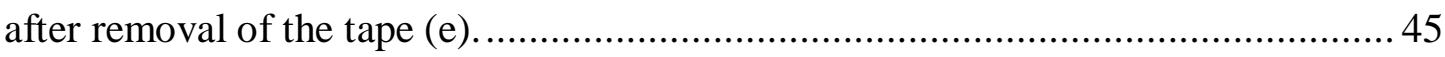

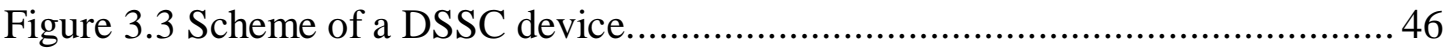

Figure 4.1 The procedure of the one-step solvothermal approach......................... 54

Figure 4.2 The TEM images of (a) STG, (b) NRTG, (c) USTG at high magnification and (d) USTG at low magnification. The insets of (a) and (b) are the TEM images of two composites at low magnification. The inset of (d) is the HRTEM image of USTG. 55

Figure 4.3 AFM image of a GO nanosheet with a height profile taken along the straight line. 56

Figure 4.4 XRD patterns of three composites (a) and Raman spectra of three composites and GO (b) 57

Figure 4.5 SEM images of electrodes prepared using (a) STG-Ctr, (b) USTG-Ctr, (c) NRTG-Ctr, (d) STG, (e) USTG and (f) NRTG. The insets are the cross sectional SEM images of corresponding electrodes. 58

Figure 4.6 J-V characteristics of DSSCs with different electrodes prepared using (a) STG and STG-Ctr, (b) USTG and USTG-Ctr, and (c) NRTG and NRTG-Ctr, during the optimizations. 60 
Figure 4.7 J-V characteristics of the four cells with different electrodes. 61

Figure 4.8 Plots of [F(Rhv] ${ }^{1 / 2}$ vs. hv of the four nanocomposites calculated based their DRS results. 62

Figure 4.9 IPCE spectra of the four cells with different electrodes. 62

Figure 4.10 Nyquist plots of the four cells with different electrodes. The inset is the equivalent circuit of the devices. 64

Figure 4.11 Bode plots of the four cells with different electrodes. 65

Figure 5.1 TEM images of S1 (a, d, g), S2 (b, e, h) and S3 (c, f, i) at different magnification. The white circles in $\mathrm{g}$, $\mathrm{h}$ and i represent the $\mathrm{TiO}_{2}$ nanoparticles loaded on graphene nanosheets. 70

Figure 5.2 SEM images of S1 (a), S2 (b) and S3 (c) ........................................ 71

Figure 5.3 XRD patterns of S1 (a), S2 (b) and S3 (c)......................................... 71

Figure $5.4 \mathrm{~J}$ - $V$ characteristics (a) and IPCE spectra (b) of the three devices.............. 72

Figure 5.5 Nyquist plots (a) and Bode plots (b) of the three devices. 74

Figure 5.6 The equivalent circuit of the DSSC devices based on the Nyquist plots. $\mathrm{R}_{\mathrm{ct} 2}$ are fitted to be 18.7, 12.6 and 10.3 ohm for S1, S2 and S3, respectively. 74

Figure 5.7 C-AFM dark current images of the composite electrodes based on S1 (a), S2 (b) and S3 (c). The scan size is $400 \mathrm{~nm} \times 400 \mathrm{~nm}$ and the bias is5 V applied to FTO substrate. Trend comparison between c-AFM average current of the three composite electrodes (dotted line) and $J_{\mathrm{sc}}$ of the three bulk devices (dashed line) (d). 76

Figure 5.8 Topography (a, b, c) and dark current images (d, e, f) of the electrodes based on S1 (a, d), S2 (b, e) and S3 (c, f). The scan size is $4 \times 4 \mu \mathrm{m}$ and the bias is -5 
Figure 5.10 Tafel plots (a) and log I vs. log V plots (b) based on the I-V curves of the three electrodes. Black dotted lines in (b) are the fittings to SCLC model. 79

Figure 5.11 EDX results of S1 (a), S2 (b) and S3 (c) based electrodes and TGA results of graphene (d) and the polymers used in paste preparation. ${ }^{\ddagger}$ 79

Figure 5.12 EDX results of S1 (a), S2 (b) and S3 (c) based electrodes and TGA results of graphene (d) and the polymers used in paste preparation. ${ }^{\ddagger}$ 80

Figure 6.1 TEM (a, b), HRTEM (c) images and SAED pattern (d) of T150. 85

Figure 6.2 SEM image (a) and particle size distribution diagram (b) of T150. Inset of (a) is a magnification image and the scale bar is $100 \mathrm{~nm}$. 86

Figure 6.3 The procedure of the facile solvothermal approach. 87

Figure 6.4 TEM images (a) and SEM images (b) of T110 (a1, b1), T130 (a2, b2), T150 (a3, b3), T170 (a4, b4) and T190 (a5, b5). The scale bars in (a) and the insets of (a) are $20 \mathrm{~nm}$ and $0.2 \mu \mathrm{m}$, respectively. .88

Figure 6.5 XRD patterns of the five microspheres and P25 powders. .89

Figure 6.6 UV-Vis DRS of the five microspheres and P25 powders. 90

Figure 6.7 J-V characteristics of the six devices with different anodes. 91

Figure 6.8 IPCE (a) and Nyquist plots (b) of the devices based on T150 and P25..... 92 Figure 6.9 SEM images of the electrode films prepared using T150 (a), P25 (b) and a mixture of weight ratio of T150 and P25 at 80:20 (c) and 60:40 (d). 93 


\section{List of tables}

Table 4.1 Parameters for solar cells based on the different electrodes. 60

Table 4.2 Specific surface area and pore volume of different electrode films 60

Table 4.3 Parameters of equivalent circuits fitted from EIS measurement of four cells 64

Table 5.1 Performance parameters of the three bulk devices 72

Table 5.2 Dye loading and BET results of the three electrodes. 73

Table 6.1 Morphology parameters of the hierarchical microspheres and P25. 89

Table 6.2 Performance parameters of the microspheres and P25 based devices 91

Table 6.3 Performance parameters of the T150:P25 (60:40 wt ratio) composite devices 94 


\section{List of abbreviations}

\section{Chemical Names}

\begin{tabular}{|l|l|}
\hline $\mathrm{AcOH}$ & Acetic acid \\
\hline $\mathrm{BzOH}$ & Benzyl alcohol \\
\hline $\mathrm{Cl}^{-}$ & Chloride ion \\
\hline $\mathrm{EtOH}$ & Hydrochloric acid \\
\hline $\mathrm{HCl}$ & Sulfuric acid \\
\hline $\mathrm{H}_{2} \mathrm{SO}_{4}$ & Hydrogen peroxide \\
\hline $\mathrm{H}_{2} \mathrm{O}_{2}$ & Iodide ion \\
\hline $\mathrm{I}^{-}$ & Triiodide ion \\
\hline $\mathrm{I}_{3}{ }^{-}$ & Potassium permanganate \\
\hline $\mathrm{KMnO}_{4}$ & Potassium peroxodisulfate \\
\hline $\mathrm{K}_{2} \mathrm{~S}_{2} \mathrm{O}_{8}$ & Sodium ion \\
\hline $\mathrm{Na}^{+}$ & Platinum \\
\hline $\mathrm{Pt}^{+}$ & Phosphorus pentoxide \\
\hline $\mathrm{P}_{2} \mathrm{O}_{5}$ & Titanium(III) chloride \\
\hline $\mathrm{TiCl}_{3}$ & Titanium tetrachloride \\
\hline $\mathrm{TiCl}_{4}$ & Titanium dioxide \\
\hline $\mathrm{TiO}_{2}$ & Titanium isopropoxide \\
\hline $\mathrm{TIP}$ & \\
\hline
\end{tabular}

\section{Physical Variables}

\begin{tabular}{|l|l|}
\hline FF & Fill factor \\
\hline IPCE & Incident photon-to-electron conversion efficiency \\
\hline$J$ & Current density \\
\hline $\mathrm{P}$ & Pressure \\
\hline $\mathrm{R}$ & Reflectance \\
\hline $\mathrm{V}$ & Voltage \\
\hline $\mathrm{Z}$ & Impedance \\
\hline$\lambda$ & Wavelength \\
\hline$\eta$ & Power conversion efficiency \\
\hline
\end{tabular}




\section{Abbreviations}

\begin{tabular}{|l|l|}
\hline AFM & Atomic force microscopy \\
\hline AM & Air mass \\
\hline CB & Conduction band \\
\hline CV & Cyclic voltammetry \\
\hline C-AFM & Conducting-atomic force microscopy \\
\hline DRS & Diffuse reflectance spectra \\
\hline DSSC & Dye-sensitized solar cell \\
\hline EIS & Electrochemical impedance spectra \\
\hline FESEM & Field emission scanning electron microscope \\
\hline FTO & Fluorine-doped tin oxide \\
\hline HOMO & Highest occupied molecular orbital \\
\hline HRTEM & High resolution transmission electron microscopy \\
\hline LUMO & Lowest unoccupied molecular orbital \\
\hline PCE & Power conversion efficiency \\
\hline NHE & Normal hydrogen electrode \\
\hline TCO & Transparent conducting oxide \\
\hline VB & Valence band \\
\hline XRD & X-ray diffraction \\
\hline 1D & One dimensional \\
\hline 2D & Two dimensional \\
\hline 3D & Three dimensional \\
\hline
\end{tabular}




\begin{abstract}
Dye-sensitized solar cell (DSSC) has become one of the most promising alternatives to conventional Si-based photovoltaic devices, due to its low-cost, relatively high efficiency, easy fabrication process and light weight. Titanium dioxide $\left(\mathrm{TiO}_{2}\right)$ is a widely used photoanode material with high stability, low toxicity and suitable electronic structure for DSSC. Most breakthroughs in power conversion efficiency (PCE) of the DSSCs are based on $\mathrm{TiO}_{2}$-photoanodes. To date, the PCE of nanocrystalline $\mathrm{TiO}_{2}$-based DSSC has reached $12.3 \%$ at $\mathrm{AM} 1.5 \mathrm{G}$ full sun $(13.1 \%$ at 50.9\% sun). However, further improvements in cell performance and stability are still necessary to deliver commercial viability of DSSC modules. Some unresolved issues in DSSC including the use of corrosive redox couple (i.e. $\mathrm{I}^{-} / \mathrm{I}_{3}{ }^{-}$) and limited film thickness of the photoanodes are attributed to the relatively slow electron transport in the mesoporous $\mathrm{TiO}_{2}$ anode films, which hinder the PCE improvement, stability and scale up of the DSSCs. Therefore, a major challenge in commercialization of the nanocrystalline $\mathrm{TiO}_{2}$-based DSSC is enhancing electron transport across the $\mathrm{TiO}_{2}$ matrix to further improve its efficiency and stability.

The major contribution of this dissertation is the innovation of new $\mathrm{TiO}_{2}$-based nanocomposites and nanostructures which show significantly enhanced PCE of DSSC, and the interrogation and fundamental understanding of the mechanisms which contribute towards the enhancement.
\end{abstract}

To improve electron transport property of the anode films, graphene was incorporated into the $\mathrm{TiO}_{2}$-based photoanodes. We developed a one-step solvothermal 
approach to synthesize uniform graphene- $\mathrm{TiO}_{2}$ composites with three different $\mathrm{TiO}_{2}$ nanostructures, including ultra-small $2 \mathrm{~nm}$ nanoparticles (labelled as USTG), $12 \mathrm{~nm}$ nanoparticles (STG) and nanorods (NRTG), controlled by simply adjusting the solvothermal reaction conditions. Using the three composites as photoanode materials, the effect of nanostructure of graphene-composited $\mathrm{TiO}_{2}$ on the performance of dyesensitized solar cells was investigated. The photoanode based on ultra-small $2 \mathrm{~nm}$ $\mathrm{TiO}_{2}$-graphene composite exhibits the highest efficiency, which is attributed to the synergistic effects of the high specific surface area produced from the ultra-small $\mathrm{TiO}_{2}$-formed porous structure and efficient electron transport in the incorporated graphene with the compact $\mathrm{TiO}_{2}$ particles as electron leakage barrier.

From the comparison between the USTG and STG based DSSCs of the abovementioned work, a size effect of graphene-composited $\mathrm{TiO}_{2}$ on the DSSC performance was observed. The anode based on smaller-sized composite $\mathrm{TiO}_{2}$ gave a higher PCE, with a higher photocurrent density and lower electron transfer resistance. The mechanism of this phenomenon remained unclear from bulk device measurements. To understand the nanoscale electronic properties of the graphene$\mathrm{TiO}_{2}$ films and reveal the size effect mechanism, conducting atomic force microscopy (c-AFM) was applied for nanoscale characterization of DSSC photoanodes. This is the first demonstration of applying c-AFM for DSSC studies. Three graphene- $\mathrm{TiO}_{2}$ composites with different $\mathrm{TiO}_{2}$ particle size were prepared using the one-step solvothermal approach and utilized to prepare the electrode films, of which the nanoscale electronic properties were measured and ultimately correlated to the bulk 
device performance, revealing a size-dependent electron transport property of the graphene- $\mathrm{TiO}_{2}$ composite photoanodes. The short-circuit current density and fill factor of the devices are improved as $\mathrm{TiO}_{2}$ particle size decreases, which is attributed to a more continuous electron transfer network and higher electron mobility of the smaller-sized $\mathrm{TiO}_{2}$ based electrode. The continuous conduction network, from the more flexible smaller-sized $\mathrm{TiO}_{2}$-graphene nanosheets, reduces the internal resistance at $\mathrm{TiO}_{2} / \mathrm{TiO}_{2}$ and $\mathrm{TiO}_{2} / \mathrm{FTO}$ interfaces. The high electron mobility, due to the continuous conduction network renders electron transfer fast and efficient.

To integrate the features of large specific surface area, strong scattering and efficient electron transport into a single photoanode, hierarchical microspheres constructed with single crystal rutile $\mathrm{TiO}_{2}$ nanorods as multi-functional photoanode materials were designed and synthesized by combining an acid thermal crystallization and a self-assembly process of the nanorods via a solvothermal amphiphile-water microreactor strategy. The morphological evolution and crystallinity of the hierarchical microspheres are reaction temperature dependent. A great improvement (20\%) in PCE for microsphere-based device was achieved compared to P25 reference cell, which is attributed to the synergistic effects of the large specific surface area, enhanced scattering effect, and efficient electron transport property of the microspheres. Using conventional P25 nanoparticles as a void filler, the microspherebased photoanode exhibits a maximum PCE of 7.95\% at an anode film thickness of $27.2 \mu \mathrm{m}$. 
In summary, this thesis dissertation, which reports interdisciplinary research works involving the design and synthesis of novel $\mathrm{TiO}_{2}$ nanocomposites and nanostructures as high performance photoanode materials and their fundamental studies, has contributed to further PCE enhancement of DSSC, and revealed the mechanisms of the novel anode materials in DSSC performance improvement. 


\section{Chapter 1 Introduction}

\subsection{Background and Significance}

The growing worldwide demand for energy has accelerated the depletion of the fossil fuels reserves and brought on a critical global issue: energy crisis [1, 2]. The exhaust from the combustion of fossil fuels has been implicated in climate change and environmental pollution [2, 3]. Extensive research on alternative clean energy sources has been carried out for the sustained economic growth and global environment conservation. The worldwide energy consumption was $3.73 \times 10^{20}$ Joules in 1990 and will double in the year of 2035, according to an assessment by U.S. Energy Information Administration [4]. However, the production energy from fossil fuels reserves will soon not be able to keep up with the growing energy demand [5-7]. Therefore, sustainable and renewable energy, such as wind power, geothermal energy, hydroelectricity, biofuels, and especially solar energy have attracted much attention [8-12]. Among all these renewable energies, solar energy exhibits many advantages and great potential as an inexhaustible power generation source for the next few million years [13]. The solar flux striking the earth is estimated to be $3.8 \times 10^{24}$ Joules per year, 10,000 times more than the average global energy consumption [14], which means that the energy conversed from $0.1 \sim 0.2 \%$ of the sunlight on the earth surface with a conversion efficiency of $10 \%$ will be sufficient to satisfy the current needs and completely replace the fossil fuels $[15,16]$. The solar energy conversion into electricity relies on photovoltaic devices, commonly known as solar cells, which have 
undergone three generations, including first generation crystalline silicon based photovoltaic devices [16], second generation thin-film cells [17-19], and the representative dye-sensitized solar cells (DSSCs) and organic photovoltaics (OPVs) as the third generation [20, 21]. Although the silicon based modules exhibit a conversion efficiency of $15 \sim 20 \%$ at a reduced cost of $1.25 \$ \mathrm{~W}^{-1}$ and dominate the current photovoltaic market [13, 22], its comparatively complex production process and high materials cost make them uncompetitive in price to fossil fuels and therefore hinder their wide applications [1, 2]. For thin-film technologies, CdTe modules have achieved efficiencies of $10 \sim 12.5 \%$ at cost of $0.70 \$ W^{-1}$ and module efficiency of $14 \%$ at cost of $0.50 \$ \mathrm{~W}^{-1}$ can be expected. Copper indium gallium selenide (CIGS) modules are now commercially available, with conversion efficiencies of $12 \sim 15 \%$ at cost less than $0.50 \$ \mathrm{~W}^{-1}$. However, scarcity of telluride, long-term toxic effects of cadmium, CIGS film uniformity challenge on large substrates and very poisoning $\mathrm{H}_{2}$ Se gas used in industrial production of CIGS film hinder the application of the thin film solar cells [23-25].

The third generation solar cells are the most promising low-cost alternatives to the conventional Si-based photovoltaic devices [23, 26, 27]. Compared to OPVs, DSSCs have some obvious advantages, including higher power conversion efficiency (PCE), better stability, longer life time, and more moderate manufacturing conditions [28]. Commercial interest in DSSCs is triggered by the breakthrough discovery that nanocrystalline $\mathrm{TiO}_{2}$-based mesoporous film sensitized by $\mathrm{N} 3$ dye is capable of delivering a significant PCE of 7 8 \%, reported by O’regan and Grätzel in 1991 [29]. 
Since then, much efforts have been devoted into this simple and low-cost technology and promoted the PCE of the DSSC to $12.3 \%$ in laboratories and $~ 6.8 \%$ as large size modules (aperture area $\geq 100 \mathrm{~cm}^{2}$ ) [30-33], which may meet the requirements of most practical applications. Other main attractions of DSSCs are:

- Good performance under non-standard conditions of any atmospheric condition, solar incidence angle and low irradiance;

- Availability of environment friendly raw materials;

- High tolerance towards impurities and normal fabrication environments;

- High price-performance ratio (10\%-efficient DSSC modules priced at $0.20 \sim 0.30 \$ \mathrm{~W}^{-1}$ can be expected);

- Applicability on flexible substrates;

- Light weight,

- Wide design opportunities due to high transparency and multi-color options.

\subsection{Motivations}

The utilization of nanocrystalline semiconductor as the support matrix has significantly increased the specific surface area of the photoanode films for increased dye adsorption, which improves the light harvesting efficiency, thus enhancing the DSSC performance [29]. However, numerous grain boundaries within the nanocrystalline films interfere with electron transport, which makes electron diffusion coefficient of the nanocrystalline $\mathrm{TiO}_{2}$ film $\left(\sim 5 \times 10^{-5} \mathrm{~cm}^{2} \mathrm{~s}^{-1}\right)$ more than two orders of magnitude smaller than that of the bulk material [34]. The charge transport in the 
semiconducting metal oxide-based electrode films (in millisecond domain) is much slower than the dye regeneration (microsecond domain) and the electron injection from the dye to the conduction band of the semiconductor (femtosecond domain), which makes the electron transport a limiting step of the charge transfer processes of the DSSCs. As the charge transport is quite slow (average transit time is 10 ms through a $\sim 10 \mu \mathrm{m}$ thick nanocrystalline film), and over its entire path, the electrons are within a few nanometers of the oxidized redox species, it is crucial that the recombination of the injected electrons with the oxidized redox species is extremely slow, which is achieved by using the conventional $\mathrm{I}^{-} / \mathrm{I}_{3}{ }^{-}$redox couple and thus $\sim 100 \%$ of charge collection efficiency can be obtained in a $\sim 10 \mu$ m thick nanocrystalline $\mathrm{TiO}_{2}$ photoanode. However, the use of volatile and corrosive $\mathrm{I}^{-} / \mathrm{I}_{3}{ }^{-}$redox couple seriously hinders the scale up and stability of the DSSCs for practical applications and requires expensive catalyst such as Pt to ensure the efficient reduction of $\mathrm{I}_{3}^{-}$at the counter electrode [35-37]. On the other hand, the $~ 100 \%$ of charge collection efficiency can only be achieved by the DSSC photoanode with a film thickness less than its electron diffusion length $\left(L_{\mathrm{n}}\right)$. For nanoparticle based DSSCs, the $L_{\mathrm{n}}$ is usually $10 \sim 14 \mu \mathrm{m}$, thus their optimal film thickness is around ten several micrometers. Simply increasing the thickness of the nanoparticle films has been proven to be unsuccessful for PCE improvement [16]. Although over 12\% conversion efficiency has been obtained from DSSCs technology in the laboratories, further improvements in cell performance and stability are still necessary to ensure at least 6\% PCE from DSSC commercial products with a lifetime of 20 years [32]. Therefore, a major challenge for the 
commercialization of nanocrystalline DSSCs is the efficient electron transport across the photoanode films to increase the electron diffusion length for increased optimal film thickness and then the increased dye loading and PCE, and to enable the use of novel redox couples which is better for DSSC scale up and stability but may be kinetically much faster in charge recombination than $\mathrm{\Gamma}_{/} \mathrm{I}_{3}{ }^{-}$.

The motivation of this $\mathrm{PhD}$ project is to enhance the photocurrent generation and electron transport in the anode films by optimizing the photoanode materials through the design and synthesis of novel nanocomposites and nanostructures of the semiconducting metal oxide, and to understand the fundamental mechanisms of the material formation and DSSC performance improvement.

\subsection{Objectives}

The overall objectives of this $\mathrm{PhD}$ project are the design, synthesis, tailoring, and characterization of novel nanocomposites and nanostructures of the semiconducting metal oxide as high performance photoanode materials, and to undertake fundamental understanding of their roles in DSSC performance improvement.

Specific goals are:

(a) Design and preparation of novel nanocomposites with controlled semiconducting metal oxide nanostructures for high performance DSSCs.

To improve dye loading and electron transport property of the anode films, novel nanocomposites of semiconducting metal oxide is designed and prepared by incorporating graphene as the charge transport enhancer with high specific surface 
area and electron mobility as the support material and electron bridge in the photoanodes. The nanostructure of semiconducting metal oxide is delicately controlled to reveal its effect on DSSC performance improvement.

(b) Nanoscale characterization of the photoanode films for further understanding the mechanism of DSSC performance improvement

To understand a size effect of the composite semiconducting metal oxide on DSSC performance improvement, conducting atomic force microscopy is applied to DSSC characterization in nanoscale for the first time. The understanding of the performance improvement mechanism can provide a direction for the design of high efficiency composite anode materials.

(c) A facile synthesis of multi-functional photoanode materials for DSSC performance improvement

To integrate the features of large specific surface area, strong scattering and efficient electron transport into a single photoanode, a three dimensional (3D) $\mathrm{TiO}_{2}$ hierarchical structure is synthesized through a one-pot solvothermal approach and utilized as multi-functional photoanode materials. The synthesis mechanism is also investigated to enable the application of this approach in the preparation of other metal oxide 3D nanostructures.

\subsection{Organization of the dissertation}

This dissertation is organized as follows:

Chapter 1 briefly introduces the background and significance of the solar cell 
technology, in particularly DSSC technology, and gives an overall motivations and objectives of this $\mathrm{PhD}$ research project.

Chapter 2 introduces the work principle, configuration and evaluation parameters of the DSSCs, and reviews the research works related in the techniques for improving the performance of DSSCs, especially $\mathrm{TiO}_{2}$-based DSSCs.

Chapter 3 describes the detailed experimental procedures for the fabrication of photoanodes and the DSSC devices, and introduces the materials and equipments used in the synthesis, characterization and evaluation of the photoanode materials and the DSSC devices.

Chapter 4 presents a one-step solvothermal approach to prepare uniform graphene- $\mathrm{TiO}_{2}$ nanocomposites with delicately controlled $\mathrm{TiO}_{2}$ nanostructures for high performance DSSCs, and investigates the effect of nanostructure of graphenecomposited $\mathrm{TiO}_{2}$ on the DSSC performance.

Chapter 5 reveals a $\mathrm{TiO}_{2}$ size-dependent electron transport property of the graphene- $\mathrm{TiO}_{2}$ photoanodes in DSSCs through c-AFM nanoscale characterization and correlate with bulk studies.

Chapter 6 introduces a simple solvothermal approach to prepare hierarchical $\mathrm{TiO}_{2}$ microspheres consisting of single-crystal rutile $\mathrm{TiO}_{2}$ nanorods as multi-functional photoanode materials, and proposes a formation mechanism for this surfactant-free synthesis.

Chapter 7 provides a general conclusion and recommendation of directions for future research. 


\section{Chapter 2 Literature review}

\subsection{Overview of dye-sensitized solar cells}

The development of sustainable alternatives to conventional fossil fuels-based power generation techniques is extremely important for the sustained economic growth and global environment conservation. Photovoltaic devices are capable of directly converting solar energy to electricity, which offers a potential solution to the energy crisis [1]. However, the wide application of Si-based photovoltaic devices in daily life is hindered by complex manufacturing process and high cost of materials [1, 2]. Therefore, there are growing interests on dye-sensitized solar cell (DSSC) as a promising alternative to the silicon-based photovoltaics, mainly due to its low cost, relative high efficiency and easy fabrication process [13, 38, 39].

\subsubsection{Configuration and working principle of the DSSCs}

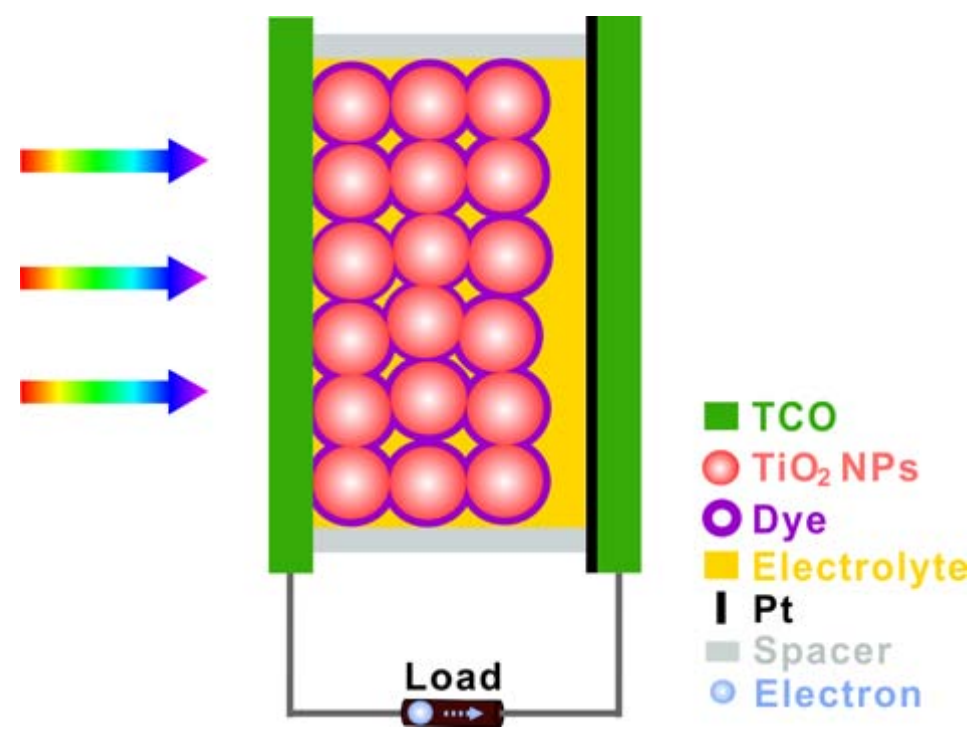

Figure 2.1 A typical DSSC configuration. 
A typical DSSC configuration is shown in Figure 2.1. At the heart of the DSSC system is a mesoporous semiconducting metal oxide (usually $\mathrm{TiO}_{2}$ ) film with a monolayer of the "light-sensitizing" dye molecules attached on the nanocrystalline surface, which is deposited on a transparent conducting oxide (TCO) substrate, serving as photoanode to harvest solar energy. The film is immersed in a redox-active electrolyte, which connects a platinum-coated TCO substrate as the counter electrode, also known as cathode. The mesoporous film should exhibit larger specific surface area for sufficient dye adsorption to achieve efficient light harvesting.

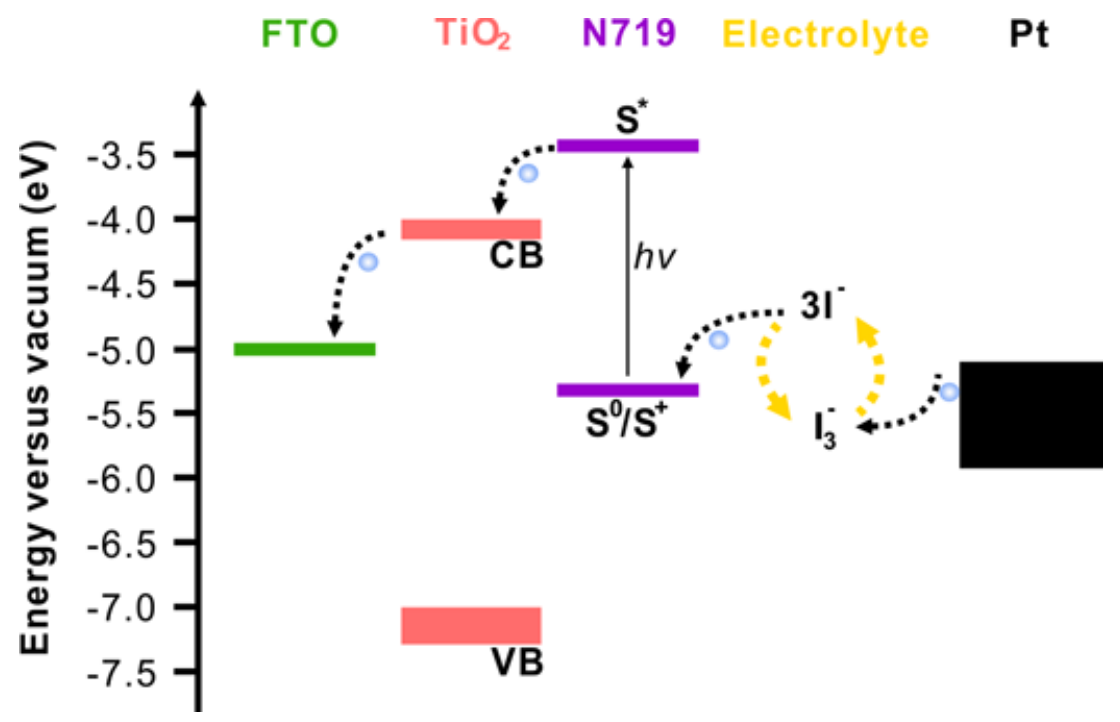

Figure 2.2 Energy level of the components involved in a DSSC consisted of $\mathrm{TiO}_{2}$, N719 and iodide/triiodide redox system.

In a classical Si-based photovoltaic cell, crystalline silicon functions as both the light harvesting material and charge transfer material, which makes the device sensitive to trace impurities as recombination centers [13, 40]. Being different from the working mechanism of silicon $p-n$ junction cells, the light harvesting and electron transfer processes in DSSC are separately accomplished by the sensitizer and 
mesoporous $\mathrm{TiO}_{2}$ film respectively. The working principle of the DSSCs can be described based on the energy level diagram of a $\mathrm{TiO}_{2}$-based DSSC with N719 dye as the sensitizer and iodide/triiodide couple as the redox system as shown in Figure 2.2. When the DSSC device is under illumination, the dye molecules absorb incident photons and promote electrons from the highest occupied molecular orbital (HOMO) to the lowest unoccupied molecular orbital (LUMO). The photoexcited dyes inject the electrons into the conduction band (CB) of $\mathrm{TiO}_{2}$, as the potential of $\mathrm{TiO}_{2} \mathrm{CB}$ is more positive than that of the LUMO of N719. The electrons in $\mathrm{TiO}_{2} \mathrm{CB}$ are transferred across the $\mathrm{TiO}_{2}$ matrix to TCO film (FTO substrate in this case) and then conducted to the external circuit to drive the load and generate electricity. The original state of the dye is subsequently restored by electron donation from iodide of the electrolyte. The regeneration of the iodide from triiodide is catalyzed by the platinum at counter electrode with the electrons migrating through the external circuit. Overall, the device generates electrical energy from sunlight without suffering any permanent chemical transformation [41-43]. When numerous electrons are injected into the $\mathrm{CB}$ of $\mathrm{TiO}_{2}$, its quasi-Fermi level rises. At open circuit under sunlight, electrons keep accumulating in the $\mathrm{CB}$ and the quasi-Fermi level approaches the $\mathrm{CB}$ level of $\mathrm{TiO}_{2}$. The maximum possible voltage of the DSSCs is determined by the difference between the Fermi level of semiconducting metal oxide and the redox potential of electrolyte. When the $\mathrm{TiO}_{2}$ and iodide/triiodide redox couple are used, the maximum possible voltage is about $0.9 \mathrm{~V}$ [44]. 


\subsubsection{Electron transfer and recombination process}
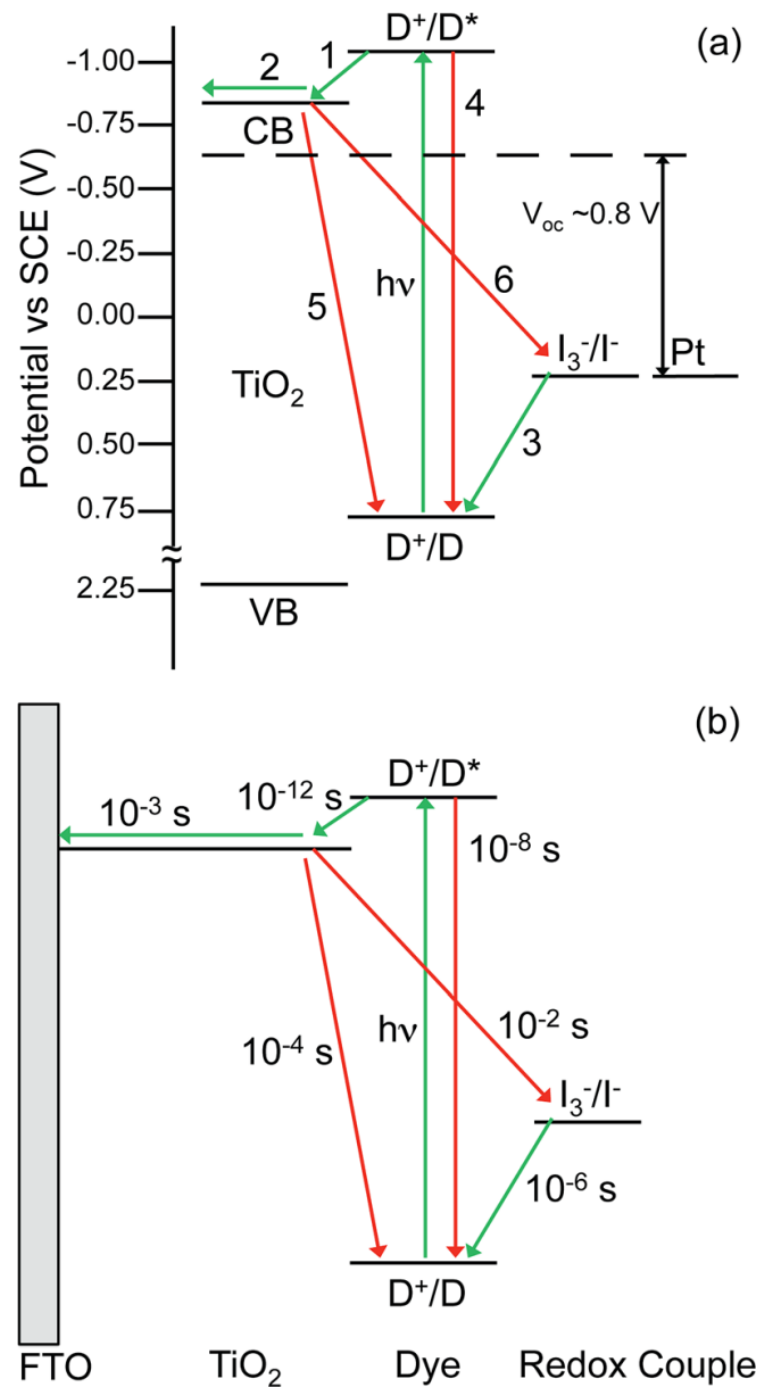

Figure 2.3 Pathways indicating favourable charge transfer (1-3) and unfavourable recombination (4-6) processes involved in the DSSCs (a), and typical time constants for the charge transfer process 1-6 (b) [44]. Copyright (2012) with permission from American Institute of Physics.

Besides the desired electron transfer processes described above, some recombination processes (or back reactions) also occur within the DSSC devices. The main electron transfer processes and their typical time constants are depicted in 
Figure 2.3. Although the electron injection (process 1) mechanism is still inconclusive, it is widely agreed that the photogenerated electrons are injected into the $\mathrm{CB}$ of the semiconducting metal oxide within an ultrafast femtosecond time scale [45-49]. The electron injection process should be significantly faster than the decay of the excited dyes, of which the lifetime is determined to be 20-60 ns [50], to ensure the sufficient kinetic advantages for high charge injection efficiency.

Compared with the ultrafast injection process, electron transport (process 2) in the nanostructured semiconductor films is much slower, typically in millisecond domain [51, 52]. The mesoporous films are quite different from their compact analogues, because of the low inherent conductivity, lack of built-in electrical field due to the small sized colloidal nanoparticles, and presence of a large area junction at the phase boundaries of the interpenetrating networks formed by the nanoparticles and the electrolyte. Due to the lack of internal electrical field, the electrons are driven by the electron concentration gradient across the mesoporous semiconductor layer via diffusion [53-55]. Several factors affect the charge transport in the semiconductor nanoparticle matrix. First, the electron transport is related to the trap density at the grain boundaries and the nanoparticlelelectrolyte interface. A low density of trap states would allow a high charge diffusion coefficient [56-59]. Second, the electron transport rate is also dependent on the light illumination intensity. Higher illumination intensity would bring about a higher transport rate, arisen from more efficient thermal activation of the trapped electrons and higher concentration of photogenerated electrons, leading to the faster diffusion [52, 60,61]. Moreover, the structure of the 
semiconductor layer is also capable of influencing the electron transport [62,63], such as a slower electron transport in a more porous oxide layer due to the formation of a more tortuous diffusion path [64].

Generally, the half-life of dye regeneration (process 3) in $0.5 \mathrm{M}$ iodide is $100 \mathrm{~ns} \sim 10$ $\mu$ s [65-67]. The regeneration kinetics is strongly dependent on the composition of electrolyte, especially the cation of the $\mathrm{I}^{-}$salts $[68,69]$. When the cations $\mathrm{are}^{\mathrm{Li}^{+}}$and $\mathrm{Mg}^{2+}$, which are capable of adsorbing onto the surface of the semiconductor, a higher $\mathrm{I}^{-}$concentration near the nanoparticle surface is allowed, resulting in rapid dye regeneration [69].

Restricted within the nano-sized semiconductor particles, the injected electrons can only move a few nanometers from the semiconductor/dye/electrolyte interface, which results in charge recombination (or back reaction) with the oxidized dyes (process 5) and the $\mathrm{I}_{3}{ }^{-}$in electrolyte (process 6 ) [57, 70-72]. The process 5 is generally in $\sim 0.1$ millisecond time domain $[65,73]$, which is much slower than the dye regeneration process (process 3), making the regeneration process kinetically favorable. Therefore, it is often assumed that the charge recombination is mainly between the photogenerated electrons and the $\mathrm{I}_{3}{ }^{-}$in electrolyte, which usually occurs at the semiconductor/electrolyte and TCO/electrolyte interfaces. The charge recombination is influenced by many factors, including the semiconductor surface states [74], $\mathrm{I}_{3}{ }^{-}$ concentration [75], trapping-detrapping of the charges in semiconductor nanoparticles [76] and molecular structure of the adsorbed dye [77, 78]. 


\subsubsection{DSSC evaluation}

\section{Standard light source for evaluation:}

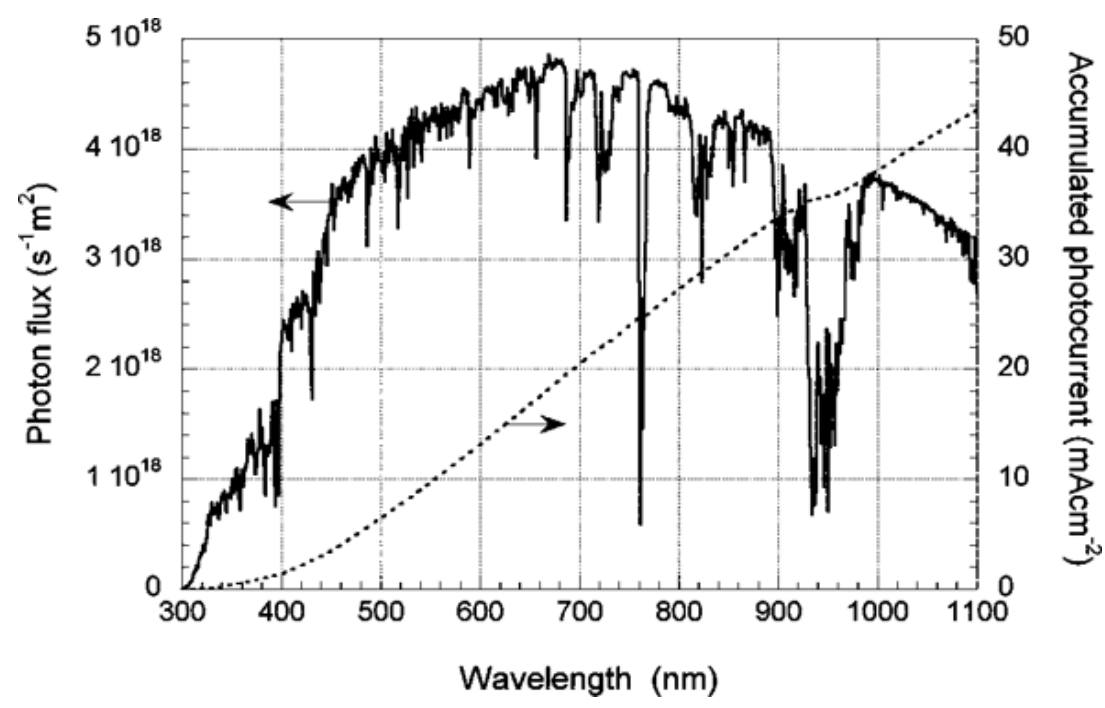

Figure 2.4 Photon flux of the AM 1.5 G spectrum at $1000 \mathrm{~W} \mathrm{~m}^{-2}$ (ASTM G173-03), and calculated accumulated photocurrent (dotted line) [36]. Copyright (2010) with permission from American Chemical Society.

The sunlight consists of ultraviolet (UV), visible light and infrared (IR) rays, and peaks in the visible region. The atmospheric absorption and the sun position can influence the solar spectrum. UV light can be filtered out by ozone, and IR can be absorbed by water $\left(\mathrm{H}_{2} \mathrm{O}\right)$ and carbon dioxide $\left(\mathrm{CO}_{2}\right)$. With a clear sky and a directly overhead sun, the radiation striking the earth surface is the maximum, by passing the shortest path length through the atmosphere. The path length is called as the air mass (AM), which can be approximated by $\mathrm{AM}=1 / \cos \varphi$, where $\varphi$ is the elevation angle of the sun [36]. The standard solar spectrum used for performance evaluations of the solar cells is AM $1.5 \mathrm{G}$ with $\varphi$ of $42.8^{\circ}$. Figure 2.4 shows the AM $1.5 \mathrm{G}$ spectrum, which is normalized to make the integrated irradiance at $1000 \mathrm{~W} \mathrm{~m}^{-2}$. Compared to 
the Si-based photovoltaics with perfectly flat surfaces, DSSCs are more suitable for diffuse light and less sensitive to the sun movements due to their rough surfaces [36]. Figure 2.4 also indicates the maximum short-circuit current density of a solar cell device by converting all incident photons below the absorption onset wavelength into electric current [79]. For instance, the maximum short-circuit current density for a solar cell with an absorption onset of $700 \mathrm{~nm}$ is $\sim 21 \mathrm{~mA} \mathrm{~cm}^{-2}$.

\section{Photocurrent density-voltage (J-V) characteristic:}

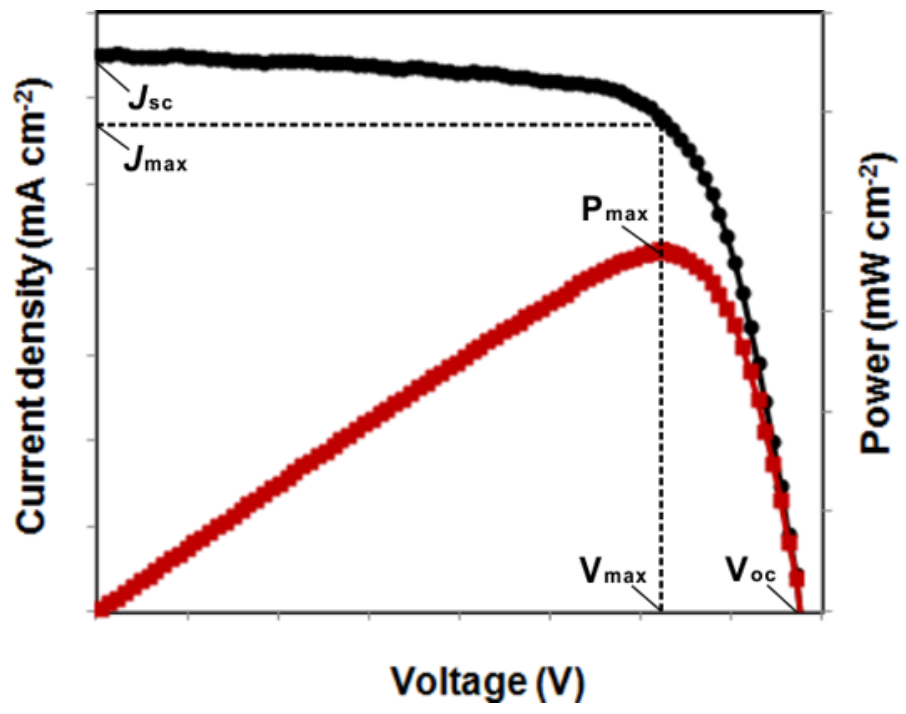

Figure 2.5 A typical $J$-V curve of a solar cell under simulated sunlight (circle) and power output curve (square) calculated based on the $J$-V curve.

The power conversion efficiency (PCE or $\eta$ ) of the solar cells is calculated using the data of the $J$-V curves obtained from photoelectric current measurements. To compare the PCE of the solar cells prepared in different laboratories, the $J$-V curves should be measured under standard conditions, such as the standard solar spectrum (AM 1.5G with a power density of $1000 \mathrm{~W} \mathrm{~m}^{-2}$ ) and the prescriptive cell temperature $\left(25^{\circ} \mathrm{C}\right)$ [80]. Besides the PCE, other photovoltaic parameters, including short-circuit 
current density $\left(J_{\mathrm{sc}}\right)$, open-circuit voltage $\left(\mathrm{V}_{\mathrm{oc}}\right)$ and fill factor $(\mathrm{FF})$, can also be obtained from the $J-\mathrm{V}$ curves as shown in Figure 2.5.

The $J_{\text {sc }}$ is the photocurrent per unit active area of the device, measured at an applied potential of $0 \mathrm{~V}$. For a DSSC, the $J_{\mathrm{sc}}$ is determined by the irradiance incident on the cell surface, dye loading, molecular structure of the dye and electrochemical properties of the mesoporous electrode film $[38,81]$. The $\mathrm{V}_{\text {oc }}$ is mainly determined by the difference between the Fermi level of the metal oxide and the electrochemical potential of the redox couple. Meanwhile, it is also dependent on the recombination rate and the sensitizer adsorption mode [82].

The FF measures the ideality of the solar cells and is defined as the ratio of maximum power output $\left(\mathrm{P}_{\max }\right)$ to the product of $J_{\mathrm{sc}}$ and $\mathrm{V}_{\mathrm{oc}}$. It can be calculated from $F F=\frac{J_{\max } V_{\max }}{J_{s c} V_{o c}}$

where $J_{\max }$ and $\mathrm{V}_{\max }$ are the photocurrent density and the voltage corresponding to the $\mathrm{P}_{\max }$ point (see Figure 2.5). The $\mathrm{FF}$ can be qualitatively determined from the squareness of the $J$-V curve. The charge recombination processes within the DSSC are responsible for the poor fill factor. To achieve a high FF, the parallel shunt resistance within the DSSC needs to be as high as possible while the series resistance has to be as low as possible.

The PCE is defined as the ratio of $\mathrm{P}_{\max }$ to the incident irradiance $\left(\mathrm{P}_{\text {in }}\right)$ on the device surface (Equation 2.2). Higher $J_{\mathrm{sc}}, \mathrm{V}_{\mathrm{oc}}$, and FF can bring a higher PCE. As all these photovoltaic parameters can be directly influenced by the properties of the 
mesoporous semiconductor network, photoanode performance optimization is an effective strategy to improve the DSSC performance.

$\eta=\frac{P_{\max }}{P_{\text {in }}}=\frac{J_{s c} V_{o c} F F}{P_{\text {in }}}$

Incident photon-to-current conversion efficiency (IPCE):

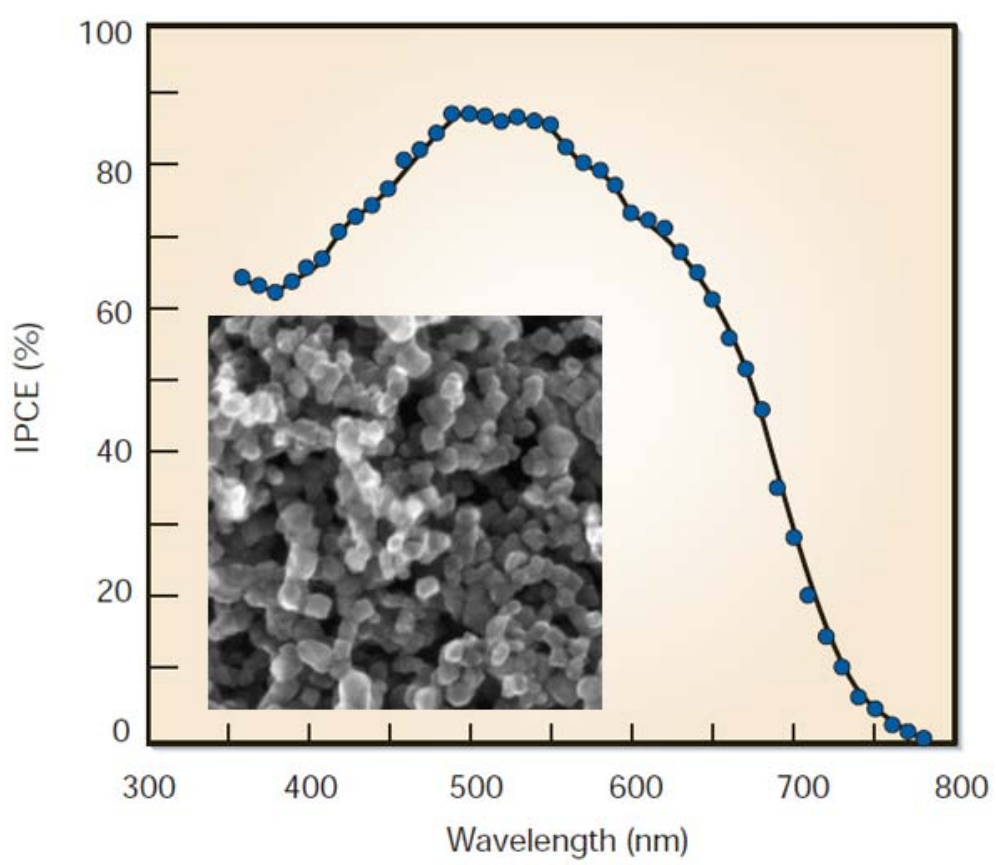

Figure 2.6 A typical plot of IPCE as a function of the excitation wavelength for a nanocrystalline anatase film (the inset) sensitized by the surface-anchored ruthenium complex cis-RuL $2(\mathrm{SCN})_{2}$ [41]. Copyright (2001) with permission from Nature Publishing Group.

The PCE only measures the overall conversion of the incident radiation power to the electrical power, while IPCE is capable of providing the information about the monochromatic quantum efficiency of a solar cell. The IPCE measures the percentage of the absorbed monochromatic light being converted to the current (Figure 2.6) and 
is defined as the number of electrons flowing through the external circuit under short circuit conditions per incident photon at a given wavelength (Equation 2.3). Obviously, a mesoporous semiconductor network with high specific surface area can deliver a high IPCE.

$I P C E=1240 \frac{J_{s c}(\lambda)\left[\mathrm{Acm}^{-2}\right]}{\lambda[\mathrm{nm}] P_{\text {in }}(\lambda)\left[W \mathrm{Cm}^{-2}\right]}$

\section{Electrochemical impedance spectra (EIS):}

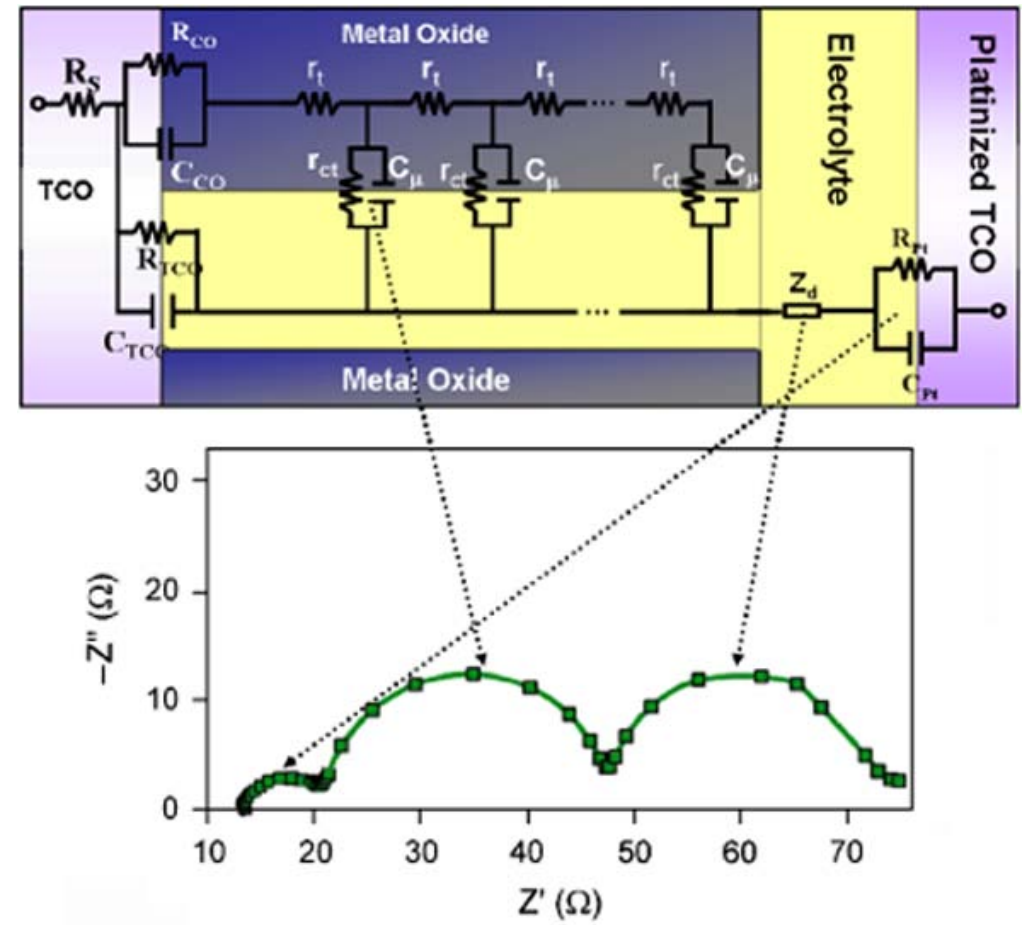

Figure 2.7 A typical Nyquist plot of a DSSC (bottom panel) and a corresponding equivalent circuit (top panel) [38]. Copyright (2009) with permission from John Wiley and Sons.

EIS is a powerful technique to investigate the electrical transport kinetics in DSSCs. Figure 2.7 shows a typical impedance spectrum (Nyquist plot) with its equivalent 
circuit, consisting of a series of parallel connected resistors and capacitors. The $r_{c t}$ is the charge transfer resistance of the recombination process between the electrons in semiconductor and the electrolyte; $\mathrm{C}_{\mu}$ is the chemical capacitance of the nanocrystalline film; $r_{t}$ is the electron transport resistance through the mesoporous film; $\mathrm{Z}_{\mathrm{d}}$ reflects the diffusion of the ions in electrolyte; $\mathrm{R}_{\mathrm{Pt}}$ and $\mathrm{C}_{\mathrm{Pt}}$ are the charge transfer resistance and double-layer capacitance at the counter electrode, respectively; $\mathrm{R}_{\mathrm{TCO}}$ and $\mathrm{C}_{\mathrm{TCO}}$ are the charge transfer resistance and the capacitance at TCO/electrolyte interface, respectively; $\mathrm{R}_{\mathrm{CO}}$ and $\mathrm{C}_{\mathrm{CO}}$ are the resistance and the capacitance at the TCO/semiconductor nanoparticles interface, respectively; $\mathrm{R}_{\mathrm{s}}$ is the series resistance, including the sheet resistance of TCO and the resistance at cell junctions. Steady-state $r_{t}, C_{\mu}$ and $r_{c t}$ can be determined using EIS [38, 83]. The Nyquist plot in Figure 2.7 illustrates three semicircles, the diameters of which represent the impedance of the corresponding processes. The first semicircle represents the Faraday resistance of the redox reaction at the Pt/electrolyte interface. The second semicircle reflects the electron transfer resistance at the metal oxide/dye/electrolyte interface, which is the most decisive factor in DSSCs. The third semicircle is related to the Warburg diffusion process of the ions in electrolyte. In practical fitting process of the Nyquist plots, the equivalent circuits can be simplified by neglecting the charge transfer processes at TCO/electrolyte and TCO/metal oxide interfaces. 


\section{2 $\mathrm{TiO}_{2}$ based DSSC}

Commercial interest in DSSCs was triggered by the breakthrough discovery that nanocrystalline $\mathrm{TiO}_{2}$-based mesoporous film sensitized by $\mathrm{N} 3$ dye was capable of delivering a significant PCE of 7 8 \%, reported by O’regan and Grätzel in 1991 [29]. In 2001, Grätzel's group developed a DSSC with a PCE of $10.4 \%$ using the $20 \mathrm{~nm}$ $\mathrm{TiO}_{2}$ nanocrystalline film sensitized by black dye as photoanode and the $\mathrm{I}^{-} / \mathrm{I}_{3}{ }^{-}$redox couple as electrolyte [84]. This record was broken by the same group with PCE of $\sim 11.04 \%$ by using the N3 dye and a guanidine thiocyanate electrolyte [15]. The recent achievement is $12.3 \%$ PCE obtained using a porphyrin-sensitized $\mathrm{TiO}_{2}$ nanoparticle film and a cobalt (II/III)-based redox electrolyte [30]. All these breakthroughs in DSSC development are based on the $\mathrm{TiO}_{2}$ photoelectrodes.

\subsubsection{Introduction of titanium dioxide}

$\mathrm{TiO}_{2}$ is an important semiconductor with good stability, non-toxicity, and high photoactivity [85]. This low-cost material has been utilized as white pigment since ancient times, which verifies its safety to human and environment [85]. $\mathrm{TiO}_{2}$ has three different crystalline phases: anatase, rutile, and brookite. The anatase phase is metastable and exhibits a tetragonal structure with a band gap at $3.2 \mathrm{eV}$. The thermodynamically stable phase is rutile, the band gap of which is $3.0 \mathrm{eV}$ [86]. The transformation from anatase to rutile can be induced by heat treatment at $\sim 900 \mathrm{~K}$. The brookite phase shows an orthorhombic structure and it is rarely used due to its complex structure and the difficulties in the synthesis of its pure phase [87, 88]. 
Anatase $\mathrm{TiO}_{2}$ is always the first choice as the DSSC photoanode materials, while rutile $\mathrm{TiO}_{2}$ is commonly used as white pigment in paints, due to its strong white light scattering effect and chemically stability [89]. Anatase $\mathrm{TiO}_{2}$ is the more active phase because of its high surface hydroxyl group density and potentially higher CB edge level [90, 91]. The DSSCs based on anatase nanocrystals exhibits better performance than that based on nanostructured rutile, which is mainly attributed to the more surface hydroxyl groups and larger surface area per unit volume of the anatase based electrode film for higher dye loading, the higher CB potential and higher electron diffusion coefficient [89, 92]. However, rutile nanocrystals shows superior lightscattering characteristics and single crystal rutile $\mathrm{TiO}_{2}$ nanorods with a length up to several hundreds of nanometers exhibit fast electron transport rate [92, 93], which are the beneficial properties for the DSSCs.

\subsection{2 $\mathrm{TiO}_{2}$ and other metal oxides based electrodes}

The semiconducting metal oxides used in DSSC photoanodes are essentially wide band gap semiconductors, such as $\mathrm{TiO}_{2}, \mathrm{ZnO}, \mathrm{SnO}_{2}, \mathrm{Nb}_{2} \mathrm{O}_{5}$, and so on. However, among all these metal oxides, $\mathrm{TiO}_{2}$ is the most popular anode material due to its superior properties introduced above and the relatively high PCE achieved by the cells based on it. Moreover, many dye molecules with excellent light absorption efficiency and good stability have their LUMO positioned favourably with respect to the $\mathrm{CB}$ edge of $\mathrm{TiO}_{2}[94]$.

Since 1991, the $\mathrm{TiO}_{2}$ DSSC electrode has been extensively studied to improve its 
light harvesting efficiency and charge collection efficiency. For state-of-the-art DSSCs, the architecture of the photoanodes is as follows:

(a) A compact $\mathrm{TiO}_{2}$ blocking layer with thickness of $\sim 50 \mathrm{~nm}$, coating on FTO substrate to prevent contact between the electrolyte and the FTO, usually prepared by chemical bath deposition, spray pyrolysis, and sputtering [95].

(b) A light harvesting layer consisting of a mesoporous $\mathrm{TiO}_{2}$ film with particle size of $\sim 20 \mathrm{~nm}$ and film thickness of $\sim 10 \mu \mathrm{m}$, providing a large specific surface area for dye loading and continuous path for electron transport.

(c) A light scattering layer on the mesoporous film, consisting of a $\sim 3 \mu \mathrm{m}$ thick layer with $\sim 400 \mathrm{~nm}$ sized $\mathrm{TiO}_{2}$ particles [96].

(d) An ultrathin coating of $\mathrm{TiO}_{2}$ on the whole electrode film, prepared by chemical bath deposition using $\mathrm{TiCl}_{4}$ aqueous solution, followed by heat treatment.

$\mathrm{ZnO}$ is a distinguished alternative to $\mathrm{TiO}_{2}$ as the photoanode material $[97,98]$. It is found that the light harvesting efficiency and electron transport property of the $\mathrm{ZnO}$ based anodes is similar with those of $\mathrm{TiO}_{2}$-based ones, but $\mathrm{ZnO}$ exhibits higher electronic mobility which should be favorable for electron transport. Compared to $\mathrm{TiO}_{2}$, the electron injection from the excited dye molecules to the $\mathrm{CB}$ of $\mathrm{ZnO}$ is slightly slower but it is still in femtosecond domain [97]. The first nanocrystalline ZnO films are prepared using sol-gel techniques and sensitized by N3 dye [99]. The resulting device exhibits a monochromatic IPCE of $13 \%$ at $520 \mathrm{~nm}$ and a PCE of $0.4 \%$ under simulated sunlight. The poor performance is mainly due to the $\mathrm{ZnO}$ dissolution at its surface and formation of $\mathrm{Zn}^{2+} /$ dye aggregates in the acidic N3 solution. These 
obstacles are overcome by adding a base (such as $\mathrm{KOH}$ ) to the acidic dye solution [98] and immersing the $\mathrm{ZnO}$ electrodes in ethanolic solution under reflux [38]. Currently, ZnO photoanodes prepared using a squeegee technique show the highest overall PCE of $6.58 \%$ under AM1.5 sunlight [100].

$\mathrm{SnO}_{2}$ is another attractive semiconductor with two main advantages over $\mathrm{TiO}_{2}$ : high mobility and large band gap [2]. At room temperature, the electron mobility of $\mathrm{SnO}_{2}$ is three orders higher than that of $\mathrm{TiO}_{2}$ [101]. Its large band gap (3.8 eV) decreases the formation of oxidative holes in the VB under UV radiation, which can reduce the dye degradation rate, therefore improving the DSSC stability. The high CB position of $\mathrm{SnO}_{2}$ is capable of facilitating the electron injection from the excited dye molecules [102]. Surprisingly, the PCE of $\mathrm{SnO}_{2}$ based DSSCs is reported to be much lower than the $\mathrm{TiO}_{2}$ based ones $[102,103]$. Charge transport in $\mathrm{SnO}_{2}$-based photoanodes is in orders of magnitude faster than those in $\mathrm{TiO}_{2}$-based anodes. However, the charge recombination processes also correspondingly increase, which ultimately lowers the dye regeneration efficiency and the PCE [103]. Although a DSSC prepared using a commercialized $\mathrm{SnO}_{2}$ colloidal suspension is reported to show slower electron diffusion coefficient and longer electron lifetime than $\mathrm{TiO}_{2}$-based DSSCs, its PCE is still much lower [104]. In addition, the lower isoelectric point (IEP) of $\mathrm{SnO}_{2}(\mathrm{pH} 4-5)$, compared to $\mathrm{TiO}_{2}$ (pH 6-7), hinders the adsorption of dye molecules with acidic carboxyl groups [105]. To overcome this issue, an isolating oxide layer (such as $\mathrm{ZnO}$, $\mathrm{TiO}_{2}, \mathrm{Al}_{2} \mathrm{O}_{3}, \mathrm{MgO}$ ) is coated on the surface of $\mathrm{SnO}_{2}$ photoanodes to suppress the back reaction and improve the dye loading, which significantly improves the PCE of $\mathrm{SnO}_{2}$ 
based DSSCs. As reported [46], a maximum PCE of 7\% is achieved by MgO-coated $\mathrm{SnO}_{2}$ DSSCs.

$\mathrm{Nb}_{2} \mathrm{O}_{5}$, with a band gap energy of $3.49 \mathrm{eV}$, has also been explored as photoanode materials in DSSC [106-110]. A comparison work involving the various N3 sensitized porous metal oxide films including $\mathrm{TiO}_{2}, \mathrm{Nb}_{2} \mathrm{O}_{5}, \mathrm{ZnO}, \mathrm{SnO}_{2}, \mathrm{In}_{2} \mathrm{O}_{3}, \mathrm{WO}_{3}, \mathrm{Ta}_{2} \mathrm{O}_{5}$, and $\mathrm{ZrO}_{2}$, shows that the $\mathrm{Nb}_{2} \mathrm{O}_{5}$ based cells give the highest $\mathrm{V}_{\text {oc }}$ and the second highest IPCE of $\sim 18 \%$ with the $\mathrm{TiO}_{2}$ cells delivering the highest IPCE of $\sim 45 \%$, under similar cell fabrication conditions [111]. However, the large unit cell dimension of $\mathrm{Nb}_{2} \mathrm{O}_{5}$ reduces its surface area, lowering the $J_{\mathrm{sc}}$ of $\mathrm{Nb}_{2} \mathrm{O}_{5}$ cells [38]. By using proper chemical technique, nanocrystalline $\mathrm{Nb}_{2} \mathrm{O}_{5}$ with a specific surface area of $25 \mathrm{~m}^{2} \mathrm{~g}^{-1}$ can be obtained [112], but it is still much lower than that of nanocrystalline $\mathrm{TiO}_{2}$.

Besides the simple binary metal oxide, ternary metal oxides such as $\mathrm{SrTiO}_{3}[108$, 113] and $\mathrm{Zn}_{2} \mathrm{SnO}_{4}[114,115]$ have been developed as DSSC photoanode materials. The $\mathrm{SrTiO}_{3}$ is a semiconductor with bandgap similar to $\mathrm{TiO}_{2}(3.2 \mathrm{eV})$. However, its CB is relatively higher than that of $\mathrm{TiO}_{2}$, which can result in a higher $\mathrm{V}_{\text {oc }}$ compared to $\mathrm{TiO}_{2}$ [108]. The high dielectric constant of $\mathrm{SrTiO}_{3}$ makes it electrically mesoporous even with a large particle size of $80 \mathrm{~nm}$ [116]. The performance of $\mathrm{SrTiO}_{3}$ based DSSCs is relatively poor, which is due to its specific surface structure. The energetically favored surface of $\mathrm{SrTiO}_{3}$ is (001) face, which has two possible terminations, $\mathrm{SrO}$ and $\mathrm{TiO}_{2}$. The more basic SrO surface poorly adsorb the dye sensitizer with the negatively charged carboxylate groups, which may result in the decreased dye loading and thus the poor photovoltaic performance [38]. $\mathrm{Zn}_{2} \mathrm{SnO}_{4}$ 
nanoparticles with large band gap energy of $3.6 \mathrm{eV}$ was first synthesized from a hydrothermal process and applied in the DSSCs [114]. $\mathrm{Zn}_{2} \mathrm{SnO}_{4}$ based DSSCs show a PCE up to $3.8 \%$ which is close to the highest efficiency reported for $\mathrm{ZnO}$ cells fabricated under similar conditions (4.1\%) and much higher than that reported for $\mathrm{SnO}_{2}$ cells (1.2\%) [117]. The $\mathrm{Zn}_{2} \mathrm{SnO}_{4}$ cells also overcome the stability issue of the $\mathrm{ZnO}$ cells with acidic dyes. Currently, the short electron diffusion length remains a limiting factor for the performance of $\mathrm{Zn}_{2} \mathrm{SnO}_{4}$ cells.

\subsubsection{Challenges}

Although over $12 \%$ conversion efficiency has been obtained from DSSCs technology in laboratories, further improvements in cell performance are still necessary to ensure at least 6\% PCE from DSSC products for commercial viability [32]. The utilization of the nanocrystalline $\mathrm{TiO}_{2}$ as the support matrix has significantly increased the specific surface area of the photoanode films for increased dye adsorption, which improves the light harvesting efficiency, thus enhancing the DSSC performance [29]. However, numerous grain boundaries within the nanocrystalline films interfere with electron transport, which makes the charge collection of the DSSC photoanodes not so efficient that the II $3^{-}$redox couple needs to be used to ensure the efficient operation of the cells. However, the use of the liquid electrolyte containing corrosive $\mathrm{I}^{-} / \mathrm{I}_{3}{ }^{-}$redox couple hinders the scale up and stability of the DSSCs [37]. Besides, highly efficient DSSC photoanodes with a charge collection efficiency of $\sim 100 \%$ can only be obtained when the anode film thickness is less than 
electron diffusion length $\left(L_{\mathrm{n}}\right)$. For nanoparticle based DSSCs, the $L_{\mathrm{n}}$ is usually 10 14 $\mu \mathrm{m}$, determining that their optimal film thickness is around ten several micrometers. Simply thickening of the nanoparticle films has been proved to be unsuccessful for PCE improvement [16]. Therefore, a major challenge for the commercialization of nanocrystalline DSSCs is the efficient electron transport across the photoanode films to increase the electron diffusion length for increased optimal film thickness and then the increased dye loading and PCE, and to enable the use of novel redox couples which is better for DSSC scale up and stability but may be kinetically much faster in charge recombination than $\mathrm{\Gamma}_{/}{ }_{3}^{-}$.

\subsection{Techniques for photoanode optimization}

Charge transport properties of the $\mathrm{TiO}_{2}$ films directly influence the DSSC device performance. The main strategies to optimize the mesoporous $\mathrm{TiO}_{2}$ layer for improved electron mobility include incorporation of efficient charge transport materials, development of novel $\mathrm{TiO}_{2}$ nanostructures, surface modification of $\mathrm{TiO}_{2}$ electrodes, and electronic structure modification of $\mathrm{TiO}_{2}$ nanocrystals.

\subsubsection{Incorporation of charge transport enhancer}

\subsubsection{Conventional charge transport enhancer}

To promote the electron transport across the $\mathrm{TiO}_{2}$ network, semiconducting nanomaterials with high conductivity have been incorporated into the nanocrystalline photoanodes as efficient charge transport channels. Carbon nanomaterials are the most used charge transport enhancer in the composite electrodes to improve their 
electric conductivity, mechanical strength, and flexibility. For instance, incorporation of carbon nanotubes (CNTs) into the nanocrystalline $\mathrm{TiO}_{2}$ based photoanodes has been extensively studied [118-123]. In the composite anodes, the electrons can be rapidly transported in the CNTs across the $\mathrm{TiO}_{2}$ matrix to $\mathrm{TCO}$, without encountering the numerous grain boundaries, as illustrated in Figure 2.8 [119, 124, 125]. This can reduce the charge recombination and the transport resistance of the anodes.
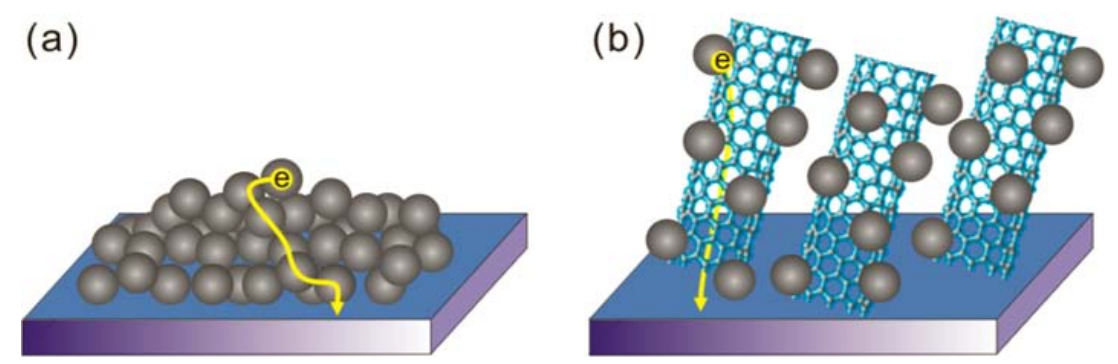

Figure 2.8 Diagrams for the photogenerated electrons transport route in plain $\mathrm{TiO}_{2}$ electrodes (a) and CNT-incorporated electrodes (b) [125]. Copyright (2012) with permission from American Chemical Society.

Multi-walled carbon nanotube (MWCNT) has been introduced into the $\mathrm{TiO}_{2}$ electrodes by simply mixing the $\mathrm{TiO}_{2}$ paste with a MWCNT suspension via ultrasonication [126]. Compared to the unmodified anode, the composite photoanode with 0.1 wt $\%$ of MWCNT loading achieved a 20\% PCE enhancement. To reduce the aggregation of CNT in the electrodes, oxygen plasma treated CNT has been developed [121]. The oxygen-containing functional groups on the nanotube surface improved the attachment of nanocrystalline $\mathrm{TiO}_{2}$ and the dispersity of $\mathrm{CNT}$, resulting in higher dye loading and lower charge recombination. The PCE of DSSC based on the treated $\mathrm{CNT}-\mathrm{TiO}_{2}$ composite photoanode was increased by $75 \%$, in comparison 
with that based on plain $\mathrm{TiO}_{2}$ photoanode [121]. Similar work was recently reported by Chan et al. [127]. The treated MWCTNs grafted with the maleic anhydride groups exhibited enhanced conductivity, further reducing the charge transport resistance of the mesoporous electrode films and leading to a 54.4\% PCE enhancement [127]. Single-walled CNT (SWCNT) has also been incorporated into the DSSC photoanodes as scaffold and electron channels, due to its unique electrical properties, wide electrochemical stability window, and high surface area $[119,128]$. It was revealed that the lifetime of the injected electrons in $\mathrm{TiO}_{2}$ is roughly $50 \%$ longer with the SWCNT network, which was mainly due to the electron equilibration between the SWCNT and the $\mathrm{TiO}_{2}$ nanoparticles. The equilibration resulted in the transfer of a fraction of electrons into SWCNT, thus stabilizing the photogenerated electrons and reducing the charge recombination [128]. A comparative study in the effects of inherent properties of the SWCNTs on DSSC performance was carried out by introducing pristine (p-), metallic (m-) and semiconducting (s-) SWCNTs into the $\mathrm{TiO}_{2}$ electrodes [129]. DSSC based on the $\mathrm{TiO}_{2} / \mathrm{s}$-SWCNT composite exhibited better performance than those based on the other two $\mathrm{TiO}_{2} / \mathrm{SWCNT}$ composites and plain $\mathrm{TiO}_{2}$. The incorporation of all three types of SWCNTs is capable of improving the charge transport of the electrodes, while only $\mathrm{TiO}_{2} / \mathrm{s}$-SWCNT composite is able to simultaneously reduce the charge transport resistance and suppress interfacial charge recombination for a higher PCE [129]. Therefore, the optimal charge transport enhancer should be a semiconducting nanomaterial with high electron mobility. 
Besides CNTs, carbon nanofibers have also been incorporated into the $\mathrm{TiO}_{2}$ based photoanodes for enhanced electron transport [130, 131]. To avoid the random arrangement in the anodes like CNTs, a vertically aligned carbon nanofiber (VACNF) array has been developed on FTO glass as the substrate for growth of the $\mathrm{TiO}_{2}$ nanoneedles on it, as shown in Figure 2.9. This core-shell vertical architecture is utilized as the DSSC photoanode and contributes a maximum IPCE of 34\%, higher than that (15\% to $25 \%)$ of $\mathrm{TiO}_{2}$ nanoparticles on SWCNTs $[119,128]$.

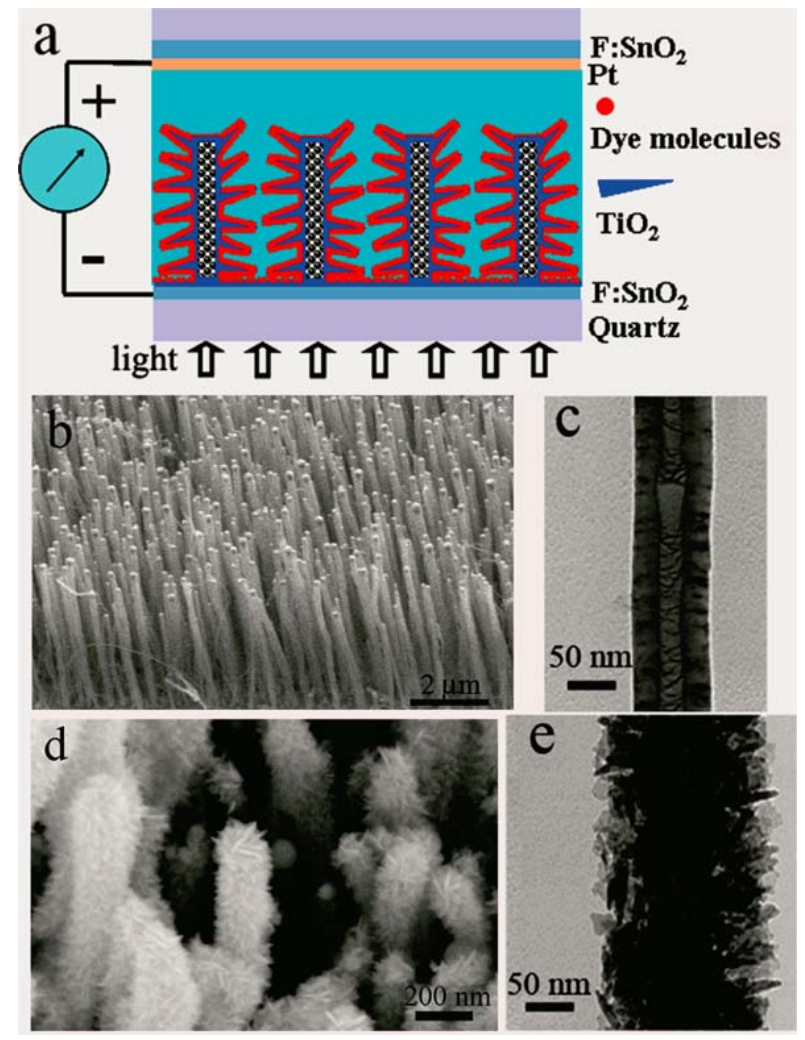

Figure 2.9 Schematic of VACNF arrays coated with anatase $\mathrm{TiO}_{2}$ nanoneedles for DSSCs (a), SEM image of the as-grown VACNF array (b), TEM image of an asgrown CNF (c), SEM image of the VACNF array coated with anatase $\mathrm{TiO}_{2}$ nanoneedles (d) and TEM image of a CNF coated with anatase $\mathrm{TiO}_{2}$ nanoneedles(e) [130]. Copyright (2009) with permission from American Chemical Society. 


\subsubsection{Graphene: a promising and efficient charge transport enhancer}

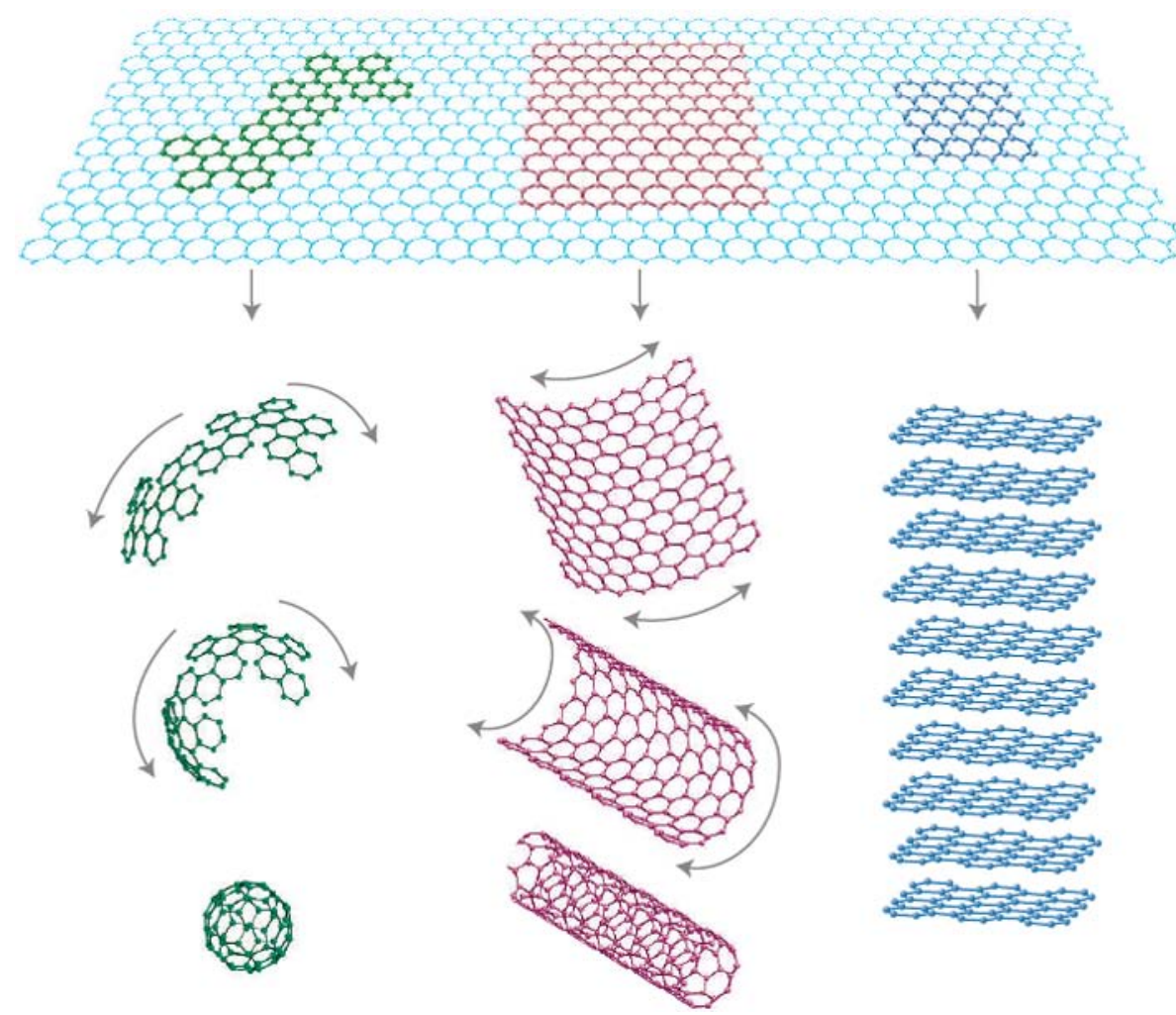

Figure 2.10 Mother of all graphitic forms [132]. Graphene is a 2D building material for carbon materials of all other dimensionalities. It can be wrapped up into 0D buckyballs, rolled into 1D nanotubes or stacked into 3D graphite. Copyright (2007) with permission from Nature Publishing Group.

Graphene, a two dimensional carbonaceous material, is a primary building material for carbon materials with all other dimensionalities as illustrated in Figure 2.10. It has attracted much attention due to its unique properties, including high thermal conductivity ( 5000 $\left.\mathrm{W} \mathrm{m}^{-1} \mathrm{~K}^{-1}\right)$ [133], excellent carrier mobility (200 $000 \mathrm{~cm}^{2} \mathrm{~V}^{-1} \mathrm{~s}^{-1}$ ) [134], large specific surface area (calculated value, $2630 \mathrm{~m}^{2} \mathrm{~g}^{-1}$ ) [135], and good mechanical stability [136]. Besides these, graphene can be obtained from micromechanical cleavage [137], thermal exfoliation [138], and chemical method 
$[139,140]$ from bulk graphite, which is cheap and naturally abundant. Based on these properties, graphene can be used in many applications, such as optical, electronic, and catalytic fields.
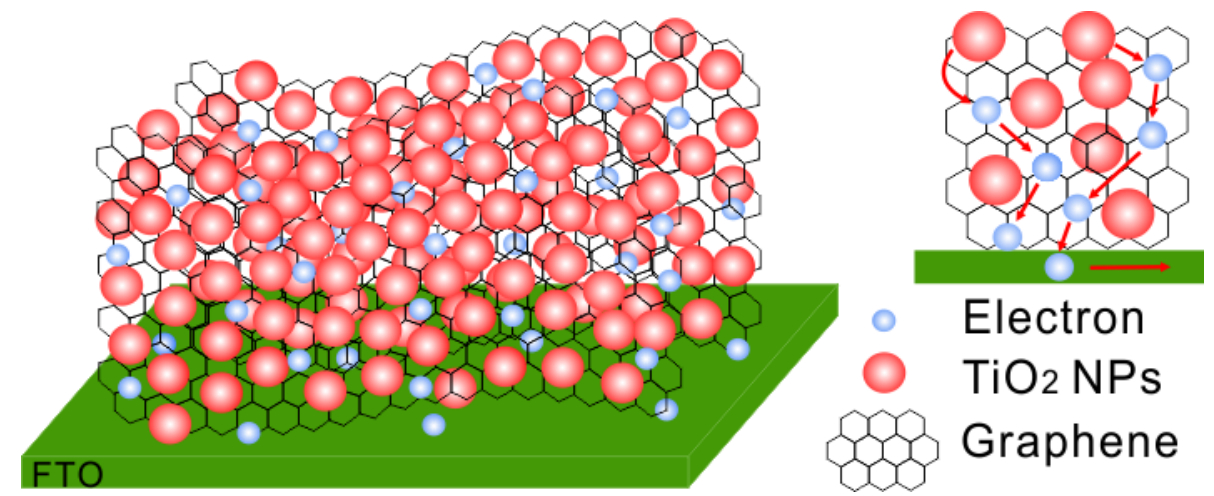

Figure 2.11 Schematic illustration of the 2D graphene serving as electron bridge in a $\mathrm{TiO}_{2}$-based photoanode.

Recently, extensive investigations have been carried out on graphene-based composite nanomaterials because of the synergistic effects of the different functional components in the composites. With excellent electron mobility and large specific surface area, graphene can be incorporated into the $\mathrm{TiO}_{2}$-based DSSC photoanodes as electron transport enhancer and support material for 40 58\% of PCE improvement [141-143]. Numerous synthetic methods to produce graphene- $\mathrm{TiO}_{2}$ composites as photoanode materials have been developed [142-144], and the positive effects of the incorporated graphene have been revealed and summarized in the following two main aspects: (1) increased dye adsorption. The incorporation of graphene gives rise to the porosity of the anode films, which increases the surface area for more dye adsorption sites, therefore enhancing the dye loading and the light harvesting efficiency; (2) significant longer electron lifetime. Graphene dispersed in $\mathrm{TiO}_{2}$ matrix forms a 
continuous 2D conduction network as shown in Figure 2.11. The photogenerated electrons in the network can be effectively transported across the $\mathrm{TiO}_{2}$ matrix, which suppresses the charge recombinations, ultimately extending the electron lifetime [141, 142].

\subsubsection{Optimization of $\mathrm{TiO}_{2}$ nanostructures}

\subsubsection{Conventional $\mathrm{TiO}_{2}$ nanostructures involved in DSSC}

Nanoparticle-based mesoporous films were regarded as a suitable material in DSSC photoanode. However, this type of structure may not be ideal for efficient electron transport, due to the following reasons: (i) numerous grain boundaries within the nanocrystalline films which interfere with electron transport and render the electron diffusion in the mesoporous films relatively slow (in millisecond domain) [37, 50], and (ii) the existence of trap states at the numerous grain boundaries, which results in the trapping/detrapping process and energy loss of the injected electrons [145-147]. The latter is also the reason why electron diffusion coefficient of the nanostructured $\mathrm{TiO}_{2}$ film $\left(5 \times 10^{-5} \mathrm{~cm}^{2} \mathrm{~s}^{-1}\right)$ is more than two orders of magnitude smaller than that of the bulk material $[61,148,149]$. To achieve efficient electron transport in plain $\mathrm{TiO}_{2}$ based electrodes, one-dimensional (1D) $\mathrm{TiO}_{2}$ nanostructures have been developed to offer single-direction electron transport pathway and extend electron diffusion length [16, 150-153]. Vertically oriented $\mathrm{TiO}_{2}$ nanotube and nanowire arrays are the most important 1D nanostructures in DSSC photoanodes. 

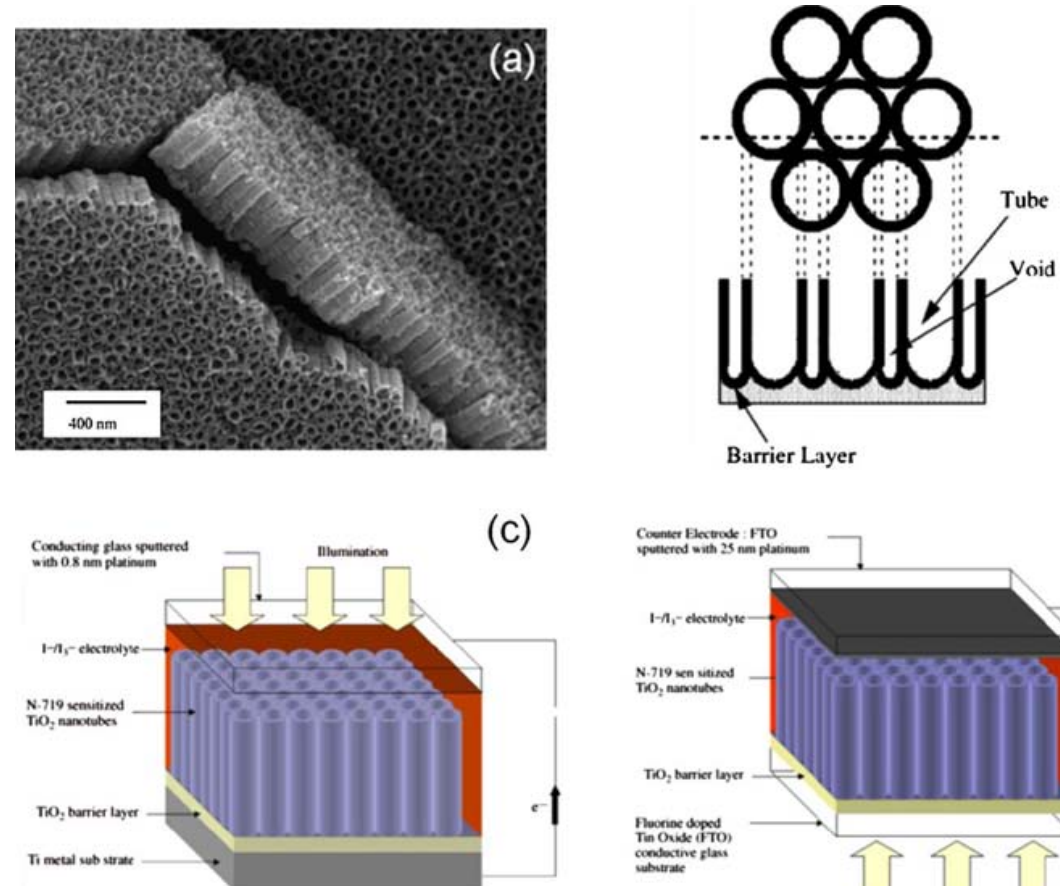

(c)

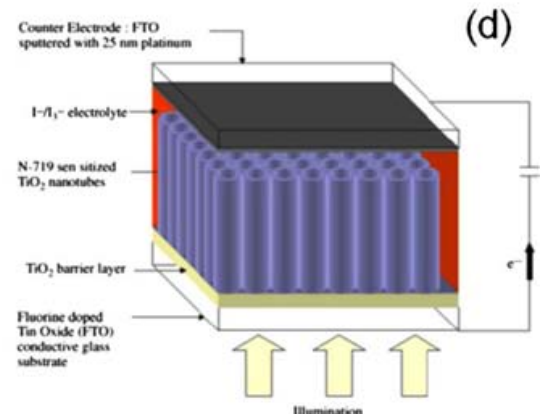

(b)

Figure 2.12 $\mathrm{TiO}_{2}$ nanotubes prepared with an anodization method and their application in DSCs: (a) morphology of the $\mathrm{TiO}_{2}$ nanotube array, (b) growth mechanism of the nanotubes and formation of a barrier layer under the nanotube film, (c) back-side illumination and (d) front-side illumination structures of the DSCs made of $\mathrm{TiO}_{2}$ nanotube array $[16,153]$. Copyright (2010) with permission from Elsevier and Copyright (2006) with permission from Elsevier.

$\mathrm{TiO}_{2}$ nanotube array exhibits large surface area due to its hollow structure as shown in Figure 2.12a. Anodization has been intensively utilized to prepare the nanotube array on a supporting titanium foil, with a typical inner diameter of $20 \sim 30 \mathrm{~nm}$ and a length of several tens micrometers [154-159]. Annealing of the prepared nanotube array at $450{ }^{\circ} \mathrm{C}$ is necessary for the transformation from amorphous to anatase phase [160]. Due to the opaque titanium foil, the DSSCs based on the $\mathrm{TiO}_{2}$ nanotube array need a cell configuration of back-side illumination (Figure 2.12c), with a nearly 
transparent counter electrode, which consists of a $0.8 \mathrm{~nm}$ thick Pt film [161]. A maximum PCE of $4.24 \%$ has been reported from this structured DSSC with a $\sim 6 \mu \mathrm{m}$ thick nanotube array film [162]. An increase in the nanotube length makes no significant contribution to the PCE $[163,164]$, probably due to the existence of an electrically insulating barrier layer between the nanotubes and the titanium foil (Figure 2.12b) [153], the thickness of which increases as the nanotubes grow, aggravating the series resistance of the cells. For the back-side illumination configuration, the light has to pass through the electrolyte before reaching the $\mathrm{TiO}_{2}$ film, which inevitably causes incident light loss. To overcome this drawback, the $\mathrm{TiO}_{2}$ nanotube array was directly prepared on FTO glass through deposition of a titanium film on the FTO substrate and subsequent anodization for the nanotube formation [165, 166], realizing the front-side illumination (Figure 2.12d). However, it is difficult in practice to prepare the high-quality titanium film on FTO glass with the film thickness larger than $1 \mu \mathrm{m}$. Besides, intimate adhesion of the nanotubes on FTO substrate is also challenging. So far, the photoanodes based on the $\mathrm{TiO}_{2}$ nanotube array prepared using this strategy exhibit smaller surface area and lower dye loading, giving a PCE of 2.9\% [167]. A two-step fabrication approach has been reported to address the film thickness limitation [168]. A layer of $\mathrm{TiO}_{2}$ nanotube array was prepared on a titanium foil first using the anodization method and then removed from the titanium foil through an acid treatment. The nanotube array was subsequently transferred onto a FTO glass, where a few drops of titanium isopropoxide were applied for the interconnection between the nanotube array and the FTO substrate. 
Using this approach, a $35 \mu \mathrm{m}$ thick $\mathrm{TiO}_{2}$ nanotube array was successfully transferred onto a FTO glass and the DSSC based on this type of photoanode structure delivered a PCE of 7\% [168].
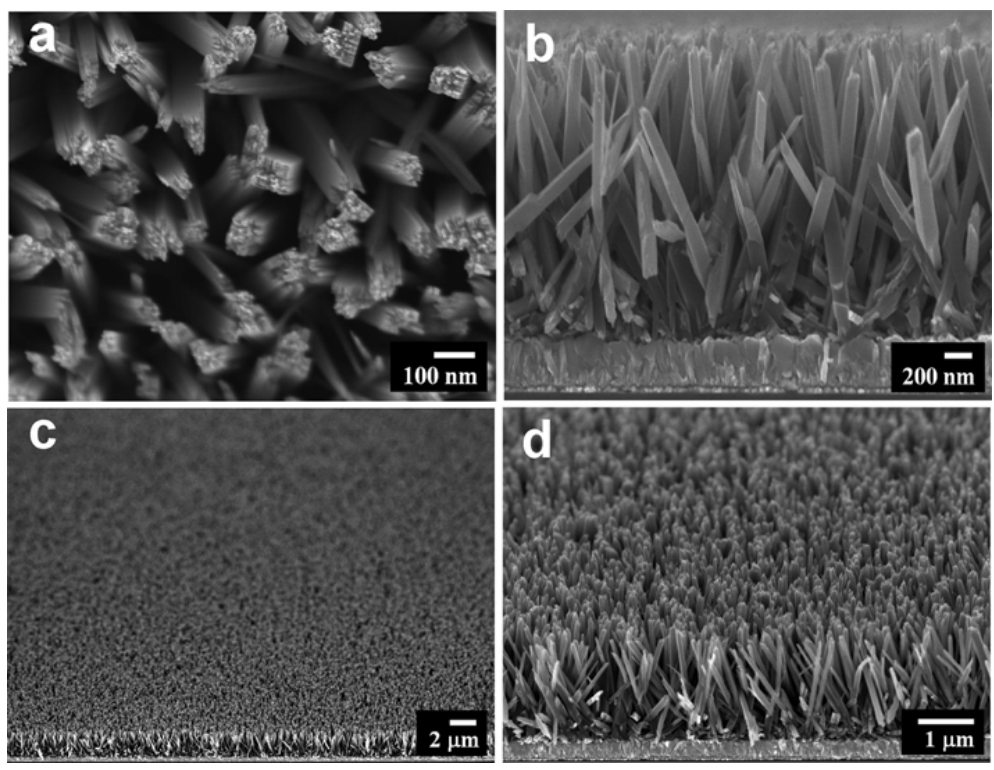

Figure 2.13 FESEM images of oriented rutile $\mathrm{TiO}_{2}$ nanorod array grown on FTO substrate in $30 \mathrm{ml}$ of deionized water, $30 \mathrm{ml}$ of hydrochloric acid, and $1 \mathrm{ml}$ of titanium butoxide at $150{ }^{\circ} \mathrm{C}$ for $20 \mathrm{~h}$ : (a) top view, (b) cross-sectional view, (c) and (d) tilted cross-sectional views [152]. Copyright (2009) with permission from American Chemical Society.

$\mathrm{TiO}_{2}$ nanowire arrays also exhibit superior electron transport properties as the DSSC photoanodes, and the preparation of the nanowire arrays on FTO substrates is much simpler, compared to the $\mathrm{TiO}_{2}$ nanotube array [151, 152]. Hydrothermal synthesis using $\mathrm{HCl}$ containing precursor is the main approach for direct preparation of $\mathrm{TiO}_{2}$ nanowire array on FTO substrate (Figure 2.13), with the single-crystal rutile nanowires grown along [001] orientation with exposed (110) crystal plane [92, 152]. Highly acidic condition and selective adsorption of $\mathrm{Cl}^{-}$on rutile (110) plane promote 
the anisotropic growth of $\mathrm{TiO}_{2}$ nanowires [169]. The single-crystal rutile nanowires exhibited fast electron transport rate due to the high electron diffusion coefficient and low density of sub-bandgap defect states [92]. The photoanode based on this nanowire array gave an overall PCE of $\sim 5 \%$ and a remarkable maximum IPCE of $\sim 90 \%$, implying a low charge recombination and efficient charge collection [151, 152]. A performance comparison study between rutile $\mathrm{TiO}_{2}$ nanowires and nanoparticles has revealed that the efficiency achieved by a $2 \sim 3 \mu \mathrm{m}$ thick rutile nanowire photoanode is higher than that achieved by a $5 \mu$ m thick rutile nanoparticle film [89], which confirms the better charge transport in the one-dimensional nanostructures.

\subsubsection{Hierarchical $\mathrm{TiO}_{2}$ microspheres: the multi-functional photoanode materials}

A high-performance photoanode is expected to possess large specific surface area for sufficient dye loading, strong scattering effect to compensate the low light absorption efficiency of the sensitizer (typically N719 or N3) in the red region, and effective electron transport. However, the above features usually negate each other for nanocrystalline based anode films. For instance, thick photoanode films prepared using $\mathrm{TiO}_{2}$ nanoparticles exhibit large specific surface area, inevitably accompanied by a large amount of grain boundaries, which is unfavourable for efficient electron transport in the $\mathrm{TiO}_{2}$ matrix. Besides, strong scattering effect requires large particles, the specific surface area of which is usually low, leading to reduction of dye loading. To balance the surface area and the scattering effect of a photoanode, a scattering layer consisting of large $\mathrm{TiO}_{2}$ particles is usually applied on top of the nanocrystalline 
$\mathrm{TiO}_{2}$ film, as shown in Figure 2.14. However, this structure would increase the series resistance of the DSSCs.

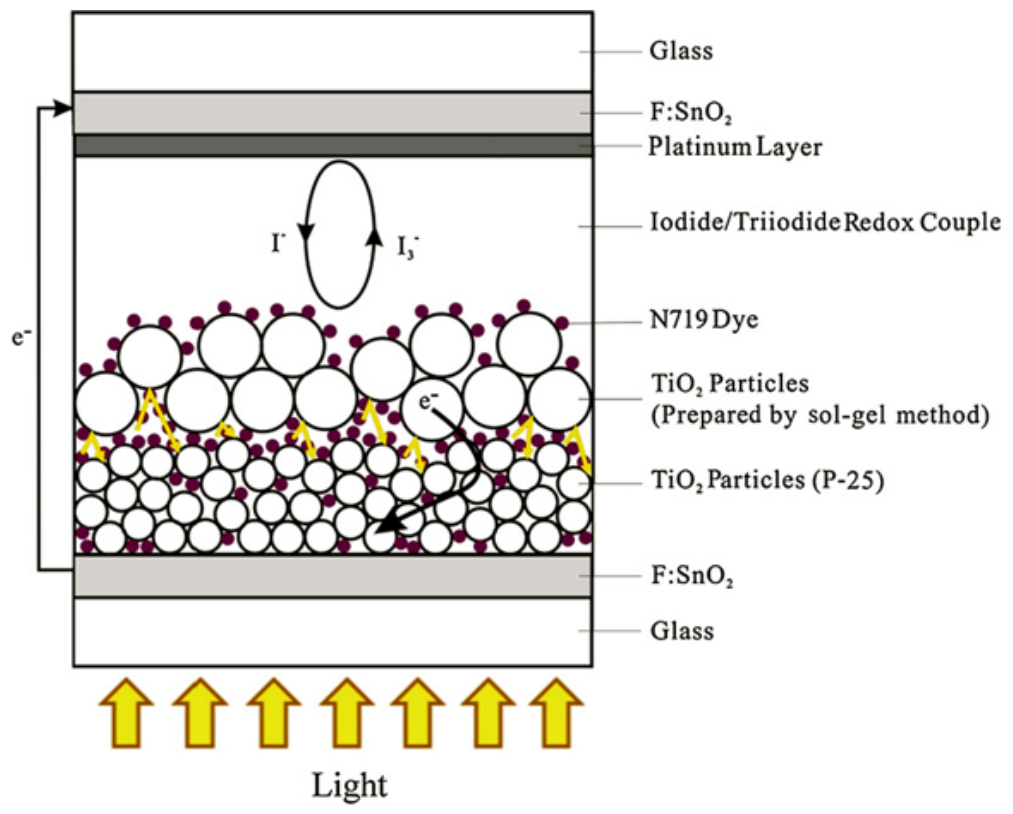

Figure 2.14 Schematic of the DSSC with a scattering layer consisting of $\mathrm{TiO}_{2}$ particles prepared by the sol-gel method [170]. Copyright (2011) with permission from Elsevier.

Hierarchical $\mathrm{TiO}_{2}$ microspheres have been synthesized and investigated as the multi-functional photoanode materials to combine the features of large surface area and strong scattering effect, without inducing any extra series resistance [171-179]. The microspheres are capable of enhancing the scattering effect of the photoanode due to its micron size while maintaining or even increasing the surface area due to its nanoscale primary unit, such as nanoparticles (Figure 2.15), nanosheets and nanorods. Besides, the bigger inter-particle pores formed by the microspheres are capable of facilitating the diffusion of $\mathrm{I}_{3}{ }^{-}$in the photoanode films, as illustrated in Figure 2.15c $[34,180]$. 

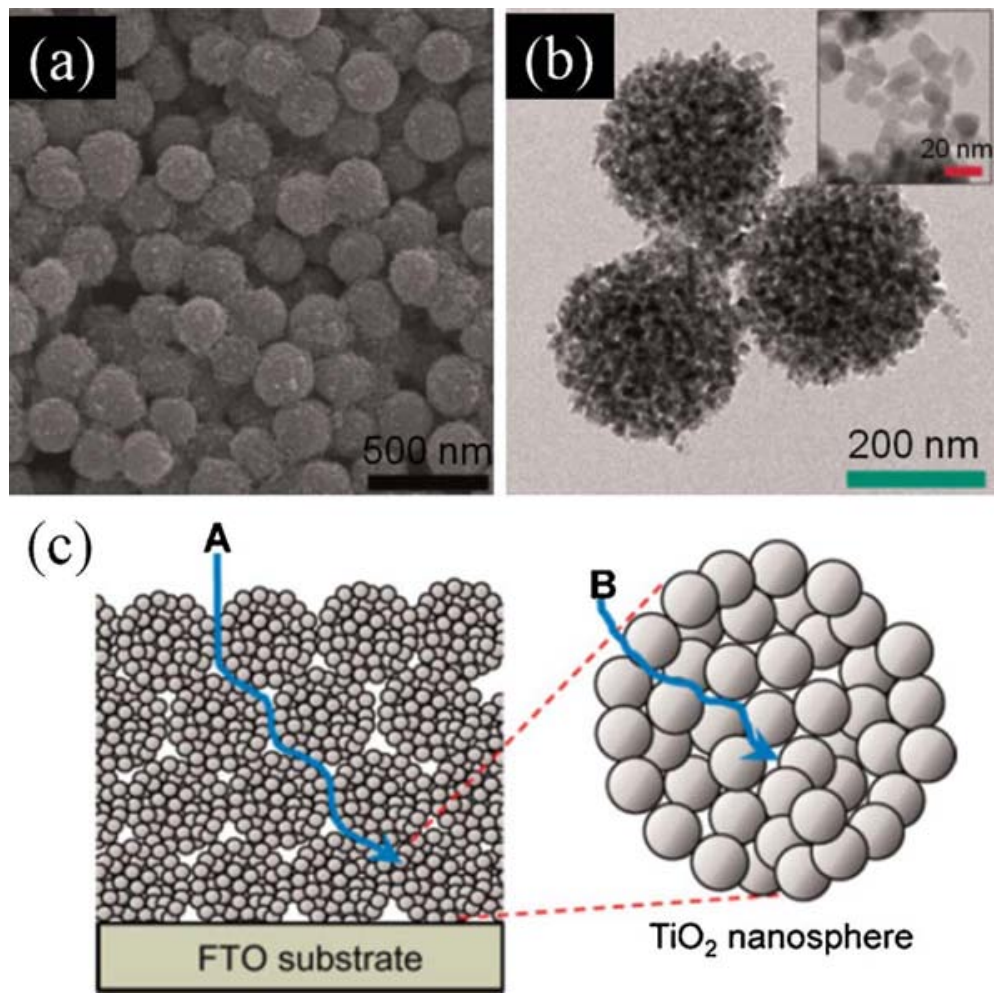

Figure 2.15 Nanoporous $\mathrm{TiO}_{2}$ spheres for application in DSCs: (a) SEM and (b) TEM images of nanoporous $\mathrm{TiO}_{2}$ spheres, and (c) schematic diagram showing the electrolyte diffusion through the external (A) and internal (B) pores in the film made of nanoporous $\mathrm{TiO}_{2}$ spheres [180]. Copyright (2011) with permission from John Wiley and Sons.

Nanoporous $\mathrm{TiO}_{2}$ spheres prepared via a two-step method have exhibited a high surface area of $117.9 \mathrm{~m}^{2} \mathrm{~g}^{-1}$. The DSSCs based on the $\mathrm{TiO}_{2}$ spheres yielded an overall conversion efficiency as high as $10.5 \%$ [180]. Mesoporous $\mathrm{TiO}_{2}$ beads with high surface area and controllable pore size has been prepared using a combined sol-gel and solvothermal process. The DSSCs based on the mesoporous beads gave a PCE of 7.20\%, higher than that (5.66\%) based on the P25 nanoparticles [181]. A novel hydrothermal route has been developed to prepare $200 \mathrm{~nm} \mathrm{TiO}_{2}$ hierarchical spheres 
with a surface area of $193 \mathrm{~m}^{2} \mathrm{~g}^{-1}$. Compared to P25-based photoanode, a 40\% of PCE enhancement has been obtained using the hierarchical spheres as photoanode material [34]. The structure of the microspheres has been optimized with different building unit, such as (001) facet-dominated $\mathrm{TiO}_{2}$ nanosheet [178], tetragonal $\mathrm{TiO}_{2}$ nanorods [182], and $\mathrm{TiO}_{2}$ nanospindles [177].

\subsubsection{Surface modification of $\mathrm{TiO}_{2}$ electrodes}

\section{$\mathrm{TiCl}_{4}$ treatment}

To facilitate dye adsorption and charge transport, extensive studies have been carried out on the surface modification of $\mathrm{TiO}_{2}$ nanoparticles. The treatment of $\mathrm{TiO}_{2}$ surface using $\mathrm{TiCl}_{4}$ is a widely used technique to enhance the performance of the DSSCs. The purposes of the $\mathrm{TiCl}_{4}$ treatment are as follows: (i) increasing the density of specific binding sites for enhanced dye loading [183-185], (ii) lowering the CB edge of $\mathrm{TiO}_{2}$ to improve the injection efficiency [183], and (iii) enhancing the interparticular connection for efficient electron transport [186].

\section{Over coating of second semiconductor with different band gap}

Interfacial charge recombination between the photogenerated electrons and the electrolyte causes a loss of photogenerated electrons $[187,188]$, and affects the $\mathrm{V}_{\text {oc }}$ by decreasing the electron concentration in the $\mathrm{CB}$ of $\mathrm{TiO}_{2}$ and $J_{\mathrm{sc}}$ by decreasing the forward injection current [189-191]. Incorporation of a second semiconductor with a different band gap to create a core-shell structure is considered as a viable strategy to suppress the interfacial charge recombination. 
Usually, the nanocrystalline $\mathrm{TiO}_{2}$ as the core material is deposited on the FTO substrate first and then a layer of shell material is coated on the $\mathrm{TiO}_{2}$ surface. The CB level of the shell material should be higher than that of the core material to establish an energy barrier at the semiconductor/electrolyte interface, which retards the back electron transport and the charge recombination [16].

The use of $\mathrm{Nb}_{2} \mathrm{O}_{5}$ shell has been reported to increase both the $\mathrm{V}_{\mathrm{oc}}$ and the $J_{\mathrm{sc}}$, giving a PCE enhancement of $37 \%[187,191,192]$. Different from $\mathrm{Nb}_{2} \mathrm{O}_{5}$, a shell layer of other semiconductor like $\mathrm{ZnO}, \mathrm{SrTiO}_{3}, \mathrm{ZrO}_{2}, \mathrm{Al}_{2} \mathrm{O}_{3}$, has been suggested to yield a surface dipole layer, which can cause an increase in the $\mathrm{V}_{\mathrm{oc}}$ and a decrease in the $J_{\text {sc }}$, eventually producing $~ 15 \%$ PCE enhancement for $\mathrm{ZnO}, \mathrm{SrTiO}_{3}, \mathrm{Al}_{2} \mathrm{O}_{3}$ and $~$ 11\% PCE decrease for $\mathrm{ZrO}_{2}$ [187]. However, in another work, the $\mathrm{Al}_{2} \mathrm{O}_{3}$-coated $\mathrm{TiO}_{2}$ nanocrystalline anode has achieved a PCE enhancement of 35\% with increased $V_{\text {oc }}$ and $J_{\mathrm{sc}}$ [193], which is attributed to the formation of an energy barrier at the semiconductor/electrolyte interface, due to the incorporation of the $\mathrm{Al}_{2} \mathrm{O}_{3}$ shell.

The mechanism of the core-shell structures used in DSCs remains unclear. The inconsistency results reported in literature are probably due to the difficulty of creating a shell layer with ideal thickness, coverage, and electrical coupling to the semiconductor core $[16,193]$. Research on this topic is still facing challenges on both scientific and technical aspects.

\section{Acid treatment}

The $\mathrm{TiO}_{2}$ surface has been also treated with different acids (such as $\mathrm{HCl}, \mathrm{HNO}_{3}$ and $\mathrm{H}_{3} \mathrm{PO}_{4}$ ) and the effect of the treatment on the photovoltaic performance of the DSSCs 
has been investigated. Acid treatment usually increases the dye adsorption by protonating the $\mathrm{TiO}_{2}$ surface [194]. Besides, anions in the acid solution such as $\mathrm{NO}^{3-}$ is reported to increase the electron lifetime via an adsorption process [195].

\subsubsection{Electronic structure modification of $\mathrm{TiO}_{2}$ nanocrystals}

Research on doped $\mathrm{TiO}_{2}$ has been extensively performed to improve its electronic structure and surface properties [196, 197]. $\mathrm{Al}$ and $\mathrm{W}$ doped $\mathrm{TiO}_{2}$ have been introduced into the DSSC photoanodes [197]. It is observed that the Al-doped $\mathrm{TiO}_{2}$ based anodes exhibits increased $\mathrm{V}_{\text {oc }}$ but reduced $J_{\mathrm{sc}}$, while $\mathrm{W}$-doped $\mathrm{TiO}_{2}$ shows the opposite effects as photoanode materials. The $\mathrm{Al}$ and $\mathrm{W}$ co-doped $\mathrm{TiO}_{2}$ increases the DSSC efficiency by enhancing the photovoltage and photocurrent [197]. Al, Ta and Sb doped $\mathrm{TiO}_{2}$ have been reported to increase the $J_{\text {sc }}$ of DSSCs and suppress the charge recombination [198-200]. Sn doping not only increases the $J_{\mathrm{sc}}$, but also shifts the flat band potential $\left(\mathrm{V}_{\mathrm{fb}}\right)$ of $\mathrm{TiO}_{2}$ negatively to increase the $\mathrm{V}_{\mathrm{oc}}$, therefore increasing the PCE by 12.1\% [201]. Recently, the effect of Nb doping on the performance of DSSCs has been reported [202-204]. As activated Nb in Ti site provides free electrons and lowers the $\mathrm{CB}$ edge at the $\mathrm{TiO}_{2}$ surface, the $\mathrm{Nb}$ doping can shift the $\mathrm{V}_{\mathrm{fb}}$ positively and increase the conductivity of the $\mathrm{TiO}_{2}$ films, therefore improving the electron injection from the excited dye to $\mathrm{TiO}_{2}$ and charge transport within $\mathrm{TiO}_{2}$ films. Ultimately, the $J_{\text {sc }}$ of Nb-doped $\mathrm{TiO}_{2}$ DSSCs increase by $\sim 50 \%$ [205]. However, the donor doping generally shows two negative effects. The increase in the conductivity decreases the shunt resistance and the positive shift of $\mathrm{V}_{\mathrm{fb}}$ decrease 
the electric potential of the electrons extracted from $\mathrm{TiO}_{2}$. As a result, there is a compromise among $J_{\mathrm{sc}}, \mathrm{V}_{\mathrm{oc}}$ and FF, and the donor doping mainly increases $J_{\mathrm{sc}}$ but decreases $\mathrm{V}_{\text {OC }}$ and FF [205].

Another way to control the electronic structure of $\mathrm{TiO}_{2}$ is to dope anion impurities to its oxygen site. Since the discovery of the visible light response of $\mathrm{N}$-doped $\mathrm{TiO}_{2}$, several anions such as $\mathrm{N}, \mathrm{C}, \mathrm{S}$, and F have been explored to enhance the visible light absorption of $\mathrm{TiO}_{2}$ [206-212]. Formation of non-oxide phase and new defect level slightly above the VB of $\mathrm{TiO}_{2}$ has been suggested to cause the red shift of the $\mathrm{TiO}_{2}$ absorption spectrum and change the electrical properties of the anion doped $\mathrm{TiO}_{2}$ [213]. The effect of the anion doping on DSSCs is related to the thermodynamic stability of the oxygen vacancies of $\mathrm{TiO}_{2}$. The replacement of oxygen with nitrogen forms O-Ti-N bond, which decreases the concentration of oxygen vacancy and shifts the flat band potential of $\mathrm{TiO}_{2}$ films [206]. These reduce the electron trapping at the defect sites, thereby increasing the electron lifetime and DSSC stability. B-doped $\mathrm{TiO}_{2}$ photoanodes increase the $J_{\mathrm{sc}}$ of DSSCs with significantly enhanced IPCE over a wide range of 370-680 nm. N, B co-doping effectively increases the PCE and stability of DSSCs and suppresses the charge recombination at the $\mathrm{TiO}_{2} /$ dye/electrolyte interface [201]. 


\section{Chapter 3 Research Methodology}

\subsection{Chemicals and materials}

Titanium isopropoxide (97\%), titanium(III) chloride solution (12\% in hydrochloric acid, 5-10\% free acid), titanium(IV) chloride ( $\geq 99 \%$ ), phosphorus pentoxide ( $\geq 98 \%$ ), sulfuric acid (95-98\%), potassium peroxodisulfate $(\geq 99 \%)$, Hydrogen peroxide (30\%), ethyl cellulose (5-15 mPa.s), ethyl cellulose (30-60 mPa.s), terpineol (anhydrous), benzyl alcohol (99.8\%), acetic acid (99.8\% ) and ethanol (anhydrous) were purchased from Sigma. Potassium permanganate ( $\geq 99 \%)$, ethanol (99.8\%), nbutanol ( $\geq 99 \%$ ) and hydrochloric acid (37\%) were supplied by Merck. Dye sensitizer $\left[\mathrm{RuL}_{2}(\mathrm{NCS})_{2}\right.$ : 2 TBA], also known as N719, and the liquid iodide electrolyte (Iodolyte AN-50) were purchased from Solaronix. Nature graphite was supplied from Bay Carbon. FTO coated glass substrate $\left(7-8 \Omega \square^{-1}\right)$ was obtained from Nippon Glass Sheet Company. Deionized (DI) water (18.2 M $)$ ) from a Millipore Q water purification system was used in all experiments.

\subsection{Fabrication of DSSC}

\subsubsection{Preparation of screen-printing pastes}

The screen-printing pastes were prepared with the obtained samples by following the below flow chart in Figure 3.1. The ethyl cellulose solution (10\% in ethanol) was prepared using ethyl cellulose (5-15 mPa.s) and ethyl cellulose (30-60 mPa.s) with a weight ratio of 9:7. 


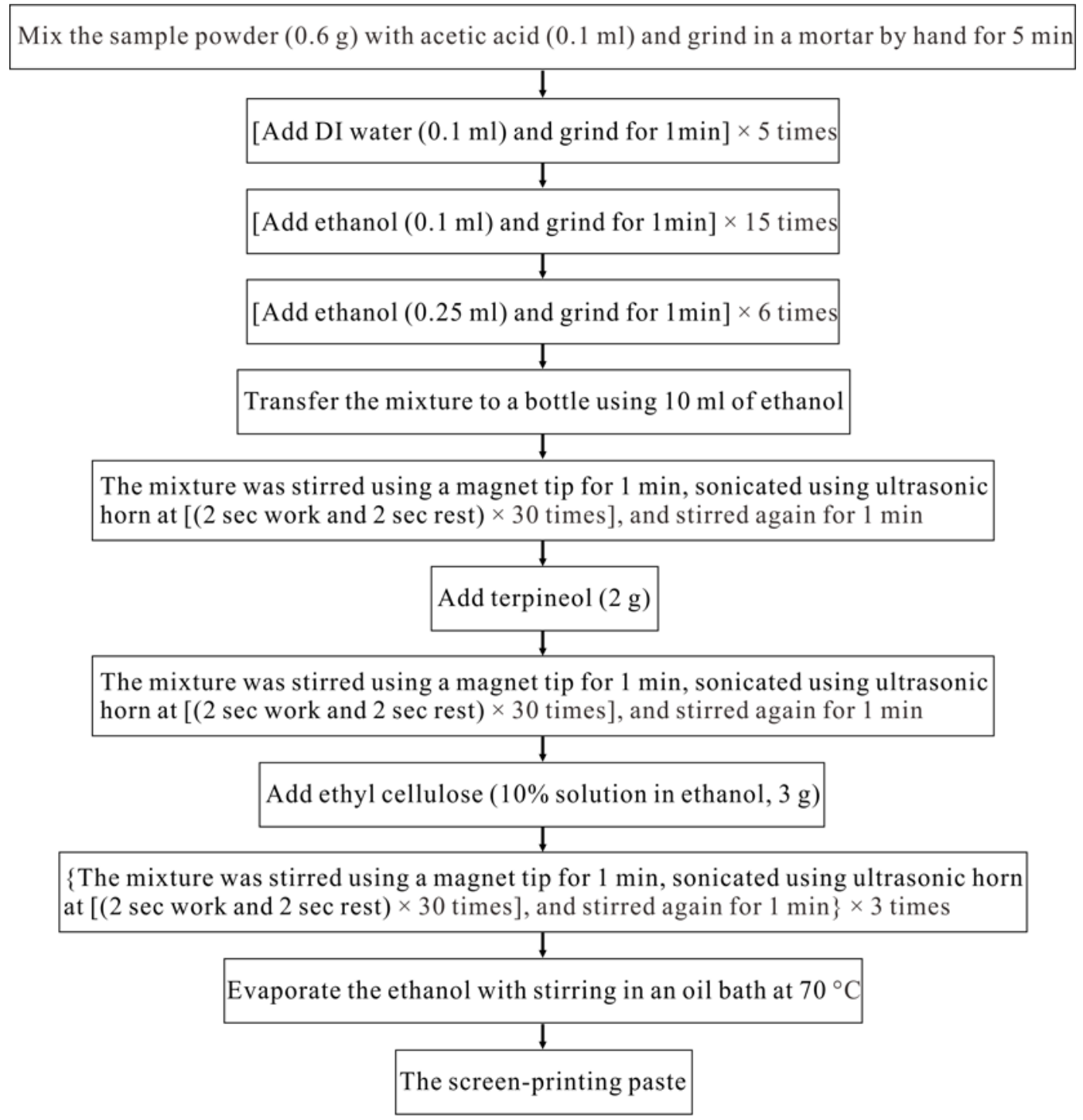

Figure 3.1 Fabrication scheme of the screen-printing pastes.

\subsubsection{Preparation of photoanode}

The FTO glass was ultrasonicated in detergent solution for 60 min and then washed 5 times in DI water for 20 min per time. The cleaned FTO glass was immersed in 40 $\mathrm{mM} \mathrm{TiCl}{ }_{4}$ solution at $70{ }^{\circ} \mathrm{C}$ for 30 min and then rinsed using DI water and ethanol. After drying in air, a layer of the as-prepared paste was coated on the FTO glass via a doctor-blade technique using a 3M Scotch tape with a hollow circle part (area $\sim 0.201$ $\mathrm{cm}^{2}$ ) as spacer (see Figure 3.2 for detailed information). After film relaxing in air for 
$3 \mathrm{~min}$, the coated FTO glass was placed on a hotplate at $125^{\circ} \mathrm{C}$ for $10 \mathrm{~min}$ to dry the film. The printing was repeated until the film reached to desired thickness. Subsequently, the coated FTO glass was calcinated in air to remove the ethyl cellulose and other additives. The annealed film was treated with $\mathrm{TiCl}_{4}$ solution again as described above, and calcinated at $450{ }^{\circ} \mathrm{C}$ for $30 \mathrm{~min}$. After natural cooling to $70{ }^{\circ} \mathrm{C}$, the electrode was sensitized by immersing in anhydrous ethanol solution, containing $0.4 \mathrm{mM}$ N719 dye for $20 \mathrm{~h}$. The sensitized electrode was washed using anhydrous ethanol for 3 times and dried in a drying cabinet to obtain the photoanode for device assembly.

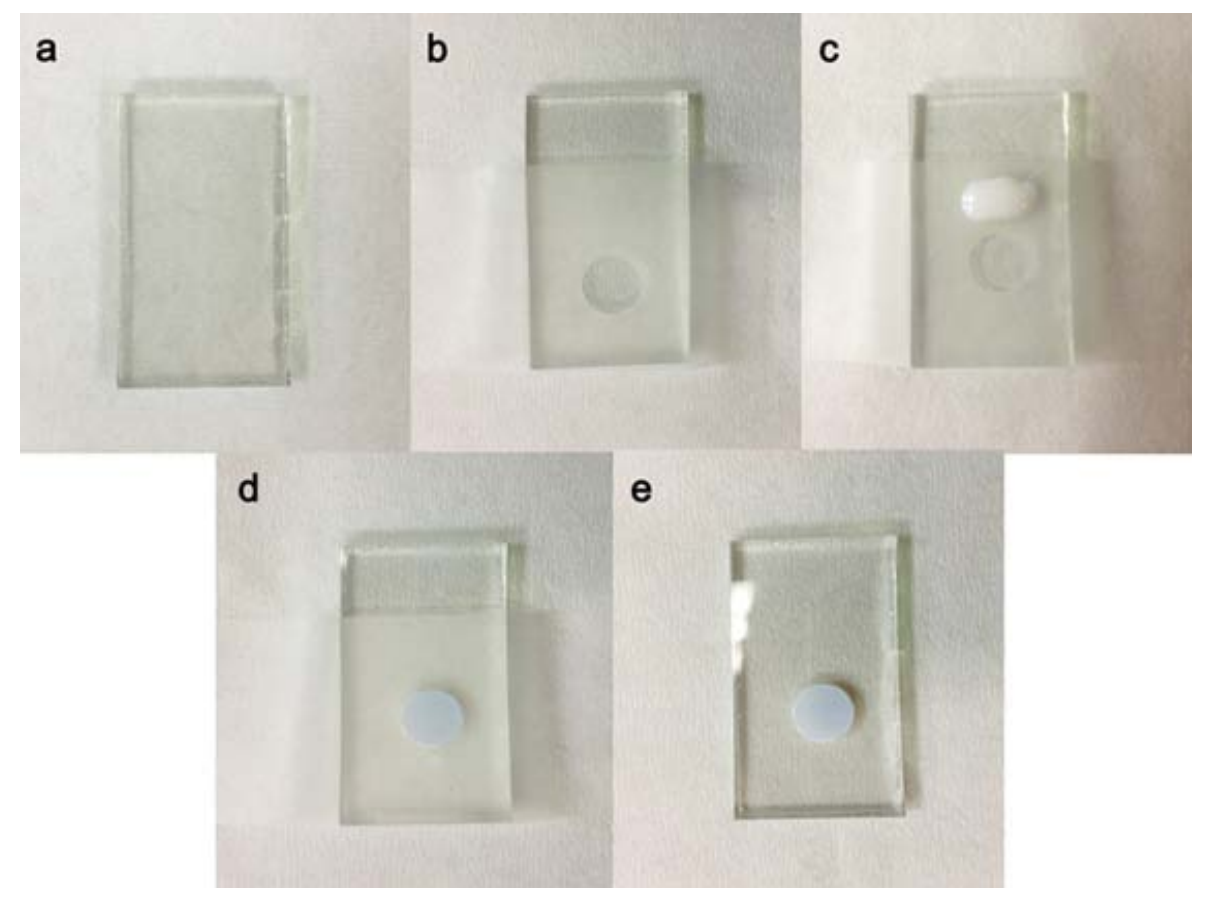

Figure 3.2 Photographs of a cleaned FTO substrate (a), FTO substrate with patterned 3M tape (b), FTO substrate with the tape and loaded paste (c), FTO substrate with the tape and paste film flatten using a razor blade (d) and FTO substrate with paste film after removal of the tape (e). 


\subsubsection{Preparation of platinized counter electrode as cathode}

Two pinholes with a diameter of $\sim 1 \mathrm{~mm}$ were first drilled across a FTO glass, after which the FTO glass was washed using the detergent and DI water as described above. Subsequently, a layer of platinum was sputtered onto the FTO substrate under 8 9 Pa at an applied current of $20 \mathrm{~mA}$ for $60 \mathrm{~s}$ using a JFC-1600 fine coater (JOEL Ltd, Japan).

\subsubsection{Assembly of device}

The photoanode was sandwiched with platinum-coated FTO counter electrode and sealed using a 20 or $35 \mu \mathrm{m}$ thick polypropylene spacer between the two electrodes through a thermal melting process at $70{ }^{\circ} \mathrm{C}$. The liquid iodide electrolyte was injected into the internal space of the device through a pre-drilled pinhole of the counter electrode, with the other pinhole for air escaping from the sealed compartment. After the injection, both pinholes were sealed with a piece of parafilm and a small cover slip. The detailed configuration of the DSSC devices fabricated in this research project is shown in Figure 3.3.

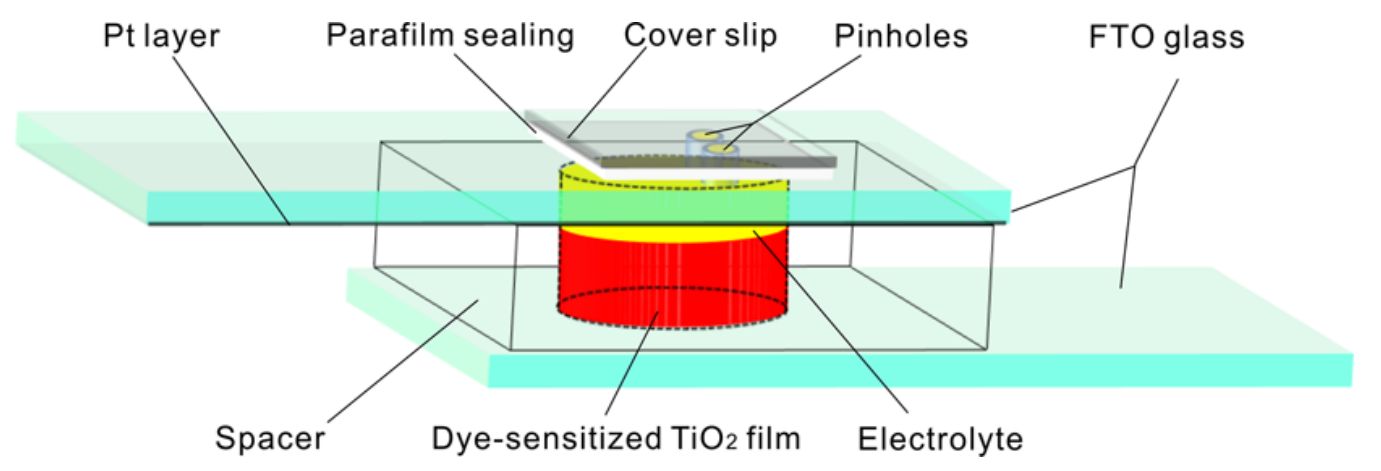

Figure 3.3 Scheme of a DSSC device. 


\subsection{Characterizations}

\subsubsection{Material characterization}

1) The morphology and thickness of the graphene oxide nanosheets were evaluated by an atomic force microscopy (AFM, Asylum Research, MFP 3D).

2) The morphologies of the obtained samples were investigated using a transmission electron microscopy (TEM, JEOL-2010 microscopes) at $200 \mathrm{kV}$.

3) The phases of $\mathrm{TiO}_{2}$ was identified by $\mathrm{X}$-ray diffraction (XRD) analysis using a Bruker D8 X-ray diffractometer with $\mathrm{Cu} \mathrm{K} \alpha$ radiation as the $\mathrm{X}$-ray source $(\lambda=$ $1.5406 \AA)$.

4) Raman spectra were obtained using a Renishaw inVia Raman microscope with excitation wavelength at $514.5 \mathrm{~nm}$ in a backscattering configuration to identify materials and study their physical properties.

5) The morphologies of the $\mathrm{TiO}_{2}$ samples and electrodes were observed using a field emission scanning electron microscopy (FESEM, JEOL JSM-6700F).

6) The particle size distribution was evaluated by a particle size analyzer (90Plus, Brookhaven Instruments Corporation).

7) The UV-Vis DRS of the obtained powders were recorded on a UV-Vis spectrophotometer (UV-Vis, Varian Cary 5000).

8) The concentration of graphene in the anode films was determined using an energy dispersive spectroscopy (EDS) equipped on the FESEM, JEOL JSM6700F. 
9) The specific surface area and pore volume of the samples and the electrode films were measured with a commercial pore and surface analyzer (Quantachrome Adsorb-6B) and calculated using the Brunauer-Emmett-Teller (BET) equation and Barrett-Joyner-Halenda (BJH) methods.

\subsubsection{Conducting AFM characterization}

All c-AFM dark current images and nano I-V curves were collected using an Asylum MFP3D mounted atop an Olympus inverted optical microscope under $\mathrm{N}_{2}$ atmosphere. Platinum-coated silicon AFM tips were used with a resonant frequency of $\sim 10 \mathrm{kHz}$ and a force constant of $\sim 4.0 \mathrm{~N} \mathrm{~m}^{-1}$. The current images of the composite electrodes were obtained at $-5 \mathrm{~V}$ applied to the FTO substrate.

\subsection{Performance evaluations}

\subsubsection{Photocurrent density-voltage $(J-V)$ characteristics}

The $J$-V characteristics of the DSSCs with different electrodes were measured by using an electrochemical analyzer (Keithley 2420 SourceMeter) under simulated sunlight (ABET Technologies Sun 2000 Solar Simulator, 100mW cm ${ }^{-2}$, AM 1.5G spectrum).

\subsubsection{Incident photon-to-current conversion efficiency (IPCE)}

The IPCE evaluation was conducted using a Newport lamp $\left(100 \mathrm{~mW} \mathrm{~cm}^{-2}\right)$ with light filters as monochromatic light source and a Si-based photovoltaic cell as reference. 


\subsubsection{Electrochemical impedance spectra (EIS)}

The EIS were performed using PARSTAT 2273 Advanced Electrochemical system (Princeton Applied Research) with frequency range from $0.1 \mathrm{~Hz}$ to $100 \mathrm{kHz}$ at an applied bias of $\mathrm{V}_{\text {oc }}$ under the illumination of one sun. 


\section{Chapter 4 Nanostructure control of graphene-composited $\mathrm{TiO}_{2}$ by a one-step solvothermal approach for high performance dye-sensitized solar cells ${ }^{1}$}

\subsection{Introduction}

Graphene, an atomic sheet composed of $s p^{2}$ hybridized carbon, has drawn much attention due to its unique mechanical and electrical properties and high theoretical surface area [133-136, 214, 215]. Graphene has been extensively investigated as a support material and electron transfer medium in inorganic composites for various applications, such as electrocatalysis, supercapacitors, hydrogen storage, and photovoltaic devices [216-221].

$\mathrm{TiO}_{2}$ is an important semiconductor with high photoactivity, good stability and relatively low toxicity $[85,143,222]$. Since the incorporation of $\mathrm{TiO}_{2}$ nanomaterials into photoanode, the power conversion efficiency (PCE) of dye-sensitized solar cells (DSSCs) has increased remarkably, thus providing a promising solar harvesting technology [29]. The enhanced performance is due to increased dye adsorption in the nanostructured $\mathrm{TiO}_{2}$ film and suitable electronic structure of $\mathrm{TiO}_{2}$. However, one of the major challenges for $\mathrm{TiO}_{2}$ DSSC commercialization is to enhance the electron transport across the $\mathrm{TiO}_{2}$ matrix to further improve the DSSC performance [142].

To date, numerous synthetic methods to produce graphene- $\mathrm{TiO}_{2}$ composites as photoanode materials have been reported [141, 142, 144, 223]. The incorporation of

\footnotetext{
${ }^{1}$ Reproduced from [Z.M. He, G.H. Guai, J. Liu, C.X. Guo, J.S.C. Loo, C.M. Li, and T.T.Y. Tan, Nanoscale, 2011. 3(11): 4613-4616] with permission from The Royal Society of Chemistry.
} 
graphene can improve the performance of $\mathrm{TiO}_{2}$-based DSSCs through enhancing electron transport while suppressing charge recombination [142, 224]. It is known that the photoactivity and electronic structure of $\mathrm{TiO}_{2}$ are strongly dependent on its nanostructure [225, 226]. For instance, smaller $\mathrm{TiO}_{2}$ nanoparticles generally provide higher specific surface area for higher photocatalytic activities and sometime result in higher band gap [227-229]. When the $\mathrm{TiO}_{2}$ nanoparticle is smaller than $20 \mathrm{~nm}$, the decrease in particle size usually results in decreased dye loading of the DSSC photoanodes due to poor infiltration of dye molecules into the anode film with small inter-particle pores [230]. However, the effect of graphene-composited $\mathrm{TiO}_{2}$ nanostructure on the DSSC performance has not been studied. The graphene nanosheets can serve as the support material and electron bridge in the anodes to enhance the film porosity and electron transport, which may be able to eliminate the negative effects induced by small $\mathrm{TiO}_{2}$ particles. Solvothermal alcoholysis has been widely used for preparing $\mathrm{TiO}_{2}$ with controllable morphology and high crystallization degree [231]. Solvothermal syntheses of $20 \mathrm{~nm}$ spherical $\mathrm{TiO}_{2}$-graphene composites and $\mathrm{TiO}_{2}$ nanosheet-graphene composites have been recently reported [215, 225], which confirms the potential application of solvothermal alcoholysis in the preparation of graphene- $\mathrm{TiO}_{2}$ composites with delicately controlled $\mathrm{TiO}_{2}$ nanostructures. Herein we report a one step solvothermal approach to prepare different graphene- $\mathrm{TiO}_{2}$ composites, including $12 \mathrm{~nm}$ spherical $\mathrm{TiO}_{2}$-graphene nanosheets (STG), ultra-small $2 \mathrm{~nm} \mathrm{TiO}_{2}$-graphene nanosheets (USTG), and $\mathrm{TiO}_{2}$ nanorod-graphene nanosheets (NRTG), by simply adjusting the solvothermal reaction 
conditions. The prepared composites were used to fabricate DSSC photoanodes and the effect of graphene-composited $\mathrm{TiO}_{2}$ nanostructure on the device properties was investigated.

\subsection{Experimental}

\subsubsection{Synthesis of graphene oxide nanosheets}

Graphene oxide (GO) was prepared via a modified Hummers’ method [139]. Graphite powder $(0.3 \mathrm{~g})$ was added into a solution of concentrated $\mathrm{H}_{2} \mathrm{SO}_{4}(1.2 \mathrm{ml})$, $\mathrm{K}_{2} \mathrm{~S}_{2} \mathrm{O}_{8}(0.5 \mathrm{~g})$, and $\mathrm{P}_{2} \mathrm{O}_{5}(0.5 \mathrm{~g})$ at $80{ }^{\circ} \mathrm{C}$ and stirred for $4.5 \mathrm{~h}$. After natural cooling to room temperature, the mixture was diluted with $100 \mathrm{ml}$ of DI water and filtered using a 0.22 micron Nylon Millipore filter, followed by washing with DI water to remove the residual acid. After drying at $60{ }^{\circ} \mathrm{C}$, the acid-treated graphite was removed from the filter and added into $12 \mathrm{ml}$ of concentrated $\mathrm{H}_{2} \mathrm{SO}_{4}$ in an ice bath. Subsequently, $1.5 \mathrm{~g}$ of $\mathrm{KMnO}_{4}$ were slowly added into the mixture under stirring to keep the temperature of the mixture below $20^{\circ} \mathrm{C}$. After stirring for $2 \mathrm{~h}$ at $35^{\circ} \mathrm{C}$, the mixture was diluted by dropwise adding $25 \mathrm{ml}$ of DI water in the ice bath to keep the temperature below $50{ }^{\circ} \mathrm{C}$. Additional $70 \mathrm{ml}$ of DI water were added after $2 \mathrm{~h}$ stirring of the mixture at room temperature. Shortly after the dilution, $2.5 \mathrm{ml}$ of $\mathrm{H}_{2} \mathrm{O}_{2}$ were added, and the color of the mixture changed to brilliant yellow along with bubbling. After washing with $\sim 1.2 \mathrm{M} \mathrm{HCl}$ aqueous solution for 5 times and DI water for 10 times, the final solid (graphite oxide) was dried under vacuum at $60{ }^{\circ} \mathrm{C}$. GO was obtained by sonicating the graphite oxide in DI water for $1 \mathrm{~h}$ at desired concentration. 
To obtain well-exfoliated GO sheets and avoid their aggregation during the drying process, GO aqueous suspension was dried through a freeze-drying approach.

\subsubsection{Synthesis of graphene- $\mathrm{TiO}_{2}$ nanocomposites}

The solvothermal approach for producing different graphene- $\mathrm{TiO}_{2}$ composites is shown in Figure 4.1. $10 \mathrm{mg}$ of GO were resuspended in $30 \mathrm{ml}$ of organic solvents by sonication for $30 \mathrm{~min}$. The solvents for STG, USTG and NRTG were ethanol (EtOH), benzyl alcohol (BzOH) and EtOH (1:2 in volume), and acetic acid (AcOH) and $\mathrm{BzOH}$ (3:17 in volume), respectively. $1 \mathrm{ml}$ of TIP was then dropwise into GO dispersion under stirring. Through sonication for $1 \mathrm{~h}$, organic titanium molecules uniformly grafted on the GO sheets by chemisorption [144]. The reduction of GO and crystallization of $\mathrm{TiO}_{2}$ were achieved simultaneously through one-step solvothermal reactions. Reaction conditions were $180{ }^{\circ} \mathrm{C}$ for $24 \mathrm{~h}, 150{ }^{\circ} \mathrm{C}$ for $12 \mathrm{~h}$ and $150{ }^{\circ} \mathrm{C}$ for $12 \mathrm{~h}$, for STG, USTG and NRTG, respectively. The resulting composites were collected by filtration, rinsed by ethanol to remove the free $\mathrm{TiO}_{2}$ particles and dried under vacuum. To facilitate comparison, pure $12 \mathrm{~nm}$ spherical $\mathrm{TiO}_{2}, 2 \mathrm{~nm}$ ultra-small $\mathrm{TiO}_{2}$ and $\mathrm{TiO}_{2}$ nanorods were prepared in a similar manner but without the addition of GO. These control samples were labelled as STG-Ctr, USTG-Ctr and NRTG-Ctr, respectively.

\subsubsection{Preparation of the electrodes}

The electrodes were prepared by doctor-blade technique using above materials on FTO glass and calcined at $450{ }^{\circ} \mathrm{C}$ in air for different time, without the $\mathrm{TiCl}_{4}$ post 
treatment. The thickness and active area of electrode films were controlled at $\sim 6 \mu \mathrm{m}$ and $0.201 \mathrm{~cm}^{2}$, respectively.

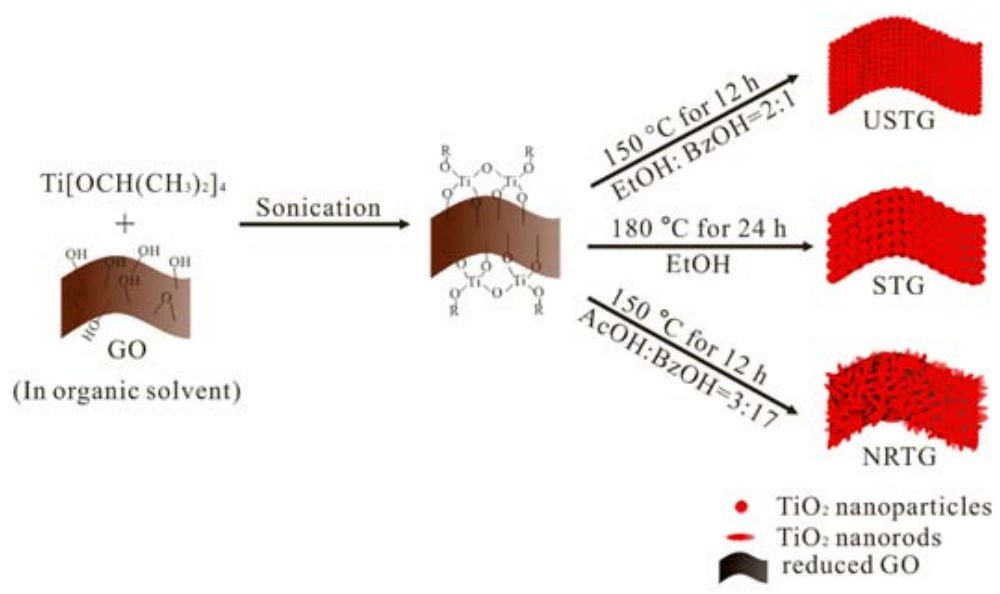

Figure 4.1 The procedure of the one-step solvothermal approach.

\subsection{Results and discussion}

The nanostructures of the three composite nanosheets were investigated using TEM (Figure 4.2). Due to the relatively smooth and planar structure of obtained GO (Figure 4.3), uniform loading of $\mathrm{TiO}_{2}$ nanocrystals on graphene sheets was achieved for all three composites. These homogenous and dense structures increase the contact between graphene and $\mathrm{TiO}_{2}$, thus fully utilizing the good charge transport properties of graphene sheets. From Figure 4.2a, the spherical $\mathrm{TiO}_{2}$ nanocrystals of STG can be clearly distinguished with an average particle size of $12 \mathrm{~nm}$. For USTG, the ultrasmall $\mathrm{TiO}_{2}$ particles were about $2 \mathrm{~nm}$ as determined from high-resolution TEM (HRTEM). The much smaller $2 \mathrm{~nm}$ size allows the $\mathrm{TiO}_{2}$ nanoparticles to form a more compact structure (evident in Figure 4.2) on the graphene sheets, which lowers the exposure of graphene to dye and electrolyte, and may reduce electron leakage from the graphene sheets back to the dye or electrolyte. HRTEM also reveals the well- 
defined crystallinity of ultra-small $\mathrm{TiO}_{2}$ with a lattice spacing of $0.35 \mathrm{~nm}$, which corresponds to anatase (101) planes. The $\mathrm{TiO}_{2}$ nanorods in NRTG with lengths up to $20 \mathrm{~nm}$ and diameters of $5 \mathrm{~nm}$ are observed. The nanorods display some overlap onto each other (Figure 4.2b) compared to the more orderly and compact arrangement of the spherical nanoparticles. These observations demonstrate the ability of the current one-step solvothermal approach to control the particle size of composited $\mathrm{TiO}_{2}$ (STG vs. USTG) as well as the morphology (STG vs. NRTG).

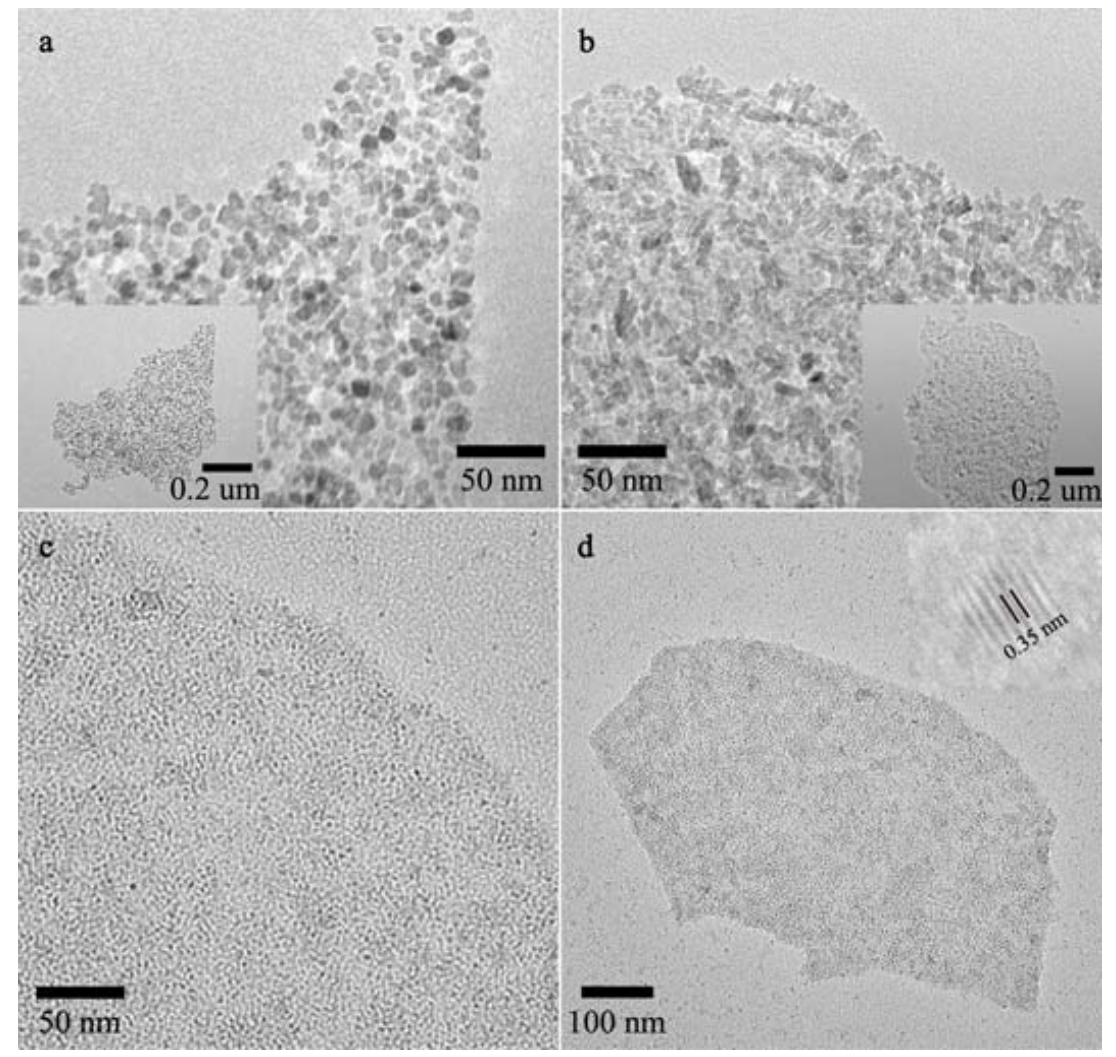

Figure 4.2 The TEM images of (a) STG, (b) NRTG, (c) USTG at high magnification and (d) USTG at low magnification. The insets of (a) and (b) are the TEM images of two composites at low magnification. The inset of (d) is the HRTEM image of USTG. 


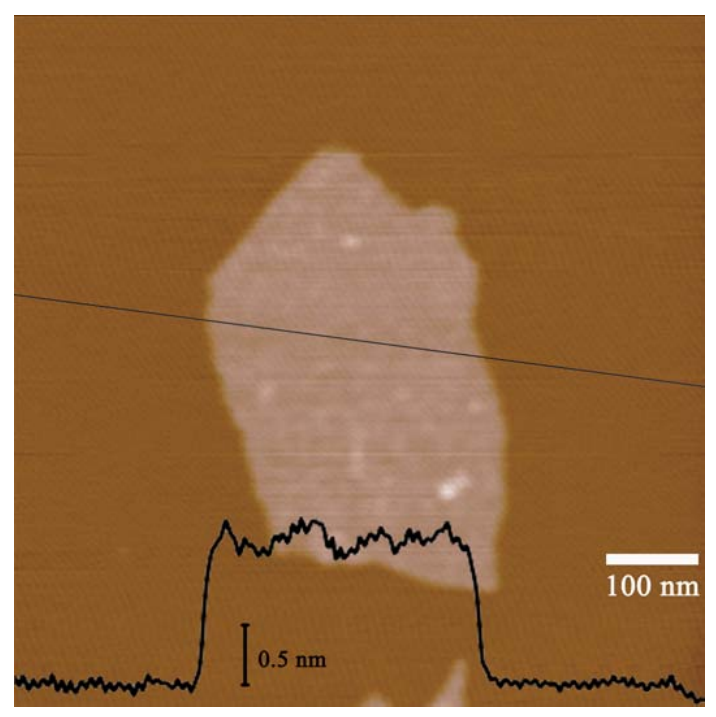

Figure 4.3 AFM image of a GO nanosheet with a height profile taken along the straight line.

The X-ray diffraction patterns of the three composites (Figure 4.4a) reveal the formation of the $\mathrm{TiO}_{2}$ anatase phase in the three composites (JCPDS 73-1764) through the one-step solvothermal reaction, which is consistent with the HRTEM result. The reduction of GO in solvothermal reactions is confirmed with Raman spectra, as shown in Figure 4.4b. GO exhibits Raman shifts at 1605 and $1358 \mathrm{~cm}^{-1}$, corresponding to the $\mathrm{G}$ ( $\mathrm{E}_{2 \mathrm{~g}}$ mode of $s p^{2}$ carbon atoms) and $\mathrm{D}$ bands (symmetry $\mathrm{A}_{1 \mathrm{~g}}$ mode), respectively [143, 232]. Upon reduction of GO with strong reductants, the G and $\mathrm{D}$ bands shift to lower values, with $\mathrm{G}$ band becoming characteristically asymmetric [232-234]. Herein, similar trends were observed for the transformation from GO/TIP to graphene- $\mathrm{TiO}_{2}$ composites, accompanying an increased $\mathrm{I}_{\mathrm{D}} / \mathrm{I}_{\mathrm{G}}$ ratio, which indicates a decrease in the average size of $s p^{2}$ domains through the reductions. The $G$ band can be affected by the density of the free electrons which are usually released from the functional groups of the GO during the reduction [235]. Besides, it 
is reported that the $\mathrm{G}$ band can blue-shift with the increased alternating pattern of single-double carbon bonds formed due to the existence of epoxy groups in GO [236]. Therefore, the red-shift of the G bands here should be related to the increased free electron density and decreased alternating pattern of single-double carbon bonds. For the red-shift of the D band upon the thermal reduction of GO, there is no clear explanation, even though the similar shifting is found for chemically reduced GO [237], chemically reduced $\mathrm{GO}^{-\mathrm{TiO}_{2}}$ [233] and solvothermally reduced GOsemiconductor [238, 239]. Thermal reduction of GO can avoid the use of toxic strong reductants, which makes this solvothermal approach a “'greener”' strategy compared to some previous synthesis methods $[142,144]$.
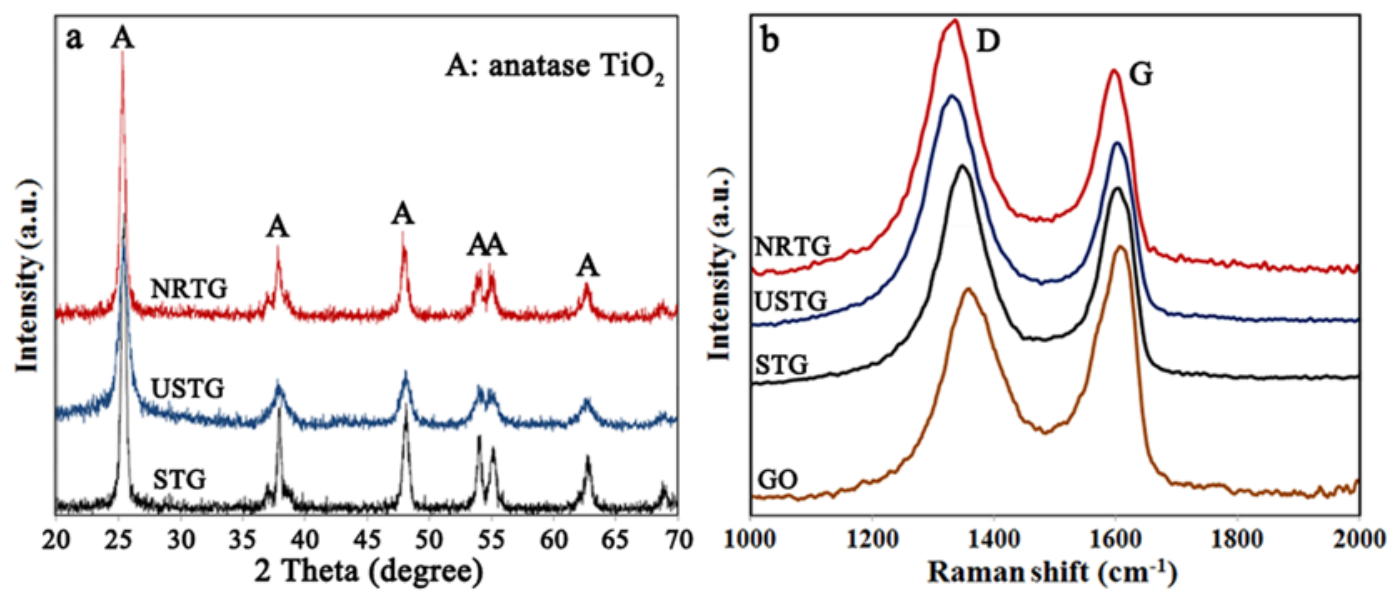

Figure 4.4 XRD patterns of three composites (a) and Raman spectra of three composites and GO (b).

Graphene- $\mathrm{TiO}_{2}$ photoanodes were prepared using the three composites by the doctor-blade technique and calcined at $450{ }^{\circ} \mathrm{C}$ for different times. The obtained electrodes are denoted in the format of sample-calcination time (min), e.g. USTG-60. For comparison, electrodes with pure STG-Ctr, USTG-Ctr and NRTG-Ctr were also 
prepared. The morphologies of pure $\mathrm{TiO}_{2}$ and composite electrodes were examined using FESEM (Figure 4.5). In general, the composite films are more porous and rougher than the plain $\mathrm{TiO}_{2}$ films, which is consistent with previous reports [141, 142]. The porous hierarchical structured electrodes are capable of improving the dye adsorption and thus enhancing the light harvesting efficiency [141, 144].

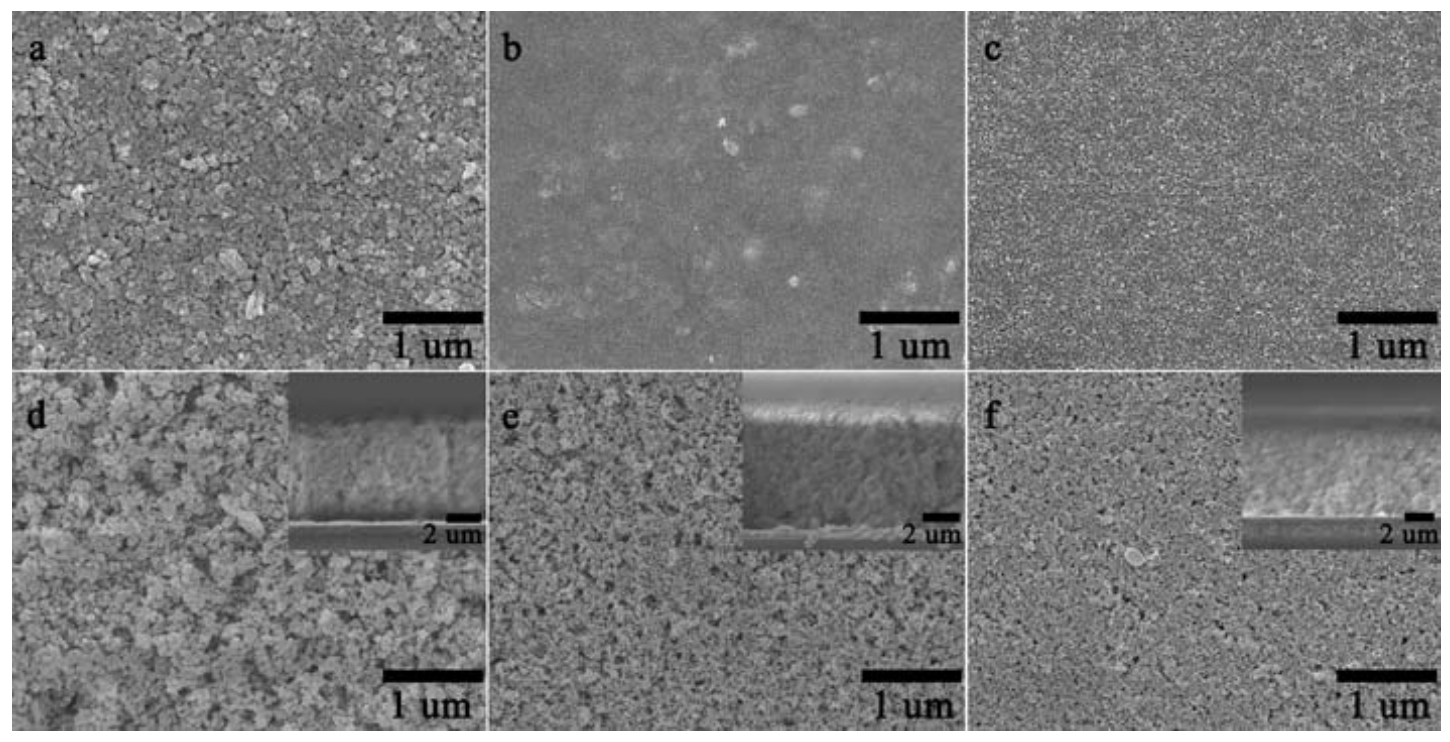

Figure 4.5 SEM images of electrodes prepared using (a) STG-Ctr, (b) USTG-Ctr, (c) NRTG-Ctr, (d) STG, (e) USTG and (f) NRTG. The insets are the cross sectional SEM images of corresponding electrodes.

Performance optimization of the various electrodes is reflected by photocurrent density-voltage $(\mathrm{J}-\mathrm{V})$ curves shown in Figure 4.6. Calcination causes graphene burnoff, especially for the exposed parts, and thus the concentration of graphene decreases slower in the electrodes prepared with compact USTG nanosheets (refer to EDX results in Table 4.1). For all three composites, the electrode with higher concentration of graphene gives lower PCE $(\eta)$, which may be due to the lower anodic reaction rate 
of dye on the $\mathrm{TiO}_{2}$ matrix in the presence of excess graphene and higher reduction rate of dye on the exposed parts of graphene sheets [144, 222]. When the weight ratio of graphene reaches $0.011 \sim 0.013$, the electrodes of the three composites exhibit optimal performance with $\eta$ increased by $44.8 \%, 77.3 \%$ and $42.8 \%$ for STG, USTG and NRTG respectively, in comparison to their respective control, clearly demonstrating that the incorporated graphene can enhance the performance of the photoanodes, which is consistent with the previous works [141, 142, 144]. As reported, the performance improvement by the incorporation of graphene is mainly due to the increased dye loading and enhanced electron transport [141, 142]. The porosity of composite electrode films is improved by the incorporation of graphene (Figure 4.5 and Table 4.2), which is beneficial for the dye adsorption as discussed above. The porous structure seems to be crucial for USTG-derived electrodes, since the enhancement for USTG is greater than the other two composites. Pure ultra-small $\mathrm{TiO}_{2}$ film is too compact for dye penetration and results in lower dye adsorption efficiency, while incorporation of graphene can effectively improve the porosity, thus rendering high specific surface area on the ultra-small $\mathrm{TiO}_{2}$ (evident in Table 4.2). The optimal graphene concentrations obtained here are higher than those reported in previous works $[142,144]$. We attribute this to the smaller particle sizes of $\mathrm{TiO}_{2}$ compared to previous ones, which allows more orderly and compact structure of the current $\mathrm{TiO}_{2}$ particles on the graphene sheets, therefore increasing the contact area with graphene. Longer calcination affects the performances of all three composites. 
This may be ascribed to the destruction of the graphene network and the collapse of porous films induced by the prolonged thermal treatment.
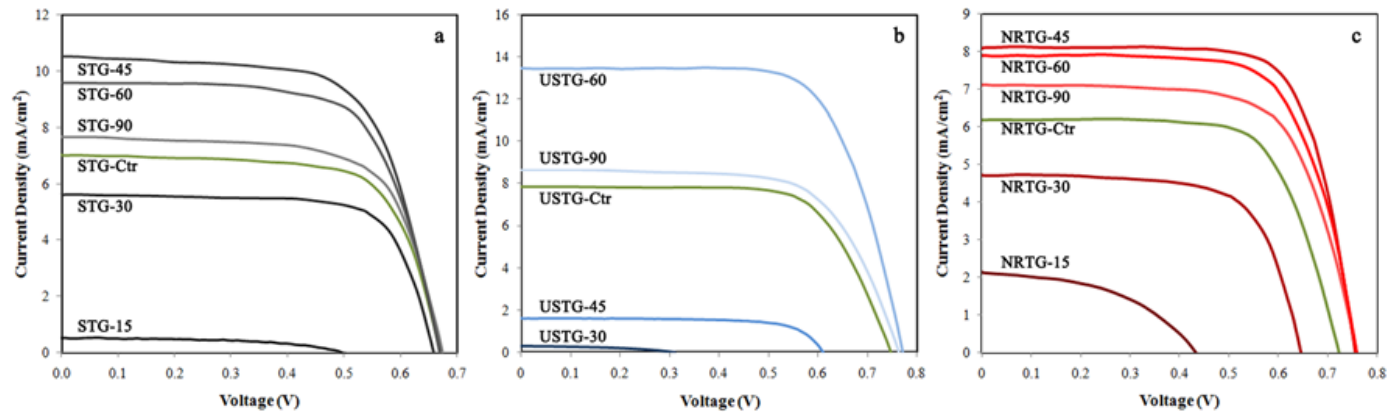

Figure 4.6 $J-V$ characteristics of DSSCs with different electrodes prepared using (a) STG and STG-Ctr, (b) USTG and USTG-Ctr, and (c) NRTG and NRTG-Ctr, during the optimizations.

Table 4.1 Parameters for solar cells based on the different electrodes

\begin{tabular}{|c|c|c|c|c|c|}
\hline & Concentration $^{\ddagger}$ & $V_{o c}(\mathrm{~V})$ & $J_{s c}\left(\mathbf{m A} / \mathbf{c m}^{2}\right)$ & FF (\%) & $\eta(\%)$ \\
\hline STG-Ctr & 0 & 0.669 & 7.02 & 68.8 & 3.23 \\
\hline STG-15 & 0.0332 & 0.482 & 0.54 & 53.8 & 0.14 \\
\hline STG-30 & 0.0198 & 0.653 & 5.63 & 73.7 & 2.71 \\
\hline STG-45 & 0.0110 & 0.669 & 10.5 & 66.6 & 4.68 \\
\hline STG-60 & 0.0089 & 0.669 & 9.59 & 68.5 & 4.39 \\
\hline STG-90 & 0.0074 & 0.669 & 7.66 & 68.7 & 3.52 \\
\hline USTG-Ctr & 0 & 0.741 & 7.85 & 70.3 & 4.09 \\
\hline USTG-30 & 0.0406 & 0.304 & 0.27 & 44.3 & 0.04 \\
\hline USTG-45 & 0.0268 & 0.609 & 1.58 & 71.7 & 0.69 \\
\hline USTG-60 & 0.0133 & 0.770 & 13.5 & 69.9 & 7.25 \\
\hline USTG-90 & 0.0107 & 0.762 & 8.67 & 67.0 & 4.42 \\
\hline NRTG-Ctr & 0 & 0.720 & 6.18 & 70.3 & 3.13 \\
\hline NRTG-15 & 0.0308 & 0.411 & 2.14 & 48.9 & 0.43 \\
\hline NRTG-30 & 0.0194 & 0.644 & 4.70 & 69.1 & 2.09 \\
\hline NRTG-45 & 0.0123 & 0.754 & 8.11 & 73.2 & 4.48 \\
\hline NRTG-60 & 0.0102 & 0.762 & 7.88 & 69.6 & 4.18 \\
\hline NRTG-90 & 0.0092 & 0.754 & 7.10 & 69.1 & 3.69 \\
\hline P25 & 0 & 0.669 & 6.20 & 68.8 & 2.85 \\
\hline
\end{tabular}

$\ddagger$ Concentration is the weight ratio of carbon determined using EDX.

Table 4.2 Specific surface area and pore volume of different electrode films

\begin{tabular}{ccccccc}
\hline & STG-Ctr & USTG-Ctr & NRTG-Ctr & STG-45 & USTG-60 & NRTG-45 \\
\hline $\mathrm{S}_{\text {BET }}\left(\mathbf{m}^{\mathbf{2}} / \mathbf{g}\right)$ & 104.3 & 123.3 & 100.8 & 132.2 & 167.2 & 130.6 \\
$\begin{array}{c}\text { Pore volume } \\
\left(\mathbf{c m}^{\mathbf{3}} / \mathbf{g}\right)\end{array}$ & 0.481 & 0.403 & 0.455 & 0.622 & 0.603 & 0.540 \\
\hline
\end{tabular}




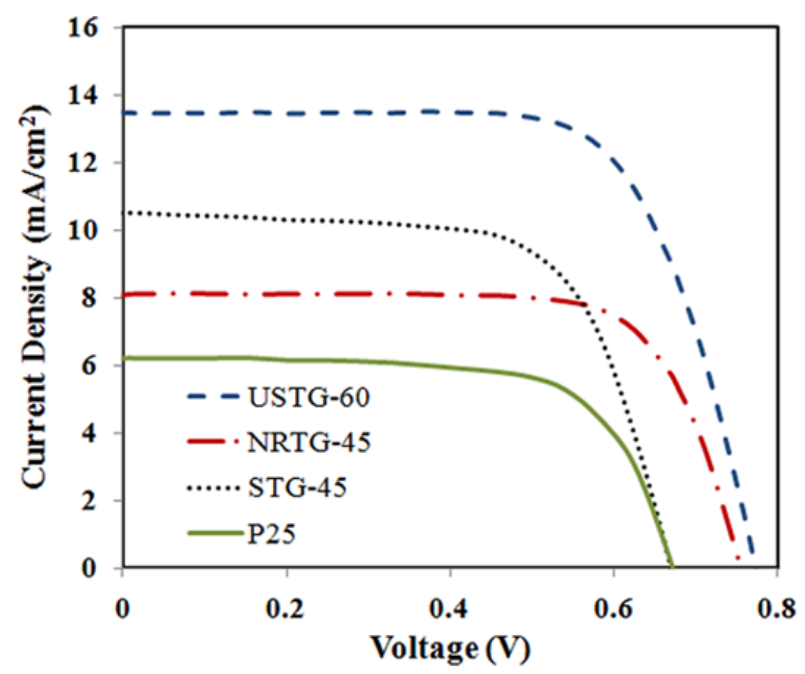

Figure 4.7 J-V characteristics of the four cells with different electrodes.

Three optimal electrodes prepared using different composites and a conventional P25 electrode as a baseline were used to investigate the effect of nanostructure of graphene-composited $\mathrm{TiO}_{2}$ on DSSCs performance. The $J$-V curves of the four cells in Figure 4.7 show that the overall photocurrent densities of three composite electrodes are higher than that of the P25 electrode. The USTG-60 electrode exhibits the highest short-circuit photocurrent density $\left(J_{\mathrm{sc}} 13.5 \mathrm{~mA} \mathrm{~cm}{ }^{-2}\right)$. For STG-45 and NRTG-45 electrodes, the $J_{\mathrm{sc}}$ are $10.5 \mathrm{~mA} \mathrm{~cm} \mathrm{~cm}^{-2}$ and $8.11 \mathrm{~mA} \mathrm{~cm}{ }^{-2}$, respectively. An interesting feature that should be noted is that the open-circuit voltage $\left(\mathrm{V}_{\mathrm{oc}}\right)$ of USTG60 and NRTG-45 electrodes is higher than that of the STG-45 electrode. Since the $\mathrm{V}_{\text {oc }}$ is mainly determined by the difference between the Fermi level of $\mathrm{TiO}_{2}$ and the redox potential of the electrolyte [41], this increment is possibly attributed to the Fermi level shift arising from the band gap broadening of smaller $\mathrm{TiO}_{2}$ crystals due to strong quantum confinement effects. The band gap of P25, STG-45, NRTG-45 and USTG60 nanocomposites is measured to be $3.00,3.14,3.21$ and $3.23 \mathrm{eV}$, respectively, as shown in Figure 4.8. The $\mathrm{V}_{\text {oc }}$ differences of the composited photoanodes (0.016 $\mathrm{V}$ for 
USTG-60 vs. NRTG-45, 0.101 V for USTG-60 vs. STG-45) are in good agreement with their band gap difference (0.02 eV for USTG-60 vs. NRTG-45, $0.09 \mathrm{eV}$ for USTG-60 vs. STG-45), confirming that the increased $V_{\text {oc }}$ is mainly induced by the band gap broadening of the smaller $\mathrm{TiO}_{2}$ particles. With the highest $J_{\mathrm{sc}}$ and $\mathrm{V}_{\mathrm{oc}}$, the USTG-60 electrode gives the highest $\eta$ with the value of 7.25\%, while $\eta$ of STG-45, NRTG-45 and P25 electrodes are lower at 4.68\%, 4.48\% and 2.85\%, respectively.

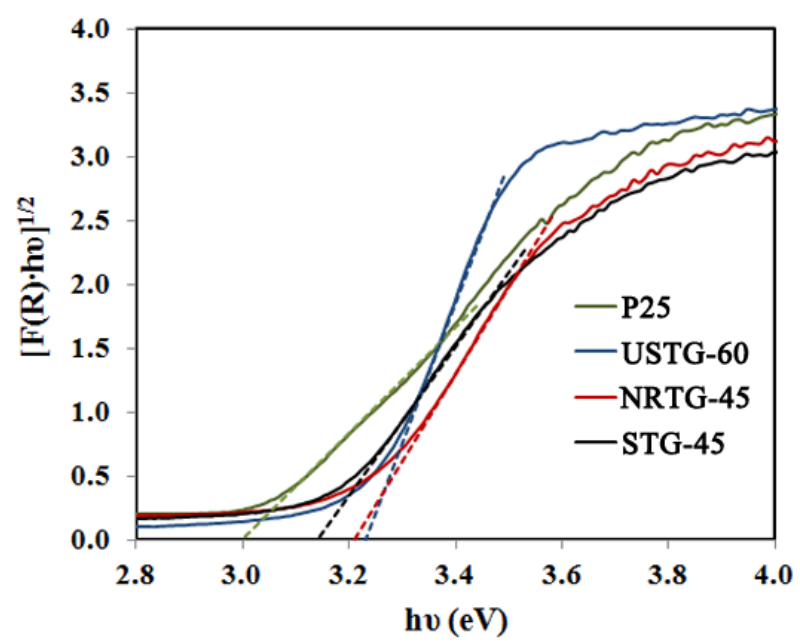

Figure 4.8 Plots of $[\mathrm{F}(\mathrm{R}) \cdot \mathrm{hv}]^{1 / 2}$ vs. hv of the four nanocomposites calculated based their DRS results.

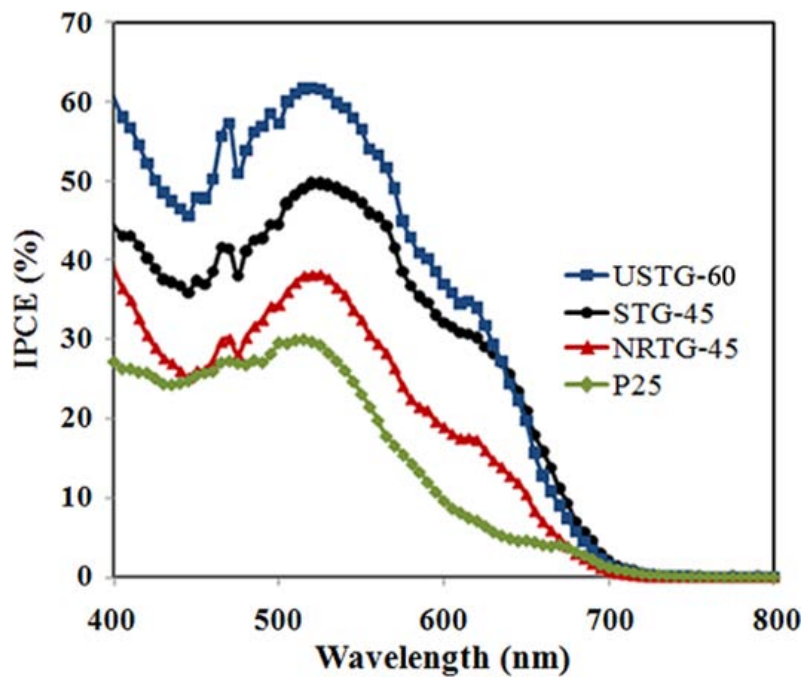

Figure 4.9 IPCE spectra of the four cells with different electrodes. 
Figure 4.9 displays the incident photon-to-current conversion efficiency (IPCE) curves as a function of wavelength. The maximum IPCE values for P25, NRTG-45, STG-45, andUSTG-60 cells are 30\%, 38\%, 49\%, and 62\%, respectively, the trend of which is in good agreement with the $J_{\mathrm{sc}}$ for all electrodes. This indicates that the significant improvement of $J_{\mathrm{sc}}$ is due to enhanced photon-to-current conversion efficiency.

To investigate the interfacial reactions of photoexcited electrons in these cells, electrochemical impedance spectra (EIS) were measured at an applied bias of $\mathrm{V}_{\text {oc }}$ under the illumination of one sun. Nyquist plots (Figure 4.10) of all four cells illustrate two well-defined semicircles. The first semicircle $(10 \sim 14 \mathrm{ohm})$ over the high-frequency region represents the Faraday resistance of the redox reaction of $\mathrm{I}^{-} / \mathrm{I}_{3}{ }^{-}$ couple at the electrolyte/Pt interface [240], while the second semicircle in the medium frequency region reflects the electron transport resistance and charge transfer resistance at the $\mathrm{TiO}_{2} /$ dye/electrolyte interface, which is the most important and decisive factor in DSSCs [241, 242]. The second semicircles of the composite cells exhibit much smaller diameters compared to that of the P25 reference cell. According to a previous report, incorporation of graphene into the DSSC photoanodes can improve the electron transport while suppress charge recombination [142]. Therefore, the much smaller diameters of the second semicircles of the composite cells can be attributed to the decreased electron transport resistance due to the incorporation of graphene and the decreased charge transfer resistance at the $\mathrm{TiO}_{2} /$ dye/electrolyte interface due to the large specific surface area of the composite photoanodes [243]. 
The resistance $\left(R_{3}\right)$ and capacitance $\left(C_{1}\right)$ represented by the second semicircles were fitted with an equivalent circuit of parallel connection of $R_{3}$ and $C_{1}$ (the inset of Figure 4.10) as listed in Table 4.3. The USTG-60 cell has the lowest $\mathrm{R}_{3}$ but highest $\mathrm{C}_{1}$ which is due to its highest specific surface area for increased high dye loading, as the higher capacitance corresponds to the presence of more charges separated effectively at the interface [241, 244].

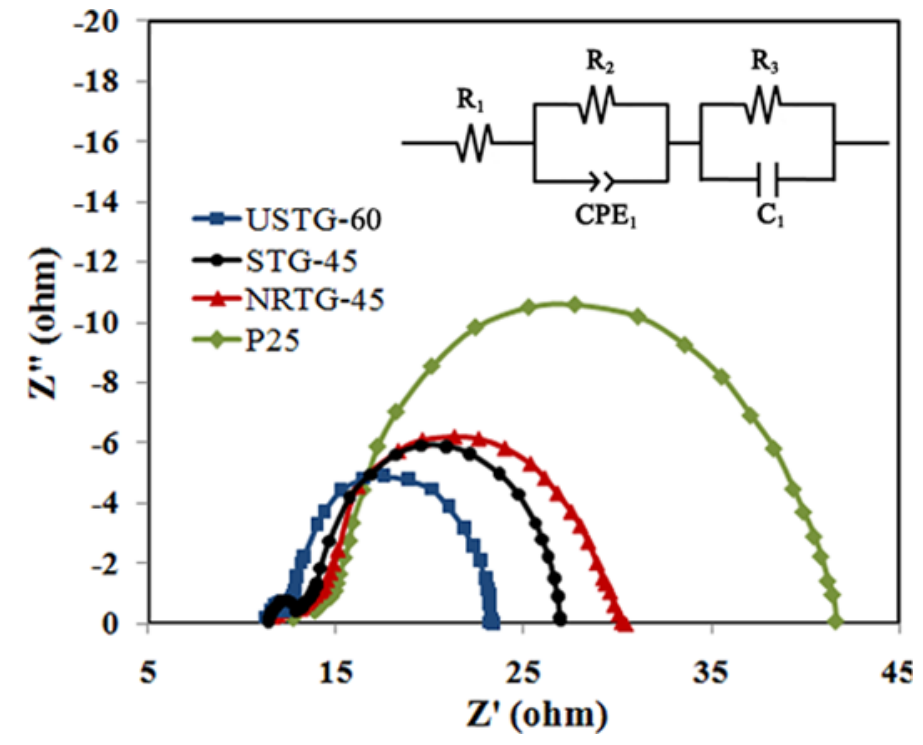

Figure 4.10 Nyquist plots of the four cells with different electrodes. The inset is the equivalent circuit of the devices.

Table 4.3 Parameters of equivalent circuits fitted from EIS measurement of four cells

\begin{tabular}{ccccc}
\hline & P25 & STG-45 & USTG-60 & NRTG-45 \\
\hline $\mathbf{C}_{\mathbf{1}}\left(\mathbf{F} / \mathbf{m}^{\mathbf{2}}\right)$ & 3.493 & 4.392 & 6.482 & 2.367 \\
$\mathbf{R}_{\mathbf{3}}(\mathbf{\Omega})$ & 24.83 & 12.90 & 10.62 & 16.21 \\
\hline
\end{tabular}

Bode plots of the cells (Figure 4.11) further confirm that second semicircle peak frequency $\left(f_{\mathrm{mp}}\right)$ of the USTG-60 cell shifts slightly to lower frequency. The $f_{\mathrm{mp}}$ can be related to the inverse of electron lifetime $\left(\tau_{\mathrm{e}}\right)$ in $\mathrm{TiO}_{2}$ films as follows: $\tau_{\mathrm{e}}=1 /\left(2 \pi f_{\mathrm{mp}}\right)$ $[141,245]$. Therefore, the peak frequency shifting of the USTG-60 cell indicates a 
longer electron lifetime in comparison with the other two composite DSSCs, which should be due to the efficient electron transfer in graphene sheets with compact electron leakage barrier formed by ultra-small $\mathrm{TiO}_{2}$ nanoparticles [141, 142, 241]. The EIS analysis offers physical insight into the role of the graphene component and the effect of composited $\mathrm{TiO}_{2}$ nanostructures in the device performance enhancement.

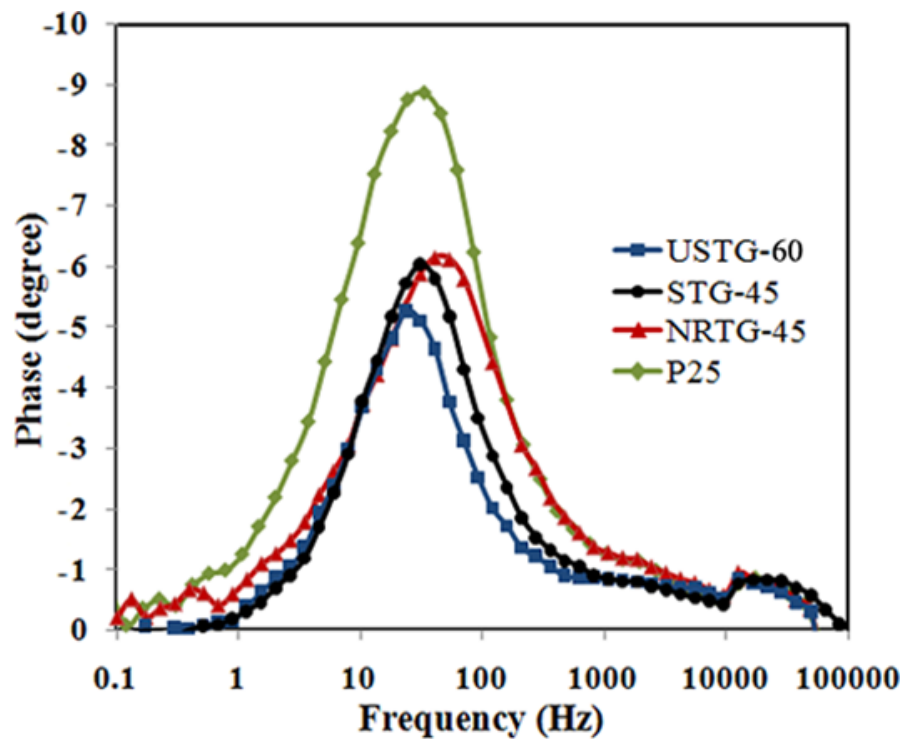

Figure 4.11 Bode plots of the four cells with different electrodes.

\subsection{Summary}

In brief, a one-step solvothermal approach is developed to synthesize graphene$\mathrm{TiO}_{2}$ composites for DSSC photoanodes, of which the $\mathrm{TiO}_{2}$ nanostructures can be controlled by simply adjusting the solvothermal reaction conditions. The photoanode based on ultra-small $2 \mathrm{~nm} \mathrm{TiO}_{2}$-graphene composite exhibits the highest efficiency, which is contributed by the synergistic effects of the high specific surface area produced from the ultra-small $\mathrm{TiO}_{2}$-formed porous structure and fast electron transfer 
in the incorporated graphene with compact $\mathrm{TiO}_{2}$ particles. The current one-step solvothermal approach can be developed as a universal method to synthesize graphene- $\mathrm{TiO}_{2}$ composites with various optimized $\mathrm{TiO}_{2}$ nanostructures for various applications such as photocatalysis, hydrogen evolution and energy storage. 


\section{Chapter 5 Understanding $\mathrm{TiO}_{2}$ Size-Dependent Electron} Transport Properties of a Graphene-TiO ${ }_{2}$ Photoanode in Dye-sensitized Solar Cell Using Conducting Atomic Force Microscopy $^{2}$

\subsection{Introduction}

Dye-sensitized solar cell (DSSC) has potential applications in low-cost energy generating devices $[2,23,26]$. To date, the power conversion efficiency (PCE) of nanocrystalline $\mathrm{TiO}_{2}$-based DSSC has reached $12.3 \%$ at $\mathrm{AM} 1.5 \mathrm{G}$ full sun $(13.1 \%$ at $50.9 \%$ sun) [30]. DSSC mainly consists of dye-sensitized $\mathrm{TiO}_{2}$ film deposited on a transparent conducting substrate as the photoanode, redox-active electrolyte and $\mathrm{Pt}$ cathode. One of the parameters that influences the device performance is the charge transport in the $\mathrm{TiO}_{2}$ film. The $\mathrm{TiO}_{2}$ film has been extensively optimized to improve its electron mobility via various strategies, such as incorporating a second semiconductor with a different band gap [117, 193], developing novel film nanostructure $[155,163,246]$ and incorporating efficient charge transport materials $[119,128]$. However, efficient electron transport in the $\mathrm{TiO}_{2}$ film still remains a major challenge in DSSC performance [142].

Graphene has excellent electron mobility, high transparency and large specific surface area, which makes it a good support material and an efficient charge carrier in DSSC photoanodes [143, 247-250]. Incorporation of graphene in $\mathrm{TiO}_{2}$ matrix can

\footnotetext{
${ }^{2}$ Reproduced from [Z.M. He, H. Phan, J. Liu, T.-Q. Nguyen, and T.T.Y. Tan, Advanced Materials, 2013. 25(47): 6900-6904] with permission from John Wiley and Sons.
} 
enhance the electron transport while reduce the charge recombination, thus improving DSSC performance [141, 142, 144, 251]. In our previous work [252], PCE enhancement was obtained for various size graphene- $\mathrm{TiO}_{2}$ composites based photoanodes. The anode based on smaller-sized composite $\mathrm{TiO}_{2}$ yields the highest PCE with a high photocurrent density and low electron transfer resistance. Even though we postulated that smaller $\mathrm{TiO}_{2}$ particle size leads to a bigger surface and hence an increased dye adsorption, the mechanism of this phenomenon remains unclear from the bulk device measurements.

In this chapter, we report the use of conducting atomic force microscopy (c-AFM) to understand the nanoscale electronic properties of the graphene- $\mathrm{TiO}_{2}$ films and attempt to unravel the size effect of graphene-composited $\mathrm{TiO}_{2}$ on DSSC performance. C-AFM is a powerful technique that is capable of simultaneously measuring surface topography and local conductivity of the electrodes [253-260]. It has been widely used to probe the nanoscale properties of organic photovoltaics [261-268], and was applied to DSSC characterization for the first time in this work. Three graphene- $\mathrm{TiO}_{2}$ composites with different $\mathrm{TiO}_{2}$ particle size were synthesized using a one-step solvothermal reaction and utilized to prepare the composite electrode films. To exclude the influence of the dye and electrolyte, plain electrodes were characterized using the c-AFM to investigate their nanoscale conductivity, which were ultimately correlated to the bulk device performance to understand the contribution of $\mathrm{TiO}_{2}$ particle size in enhanced PCE. 


\subsection{Experimental}

Three graphene- $\mathrm{TiO}_{2}$ composite nanosheets were prepared using a modified onestep solvothermal reaction reported in our previous work [252]. Briefly, GO aqueous suspension was first prepared via modified hummers' method [139] and then dried through a freeze drying approach to avoid the GO aggregation during the drying process. Subsequently, $10 \mathrm{mg}$ of GO were resuspended in $30 \mathrm{ml}$ of organic solvent (benzyl alcohol: ethanol $=2: 1$ volume ratio) by sonication for 30 min. Titanium isopropoxide (1 ml) was then added dropwise into the GO dispersion under stirring. Through sonication for $1 \mathrm{~h}$, organic titanium molecules are uniformly grafted on the GO sheets by chemisorption [144]. The reduction of GO and crystallization of $\mathrm{TiO}_{2}$ were achieved simultaneously through the solvothermal reactions and the $\mathrm{TiO}_{2}$ particle size was controlled by simply adjusting the reaction temperature from $200{ }^{\circ} \mathrm{C}$, $180{ }^{\circ} \mathrm{C}$ to $150{ }^{\circ} \mathrm{C}$. The resulting composites were collected by filtration, rinsed by ethanol to remove the free $\mathrm{TiO}_{2}$ particles and dried under vacuum. The electrodes were prepared by applying a doctor-blade technique of the above materials onto fluorine-doped tin oxide (FTO) glass and calcined at $450{ }^{\circ} \mathrm{C}$ in air for different time to optimize the graphene concentration in the electrode films. The thickness and active area of electrode films were controlled at $\sim 6 \mu \mathrm{m}$ and $0.201 \mathrm{~cm}^{2}$, respectively.

\subsection{Results and discussion}

The $\mathrm{TiO}_{2}$ particle size in graphene- $\mathrm{TiO}_{2}$ composites was controlled by simply adjusting the reaction temperature. The composites synthesized at $200{ }^{\circ} \mathrm{C}, 180^{\circ} \mathrm{C}$ and 
$150{ }^{\circ} \mathrm{C}$ were labelled as S1, S2 and S3 respectively, corresponding to the particle size of $12.1 \mathrm{~nm}, 7.8 \mathrm{~nm}$ and $2.5 \mathrm{~nm}$ respectively as determined by counting the lattice number of the $\mathrm{TiO}_{2}$ nanoparticles from transmission electron microscopy (TEM) images. Uniform $\mathrm{TiO}_{2}$ loading on graphene nanosheets is confirmed for all three composites through TEM (Figure 5.1) and scanning electron microscopy (SEM) (Figure 5.2) observations. $\mathrm{TiO}_{2}$ nanocrystalline grains can be clearly recognized in high-resolution TEM (HRTEM) images and the lattice spacing is determined to be $0.35 \mathrm{~nm}$, corresponding to anatase phase, which is consistent with XRD results (Figure 5.3).

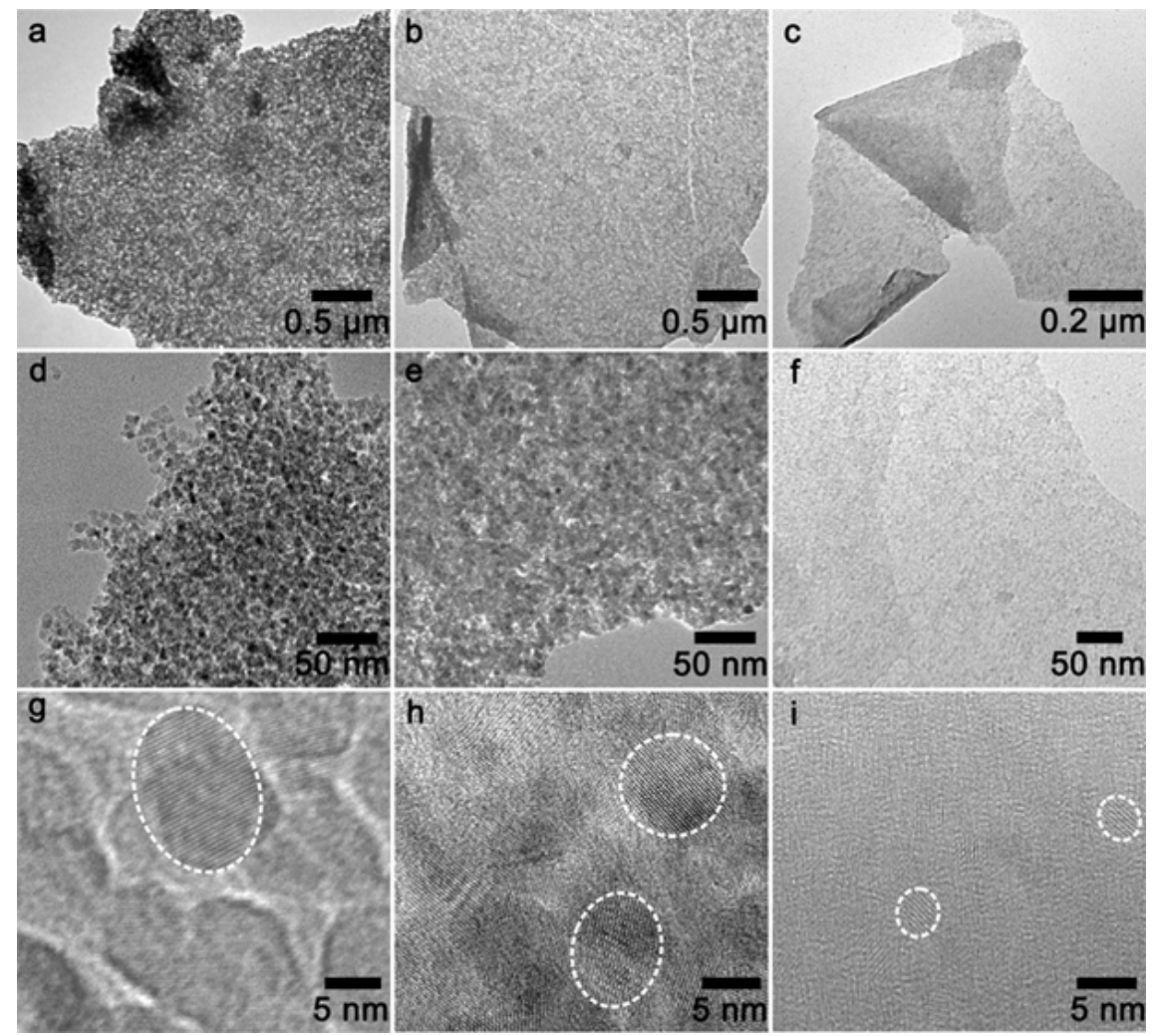

Figure 5.1 TEM images of S1 (a, d, g), S2 (b, e, h) and S3 (c, f, i) at different magnification. The white circles in $\mathrm{g}$, $\mathrm{h}$ and $\mathrm{i}$ represent the $\mathrm{TiO}_{2}$ nanoparticles loaded on graphene nanosheets. 


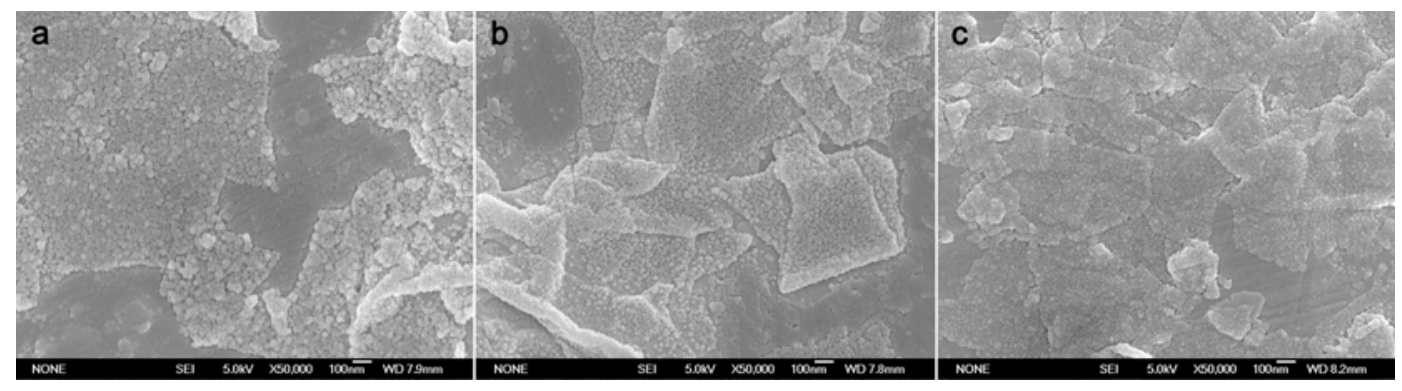

Figure 5.2 SEM images of S1 (a), S2 (b) and S3 (c).

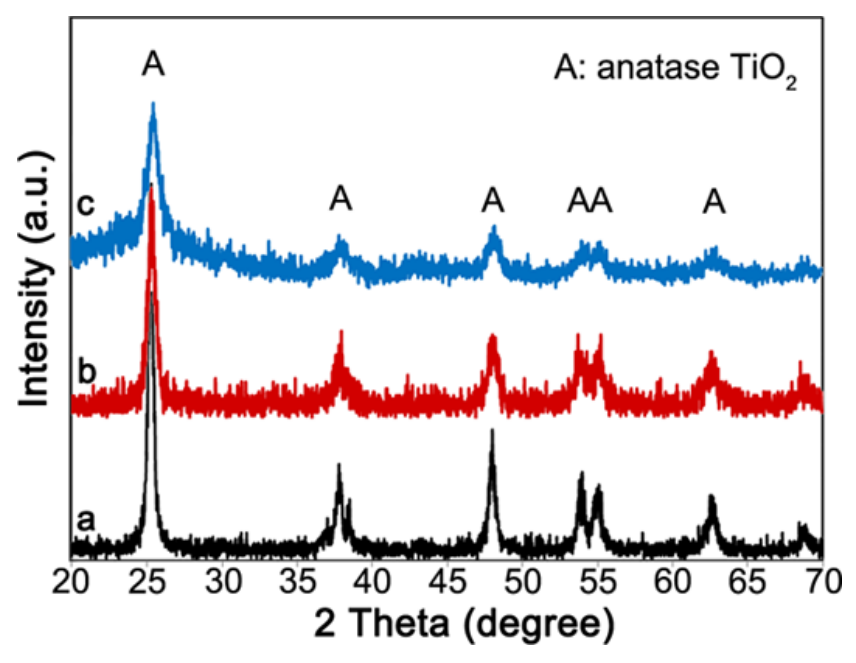

Figure 5.3 XRD patterns of S1 (a), S2 (b) and S3 (c).

Photoanodes based on the three composites were prepared using a doctor-blade technique and optimized using a calcination method reported in our previous work [252]. The optimal calcination time for S1, S2 and S3 based photoanodes was 45 min, 45 min and 60 min, determined by photocurrent density-voltage $(J-V)$ characteristics of all devices. The bulk device performances based on the three optimal photoanodes were systematically examined. Figure 5.4 a shows the $J$ - $V$ curves of the three devices, with their corresponding performance parameters summarized in Table 5.1 for comparison. S3 based DSSC exhibits the best overall performance with the highest short-circuit current density $\left(J_{\mathrm{sc}}=13.1 \mathrm{~mA} \mathrm{~cm}^{-2}\right)$, open-circuit voltage $\left(V_{\mathrm{oc}}=0.771 \mathrm{~V}\right)$ 
and fill factor $\left(F F=71.7 \%\right.$ ), which brings about the highest PCE of $7.26 \%$. The $J_{\text {sc }}$ of the three devices increases with the decreasing $\mathrm{TiO}_{2}$ particle size. The incident photon-to-current conversion efficiency (IPCE) of the three DSSCs in Figure 5.4b exhibits a similar trend as $J_{\mathrm{sc}}$. This indicates that the significant improvement of $J_{\mathrm{sc}}$ is due to enhanced photon-to-current conversion efficiency [252], which could be resultant from increased dye loading of the smaller $\mathrm{TiO}_{2}$ based photoanodes and more efficient electron transport. The increased dye loading, attributed to the increased specific surface area of the smaller-sized $\mathrm{TiO}_{2}$ based mesoporous films (see BET results in Table 5.2), ensures high effective electron generation, while the efficient electron transport reflected by the high FF of S3 based device ensures efficient collection of photogenerated electrons.
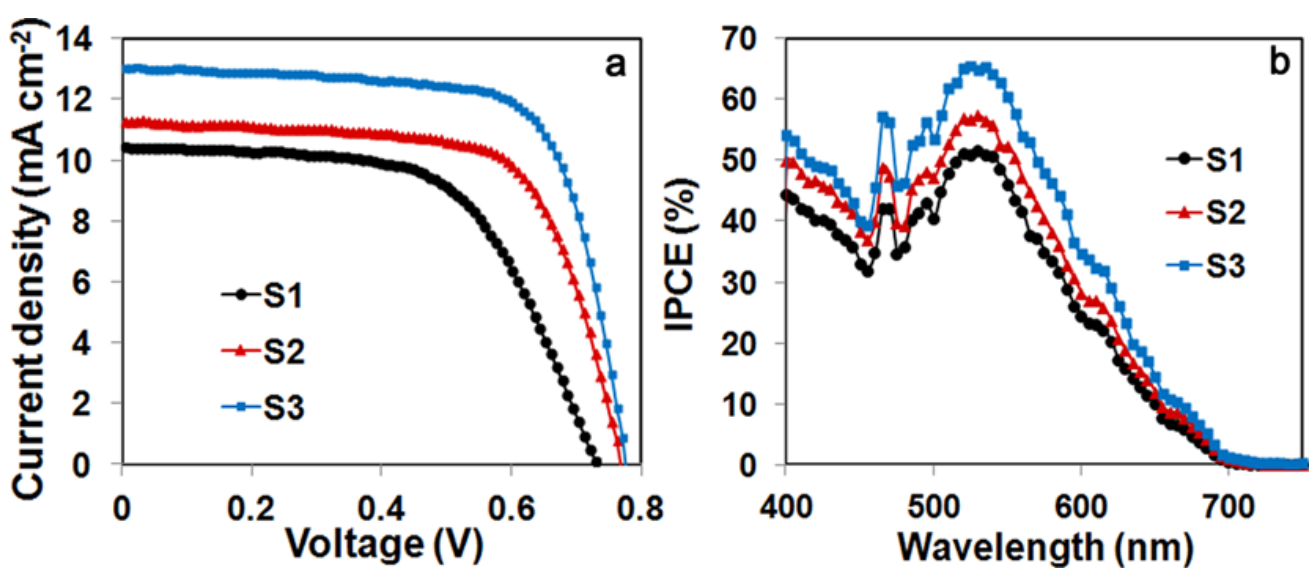

Figure 5.4 $J$ - $V$ characteristics (a) and IPCE spectra (b) of the three devices.

Table 5.1 Performance parameters of the three bulk devices

\begin{tabular}{ccccc}
\hline Sample & $\begin{array}{c}\boldsymbol{J}_{\mathbf{s c}} \\
\left.\mathbf{~ c m}^{-2}\right)\end{array}$ & $\begin{array}{c}\boldsymbol{V}_{\text {oc }} \\
(\mathbf{V})\end{array}$ & $\begin{array}{c}F F \\
(\%)\end{array}$ & $\begin{array}{c}\text { PCE } \\
(\mathbf{\%})\end{array}$ \\
\hline S1 & 10.5 & 0.728 & 62.3 & 4.76 \\
S2 & 11.2 & 0.762 & 69.5 & 5.95 \\
S3 & 13.1 & 0.771 & 71.7 & 7.26 \\
\hline
\end{tabular}


Table 5.2 Dye loading and BET results of the three electrodes

\begin{tabular}{cccc}
\hline Sample & $\begin{array}{c}\text { Dye loading } \\
\left(\mathbf{m o l ~ c m}^{-2}\right)\end{array}$ & $\begin{array}{c}\mathbf{S}_{\mathrm{BET}} \\
\left(\mathbf{m}^{\mathbf{2}} \mathbf{g}^{-1}\right)\end{array}$ & $\begin{array}{c}\text { Pore volume } \\
\left(\mathbf{c m}^{\mathbf{3}} \mathbf{g}^{-1}\right)\end{array}$ \\
\hline S1 & $1.136 \times 10^{-7}$ & 132.9 & 0.760 \\
S2 & $1.329 \times 10^{-7}$ & 152.3 & 0.729 \\
S3 & $1.427 \times 10^{-7}$ & 167.2 & 0.658 \\
\hline
\end{tabular}

The FF is generally related to the internal resistance of the DSSC [269]. S3 based device exhibits the highest $F F$, indicating its lowest internal resistance, which may be resulted from the low electron transfer resistance and charge recombination of the electrode film. To confirm this inference, electrochemical impedance spectra (EIS) of the three devices were measured at an applied bias of $V_{\text {oc }}$ under one sun. Nyquist plots of the three devices in Figure 5.5a illustrate three semicircles, whose diameters represent the impedance of the corresponding processes. The first semicircles measured in the high-frequency $(\mathrm{kHz})$ range represent the Faraday resistance of the redox reaction of $\mathrm{I}^{-} / \mathrm{I}_{3}^{-}$at the Pt/electrolyte interface. The second semicircles in medium-frequency $(1 \sim 100 \mathrm{~Hz})$ range reflect the electron transfer resistance at the $\mathrm{TiO}_{2} /$ dye/electrolyte interface, which is the most decisive factor in DSSCs. The third semicircles obtained in low-frequency $(\mathrm{mHz})$ range are related to the Warburg diffusion process of $\mathrm{I}_{3}^{-}$in the electrolyte [242, 270, 271]. As the counter electrodes and electrolyte are the same for all three devices, their Faraday resistances and Warburg diffusion processes exhibit similar diameter values. However, the diameter of the second semicircles decreases from 18.7 to 10.3 ohm with the decreasing $\mathrm{TiO}_{2}$ particle size from 12.1 to $2.5 \mathrm{~nm}$, which confirms the lower electron transfer resistance (equivalent circuit and fitted interfacial resistances are depicted in Figure 
5.6) in the smaller $\mathrm{TiO}_{2}$ based composite photoanode for the current DSSCs. [252]. Bode plots shown in Figure 5.5b further confirm that the characteristic mediumfrequency peak of the devices shifts slightly to lower frequency with the decreasing $\mathrm{TiO}_{2}$ particle size, which indicates a longer electron lifetime in the smaller-sized $\mathrm{TiO}_{2}$ based photoanode [241], therefore confirming the inferred lower charge recombination. Both Nyquist plots and Bode plots of the bulk devices reflect that the $\mathrm{TiO}_{2}$ size has a significant effect on the electron transfer kinetics of the graphene- $\mathrm{TiO}_{2}$ photoanodes.
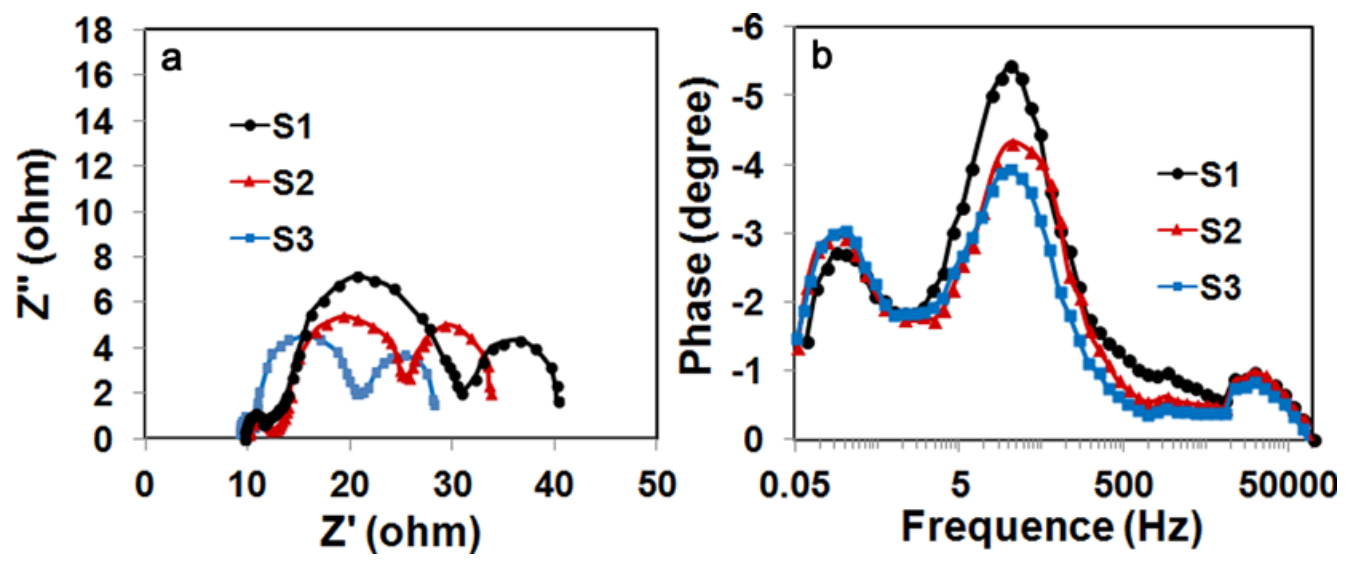

Figure 5.5 Nyquist plots (a) and Bode plots (b) of the three devices.

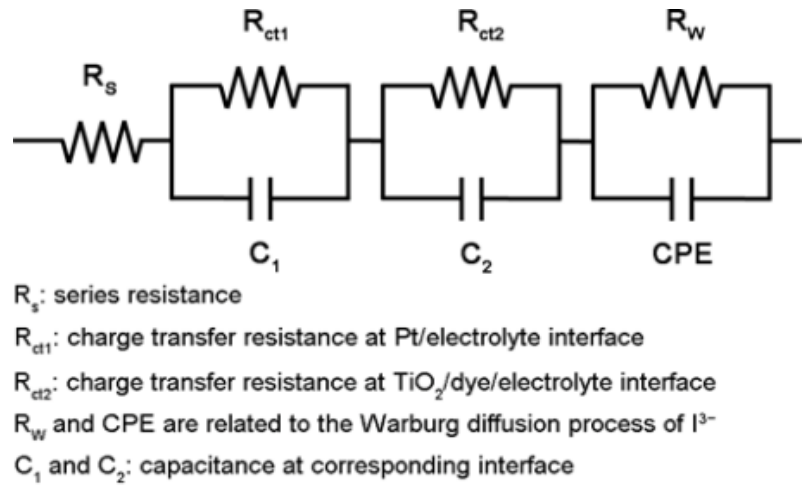

Figure 5.6 The equivalent circuit of the DSSC devices based on the Nyquist plots.

$\mathrm{R}_{\mathrm{ct} 2}$ are fitted to be $18.7,12.6$ and 10.3 ohm for $\mathrm{S} 1$, S2 and S3, respectively. 
To further examine the $\mathrm{TiO}_{2}$ size-dependent electron transport property, c-AFM was used to probe the nanoscale electronic properties of the composite electrodes. CAFM can be carried out in two modes. In the current imaging mode, a conductive tip scans over the electrode surface to collect charge carriers at a certain fixed bias and the nanoscale current structure of the electrode is mapped out in the dark condition. In the current-voltage (I-V) curve mode, the tip sits in assigned locations on the electrode films and the bias is ramped to obtain current at each bias in the dark and then use to construct the nano I-V curves. The dark current images of the three composite electrodes were presented in Figure 5.7. It is found that the current increases with decreasing $\mathrm{TiO}_{2}$ particle size, indicated by an increase of bright area (high-current) in the whole scan area. This observation implies that a more continuous electron transfer network in the smaller $\mathrm{TiO}_{2}$ based composite photoanodes leads to a more efficient electron transport and hence higher observed current. The c-AFM average current was calculated by averaging all current pixels of more than 5 dark current images with a scan size of $4 \mu \mathrm{m} \times 4 \mu \mathrm{m}$ (Figure 5.8) for each electrode. The S3 based electrode gives the highest average current of $1066 \pm 140 \mathrm{pA}$, while the current of S1 and S2 based electrodes is $143 \pm 21$ pA and $266 \pm 87$ pA, respectively. An interesting feature that should be noted is the strong correlation between the $J_{\mathrm{sc}}$ of the three bulk devices and the c-AFM average current of the three composite electrodes (Figure 5.7d). They exhibit similar trends as the $\mathrm{TiO}_{2}$ particle size decreases. As the photocurrent of DSSC is mainly affected by the internal resistance at the $\mathrm{TiO}_{2} / \mathrm{TiO}_{2}$ nanoparticle interface in an unmodified $\mathrm{TiO}_{2}$ based photoanode [272], the strong 
correlation between the $J_{\mathrm{sc}}$ and c-AFM average current indicates that the improved $J_{\mathrm{sc}}$ of the S3 based DSSC is attributed to the more continuous conduction network resulted from a more intimate contact, hence smaller dead space, between the smaller size $\mathrm{TiO}_{2}$-graphene composite nanosheets in the anode film.
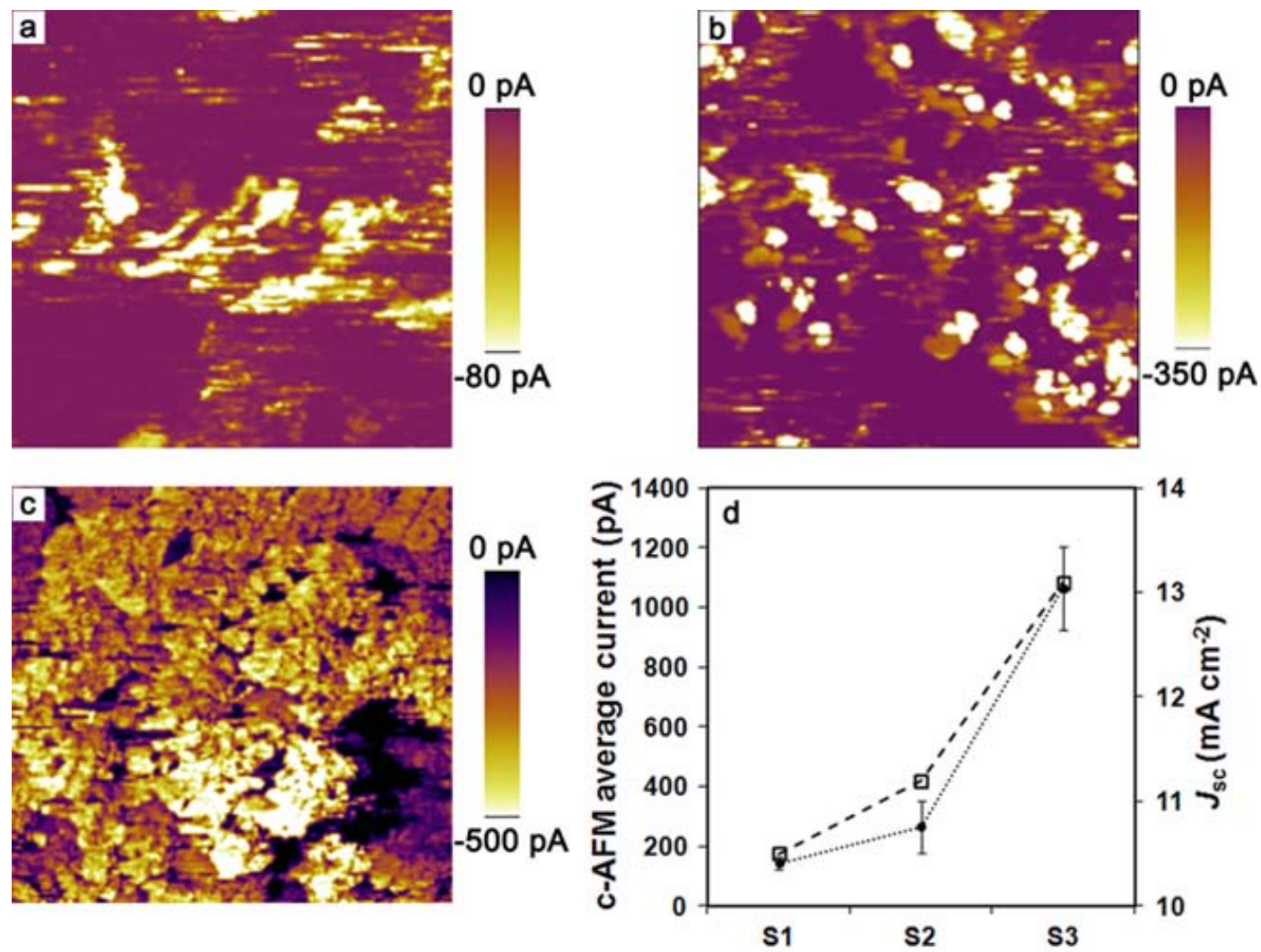

Figure 5.7 C-AFM dark current images of the composite electrodes based on S1 (a),

S2 (b) and S3 (c). The scan size is $400 \mathrm{~nm} \times 400 \mathrm{~nm}$ and the bias $\dot{\mathrm{i}} 5 \mathrm{~V}$ applied to FTO substrate. Trend comparison between c-AFM average current of the three composite electrodes (dotted line) and $J_{\text {sc }}$ of the three bulk devices (dashed line) (d). 

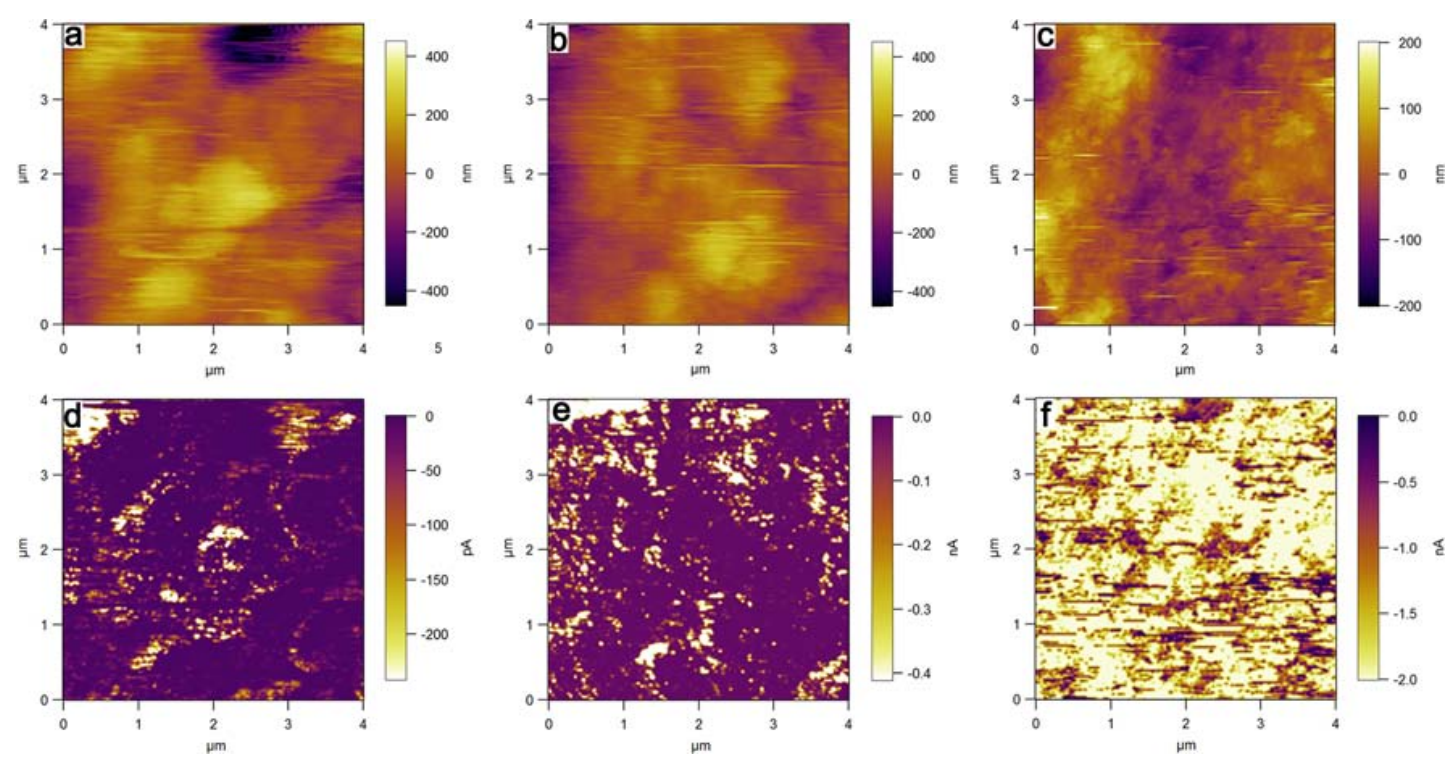

Figure 5.8 Topography (a, b, c) and dark current images (d, e, f) of the electrodes based on S1 (a, d), S2 (b, e) and S3 (c, f). The scan size is $4 \times 4 \mu \mathrm{m}$ and the bias is -5 V applied to FTO substrate.

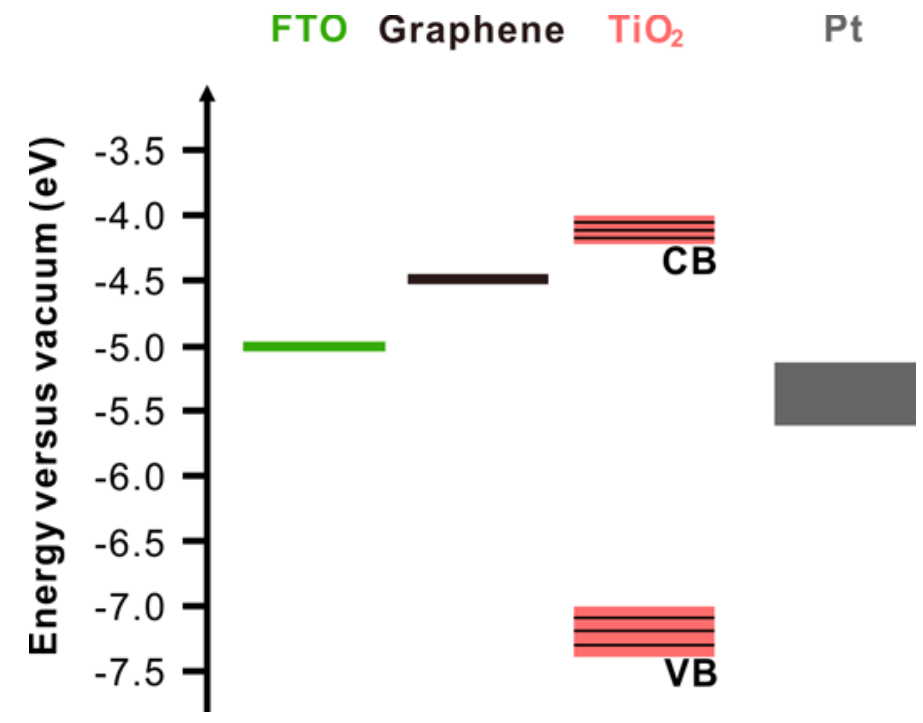

Figure 5.9 Energy level of all components involved in c-AFM testing.

Nano I-V curves of the three composite electrodes were measured to further investigate the electron transport properties. Since the work functions of FTO and Pt are much closer to $\mathrm{TiO}_{2}$ conduction band than its valance band (see energy level diagram in Figure 5.9), the $\mathrm{FTO} /$ graphene- $\mathrm{TiO}_{2}$ composite electrode and Pt tip 
assemble to form an electron-only diode. When the bias is applied to the FTO substrate and the tip is grounded, electrons are injected from the AFM tip at positive bias and from the FTO substrate at negative bias. The average nano I-V curves of the three composite electrodes were obtained based on more than $50 \mathrm{I}-\mathrm{V}$ curves for each sample and are shown in Figure 5.10a as Tafel plots. The I-V behavior of the three electrodes is similar at positive and negative bias, implying that electron injection from the tip and the substrate are both efficient. The two minima of each average I-V curve in Figure 5.10a are attributed to the background current $(<1 \mathrm{pA})$ of our system, which can be ignored. The current of average curves increases as $\mathrm{TiO}_{2}$ particle size decreases, which is consistent with the trend of average dark current in Figure 5.7d. By taking the logarithm of absolute values of the I-V curves, the segments from $-5 \mathrm{~V}$ to $0 \mathrm{~V}$ are plotted in Figure 5.10b as the space-charged limited current (SCLC) fitted curves. The contact area of the AFM tip to the electrode surface was fixed for all composite electrodes as a single contact force was used for all measurements. Radius of the tip-sample contact (a) is given by Hertzian mechanics as, a $=\left(\mathrm{RF}_{\text {contact }} / \mathrm{K}\right)^{1 / 3}$ [273], where $\mathrm{R}$ is the radius of the tip $(25 \mathrm{~nm}), \mathrm{F}_{\text {contact }}$ is the contact force of the tip on the sample surface $(200 \mathrm{nN})$, and $\mathrm{K}$ is an elastic modulus. Taking $\mathrm{K}=168 \mathrm{GPa}$ for $\mathrm{Pt}$ and ignoring the mechanical properties of the three samples by assuming that they are the same, give $\mathrm{a}=3.1 \mathrm{~nm}$, corresponding to a contact area of $30 \mathrm{~nm}^{2}$. The electron mobility was calculated using the modified SCLC model for c-AFM [274] in the case of electron injection from the substrate, with $\mathrm{TiO}_{2}$ dielectric constant of 50 [275]. The electron mobility was estimated to be $0.013 \mathrm{~cm}^{2} \mathrm{~V}^{-1} \mathrm{~s}^{-1}, 0.026 \mathrm{~cm}^{2} \mathrm{~V}^{-1} \mathrm{~s}^{-1}$, and 0.074 
$\mathrm{cm}^{2} \mathrm{~V}^{-1} \mathrm{~s}^{-1}$ for S1, S2, and S3, respectively. The electron mobility of the electrodes increases with decreasing $\mathrm{TiO}_{2}$ particle size. As the graphene concentration is similar for all three composite electrodes (refer to Figure 5.11 and Figure 5.12 with their associated discussion in smaller font), we suggest that the improved electron mobility is attributed to the smaller $\mathrm{TiO}_{2}$ particles-graphene composite which forms a more continuous and intimate conduction network.
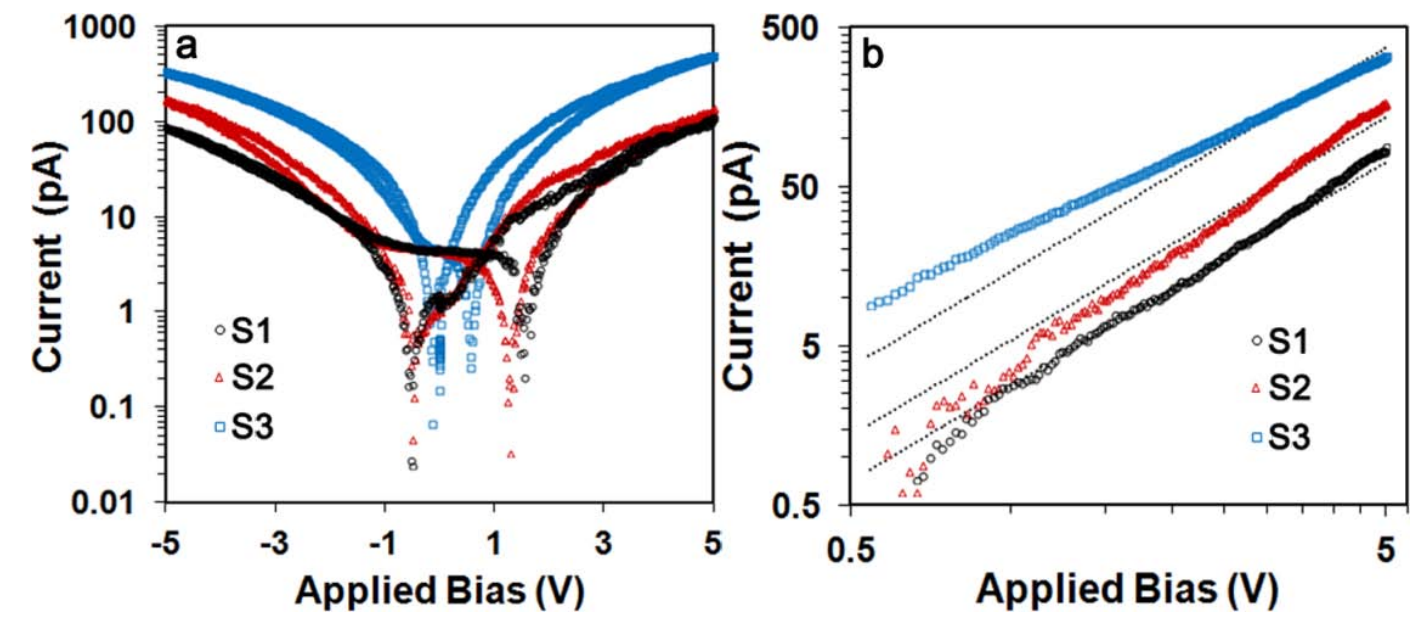

Figure 5.10 Tafel plots (a) and log I vs. log V plots (b) based on the I-V curves of the three electrodes. Black dotted lines in (b) are the fittings to SCLC model.
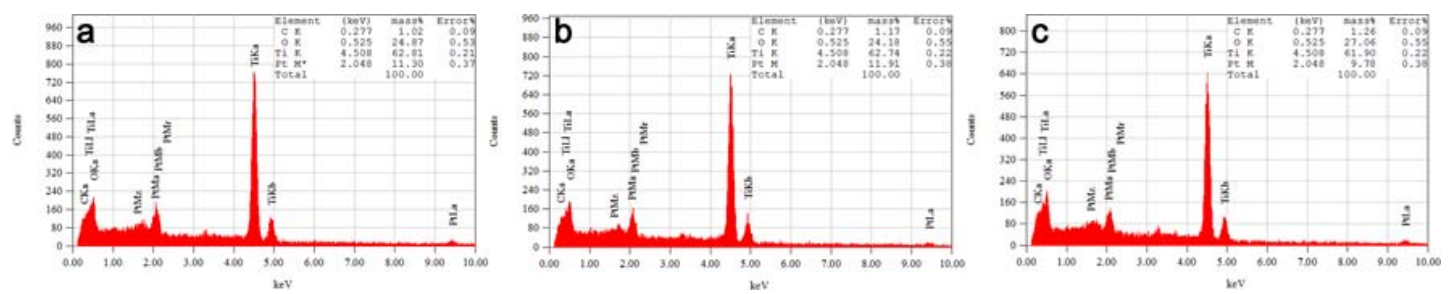

Figure 5.11 EDX results of S1 (a), S2 (b) and S3 (c) based electrodes and TGA results of graphene (d) and the polymers used in paste preparation. ${ }^{\ddagger}$ 

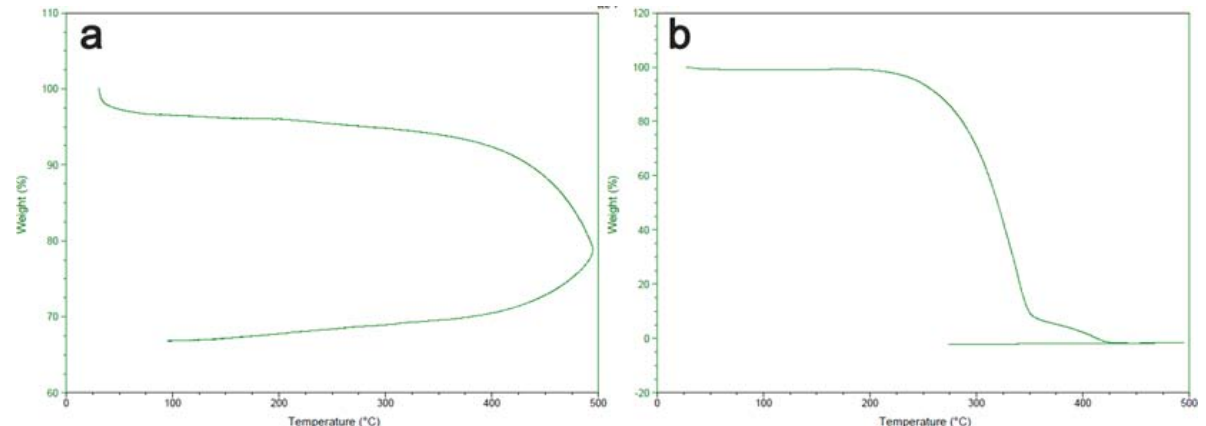

Figure 5.12 EDX results of S1 (a), S2 (b) and S3 (c) based electrodes and TGA results of graphene (d) and the polymers used in paste preparation. ${ }^{\ddagger}$

‡ The graphene concentration in the composite electrodes is reflected by the weight ratio of carbon in the electrode films determined using EDX. To confirm that the detected carbon elements are mainly from the incorporated graphene, instead of polymer residues after calcination, TGA was conducted to graphene powder and the polymers. The polymers were first dissolved in ethanol and then dried in air on the hotplate to imitate the process of paste preparation, which is to make sure that the status of the polymers for TGA test is the same with the one used in paste and film preparation. From TGA results, it can be confirmed that the polymers totally burn off below $450{ }^{\circ} \mathrm{C}$, which is consistent with the EDX results of the plain $\mathrm{TiO}_{2}$ electrodes in our previous work [252]. On the contrary, more than $65 \%$ of graphene remains after TGA test. The slightly weight losing of graphene below $350{ }^{\circ} \mathrm{C}$ may be due to the drifting away of graphene powder with the air flow used in TGA test, because of the low density of graphene powder and its electrostatic interaction. Therefore, the graphene concentration in S1, S2 and S3 based electrodes are determined to be $1.02 \%, 1.17 \%$ and $1.26 \%$, respectively.

\subsection{Summary}

In summary, this is the first study that successfully applies c-AFM to characterize DSSC photoanodes and correlates DSSC nanoscale properties to bulk device 
performance. The current study reveals a size-dependent electron transport property of the $\mathrm{TiO}_{2}$-graphene composite photoanodes. As the $\mathrm{TiO}_{2}$ particle size decreases, a more continuous electron transfer network is formed and results in a higher electron mobility of the smaller-sized $\mathrm{TiO}_{2}$ based composite electrode, indicated by c-AFM dark current images and nano I-V curves. The continuous conduction network reduces the internal resistance at $\mathrm{TiO}_{2} / \mathrm{TiO}_{2}$ and $\mathrm{TiO}_{2} / \mathrm{FTO}$ interfaces, ultimately resulting in faster and more efficient electron transfer (indicated by significantly improved $J_{\text {sc }}$ and $F F$ ) of the S3 based device. 


\section{Chapter 6 A one-pot solvothermal synthetic strategy of hierarchical microspheres with radially assembled single- crystalline $\mathrm{TiO}_{2}$-nanorods as high performance photoanode materials in dye-sensitized solar cells ${ }^{3}$}

\subsection{Introduction}

Dye-sensitized solar cells (DSSCs) have been extensively investigated as one of the most promising low-cost alternatives to conventional silicon based photovoltaics [26, 41]. The main components of DSSCs are a photoanode consists of a dye-sensitized semiconductor nanocrystalline film deposited on a transparent conducting substrate, a redox-active electrolyte and a Pt cathode. A high-performance photoanode is expected to possess large specific surface area for sufficient dye loading, strong scattering effect to compensate the low light absorption efficiency of the sensitizer (typically N719 or N3) in the red region, and effective electron transport. However, the above features usually negate each other for nanocrystalline based anode films [34]. For instance, thick photoanode films prepared using $\mathrm{TiO}_{2}$ nanoparticles exhibit large specific surface area, inevitably accompanied by a large amount of grain boundaries, which is unfavourable for efficient electron transport in the $\mathrm{TiO}_{2}$ matrix. Besides, strong scattering effect requires large particles, the specific surface area of which is usually low, leading to reduction of dye loading.

Recently, hierarchical $\mathrm{TiO}_{2}$ microspheres have been synthesized and investigated as

\footnotetext{
${ }^{3}$ Reproduced from [Z.M. He, J. Liu, J.W. Miao, B. Liu, and T.T.Y. Tan, Journal of Material Chemistry C, 2014. 2(8): 1381-1385] with permission from The Royal Society of Chemistry.
} 
the photoanode materials $[171,173,174,177-179,276]$. The microspheres are capable of enhancing the scattering effect of the photoanode due to its micron size while maintaining or even increasing the surface area due to its nanoscale primary unit, such as nanoparticles and nanosheets, thus improving the DSSC performance. Single crystal rutile $\mathrm{TiO}_{2}$ nanorod with a length up to several hundreds of nanometers exhibits fast electron transport due to its low density of sub-bandgap defect states and small amount of grain boundaries [92, 93, 152]. To integrate the effects of large specific surface area, strong scattering and efficient electron transport into a single photoanode, hierarchical microspheres constructed with single crystal rutile $\mathrm{TiO}_{2}$ nanorods have been developed and and utilized to prepare the DSSC anodes through direct growth [176] and screen printing [175] of the microspheres on transparent conducting substrate. However, the former approach may face challenges in production scale up and film thickness control. For the latter, $\mathrm{Na}^{+}$residues derived from sodium salts involved in the microsphere synthesis process can limit the power conversion efficiency (PCE) of DSSC [277], therefore demonstrating a modest 3.57\% in PCE, only 13\% enhancement compared to P25 at a thickness of $16 \mu \mathrm{m}$. Besides, big rod bundles with a diameter of more than $100 \mathrm{~nm}$ formed by densely packed nanorods in microspheres decrease the surface area of the photoanodes, only giving a PCE of 2.94\% at an anode film thickness of 20 $\mu \mathrm{m}$ [179].

Herein, we demonstrate a facile solvothermal strategy to prepare $\mathrm{TiO}_{2}$ microspheres constructed with loosely assembled single crystal rutile nanorods. The conceived strategy involved the use of $n$-butanol as an amphiphile for the formation of 
microreactors in which an acid thermal crystallization process and a self-assembly process of $\mathrm{TiO}_{2}$ nanorods into microspheres occurred during the one-step solvothermal reaction. Instead of titanium alkoxides, $\mathrm{TiCl}_{3}$ is utilized as the $\mathrm{Ti}$ source, which has the attractive attributes of high water solubility to enable rutile nanorods formation in the water-rich microreactors, as well as high stability and low cost [278]. In addition, the current method does not require any pre-treatment, such as the mixing of the reaction precursor by stirring or sonication, thus making this approach very simple for particle morphology tunability and economical for large scale production.

\subsection{Experimental}

$3 \mathrm{ml}$ of $12 \% \mathrm{TiCl}_{3}$ acidic aqueous solution diluted with $3 \mathrm{ml}$ of DI water were added into a Teflon-lined autoclave of $18 \mathrm{ml}$ capacity, followed by addition of $6 \mathrm{ml}$ of n-butanol. Subsequently, the autoclave was sealed and placed in an oven at desired reaction temperature for $4 \mathrm{~h}$. After natural cooling to room temperature, the product was washed using DI water and ethanol for 3 times and dried in air. The reaction temperature was controlled at $110,130,150,170$ and $190{ }^{\circ} \mathrm{C}$, respectively. The obtained serial samples were labelled with the corresponding reaction temperature. For instance, the sample prepared at $150{ }^{\circ} \mathrm{C}$ was labelled as $\mathrm{T} 150$. The electrodes were fabricated via the doctor-blade technique using the above materials and P25 (Degussa) on FTO glass and calcined at $500{ }^{\circ} \mathrm{C}$ in air for $30 \mathrm{~min}$. The thickness and active area of the anode films were controlled at $\sim 9 \mu \mathrm{m}$ and $0.201 \mathrm{~cm}^{2}$, respectively.

\subsection{Results and discussion}

TEM images of the as-prepared T150 in Figure 6.1a and 6.1b exhibit a dandelion- 
like spherical morphology, consisting of numerous $\mathrm{TiO}_{2}$ nanorods radiating from the center with an average diameter of $14 \mathrm{~nm}$. From HRTEM image, the lattice distance highlighted in Figure 6.1c was determined to be $0.328 \mathrm{~nm}$, which corresponds to rutile (110) planes, indicating that the nanorod growth direction is along the [001] orientation [279]. The selected area electron diffraction (SAED) pattern in Figure 6.1d confirms the single-crystalline nature of the $\mathrm{TiO}_{2}$ nanorods, which is very crucial for DSSC, as fast electron transport through the single-crystal nanorods can be achieved. Besides, the smooth side surfaces and high crystallinity of the nanorods are capable of suppressing the electron trapping at surface defects [176]. Figure 6.2a shows the FESEM image of T150 microspheres with loosely assembled nanorods, which brings about a high specific surface area. The size distribution of the microspheres was also examined and the result is displayed in Figure 6.2b, showing that the mean diameter of T150 microspheres is $831 \mathrm{~nm}$.

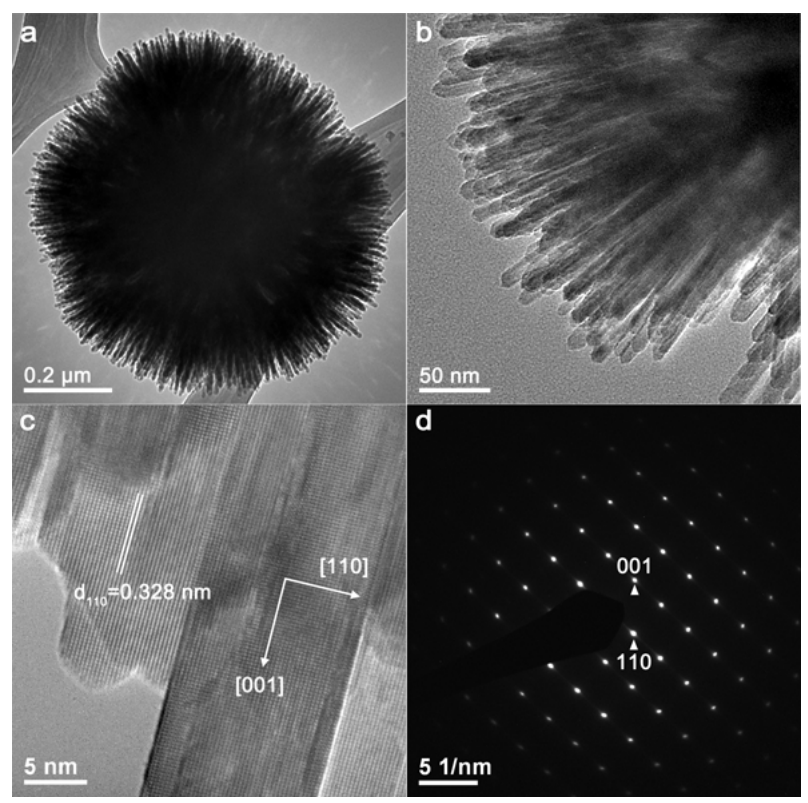

Figure 6.1 TEM (a, b), HRTEM (c) images and SAED pattern (d) of T150. 

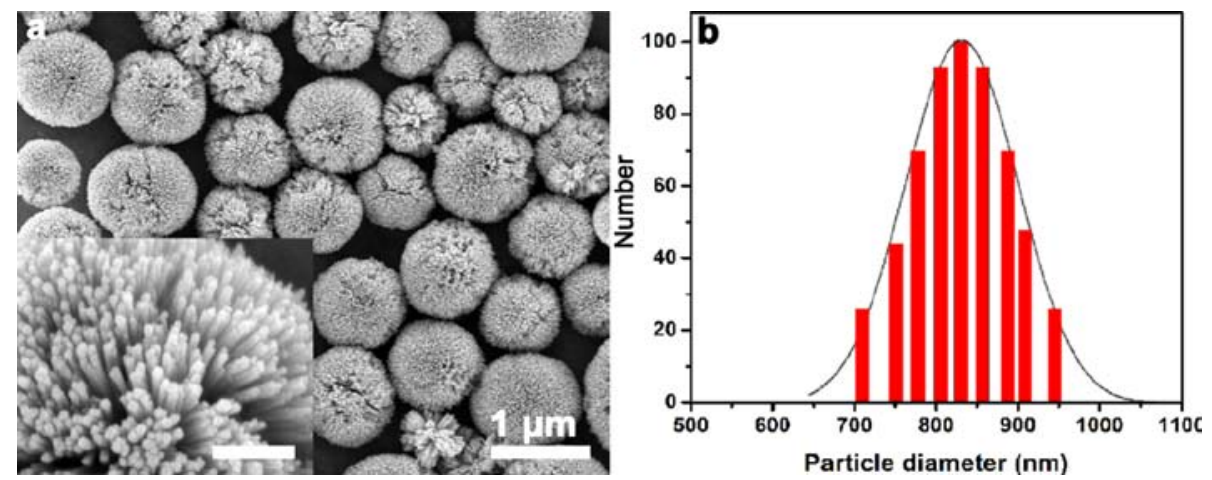

Figure 6.2 SEM image (a) and particle size distribution diagram (b) of T150. Inset of

(a) is a magnification image and the scale bar is $100 \mathrm{~nm}$.

Based on TEM observation, a formation mechanism of the hierarchical microspheres is proposed and presented in Figure 6.3. The water-rich microreactor droplets formed by an amphiphile-water system is an ideal soft template for selfassembly of the nanocrystals into a three dimensional microstructure [279]. Highly acid condition and selective adsorption of $\mathrm{Cl}^{-}$on rutile (110) plane favours the formation of rutile phase and promotes the anisotropic growth of $\mathrm{TiO}_{2}$ into nanorods along [001] orientation [169]. Therefore, random $\mathrm{TiO}_{2}$ nanorods form in the water phase in the presence of $\mathrm{HCl}$ (from the acidic $\mathrm{TiCl}_{3}$ solution) at the beginning of the reaction. The $\mathrm{Cl}^{-}$adsorption on (110) plane gives rise to repulsive forces between the side walls of the nanorods [280]. Consequently, the nanorods joint on the (001) plane (the highest energy plane of rutile $\mathrm{TiO}_{2}$ ) and assemble into spherical structure in the microreactors to minimize their surface area and reduce the total free energy [281]. The repulsive force between the nanorods avoids the aggregation of the nanorods into the rod bundles and results in the loosely-packed structure. The grooves at the edges and joints of the assembled nanorods are favourable sites for adatom attachment to 
form new atomic layers and eventually new single crystals with smooth side surface [282]. As the reaction progresses, spheres increase in size, finally forming hierarchical $\mathrm{TiO}_{2}$ microspheres consisting of loosely assembled single-crystal rutile nanorods.

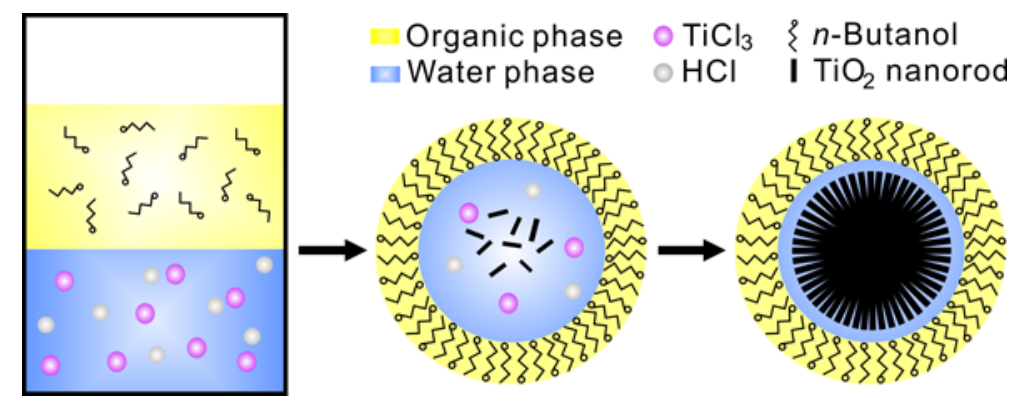

Figure 6.3 The procedure of the facile solvothermal approach.

To investigate the effect of reaction temperature, a series of samples was prepared at $110,130,170$ and $190{ }^{\circ} \mathrm{C}$, which are labelled with the corresponding reaction temperature. We observed a temperature-dependent morphological evolution of the microspheres (evident in Figure 6.4 and Table 6.1). As the reaction temperature increases, the particle size of the microspheres decreases while the diameter of nanorod increases, which can be attributed to enhanced mixing of water and $n$-butanol to generate a smaller water phase "microreactor", and a faster growth kinetic of nanorod induced by high temperature. Moreover, the assembly of the nanorods was observed to become looser with increasing temperature, and destruction of the spheres occurred at $190{ }^{\circ} \mathrm{C}$, indicating the loss in stability of the microemulsion at this temperature. The specific surface area of the microspheres is inevitably affected by the above morphological changes and was determined to be $84.69,97.07,89.24$, and $63.68 \mathrm{~m}^{2} \mathrm{~g}^{-1}$ for T110, T130, T150 and T170, respectively. The surface area of T190 is $49.28 \mathrm{~m}^{2} \mathrm{~g}^{-1}$, lower than that $\left(58.18 \mathrm{~m}^{2} \mathrm{~g}^{-1}\right)$ of P25. 


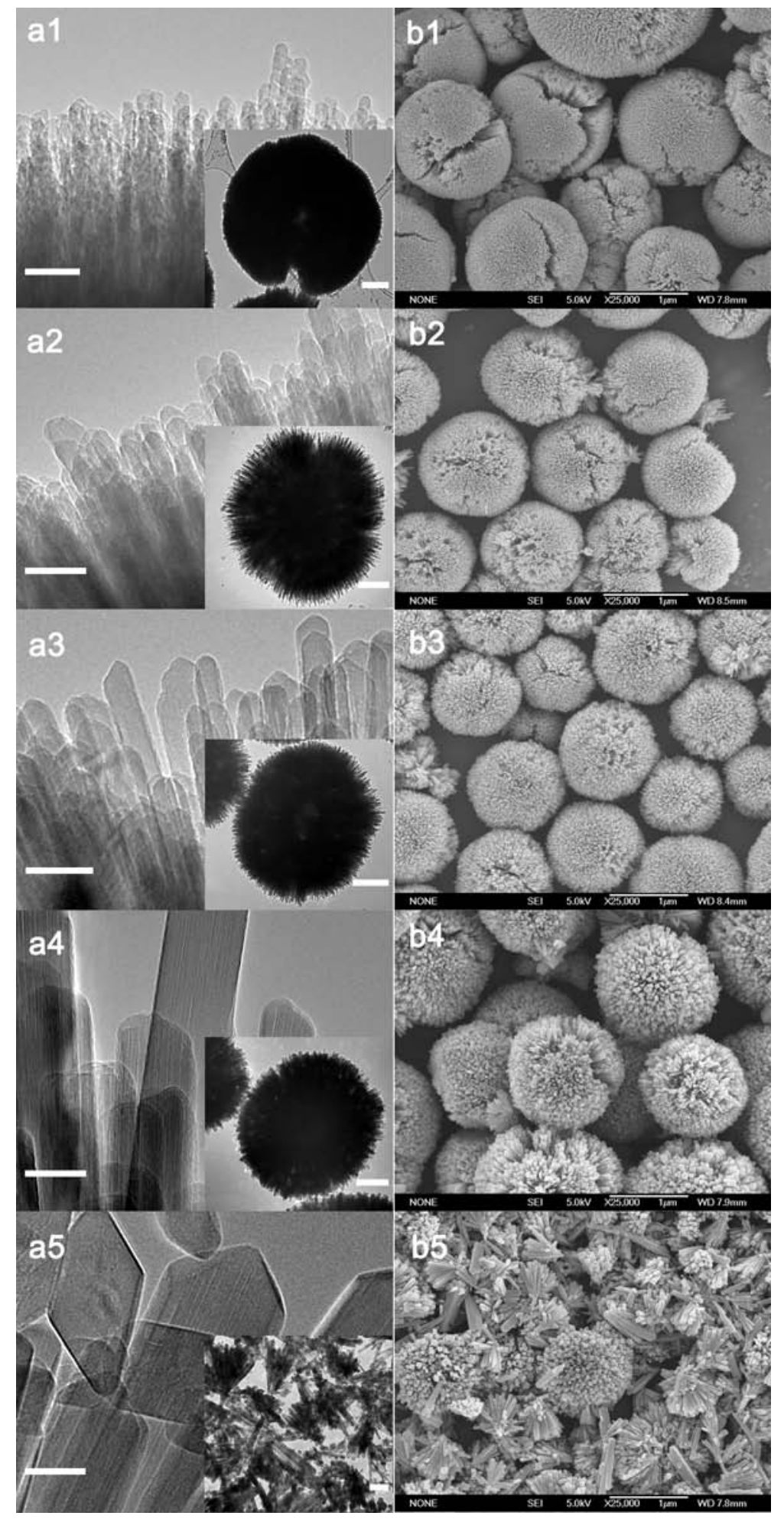

Figure 6.4 TEM images (a) and SEM images (b) of T110 (a1, b1), T130 (a2, b2), T150 (a3, b3), T170 (a4, b4) and T190 (a5, b5). The scale bars in (a) and the insets of (a) are $20 \mathrm{~nm}$ and $0.2 \mu \mathrm{m}$, respectively. 
Table 6.1 Morphology parameters of the hierarchical microspheres and P25

\begin{tabular}{ccccc}
\hline Sample & $\begin{array}{c}\text { Average particle size } \\
(\mathbf{n m})\end{array}$ & $\begin{array}{c}\text { Average Rod diameter } \\
(\mathbf{n m})\end{array}$ & $\begin{array}{c}\mathbf{S}_{\mathrm{BET}} \\
\left(\mathbf{m}^{\mathbf{2}} \mathbf{g}^{\mathbf{- 1}} \mathbf{)}\right.\end{array}$ & $\begin{array}{c}\text { Pore volume } \\
\left(\mathbf{c m}^{\mathbf{3}} \mathbf{g}^{\mathbf{- 1}} \mathbf{)}\right.\end{array}$ \\
\hline T110 & 1032 & 7 & 84.69 & 0.2064 \\
T130 & 925 & 10 & 97.07 & 0.2416 \\
T150 & 831 & 14 & 89.24 & 0.2741 \\
T170 & 853 & 21 & 63.68 & 0.3469 \\
T190 & 463 & 30 & 49.28 & 0.1968 \\
P25 & 27 & -- & 58.18 & 0.1616 \\
\hline
\end{tabular}

XRD patterns of T110, T130 and T150 primarily exhibit characteristic peaks of rutile $\mathrm{TiO}_{2}$ as shown in Figure 6.5, which is consistent with HRTEM observation. For $\mathrm{T} 170$ and $\mathrm{T} 190$, the peaks corresponding to anatase $\mathrm{TiO}_{2}$ appear. We speculate that at higher temperatures, there may be less $\mathrm{HCl}$ for the anisotropic growth of rutile nanorods due to the increased dissolution of $\mathrm{HCl}$ in $n$-butanol. The crystallinity of the microspheres is improved at high reaction temperature, which is revealed by the decreased full width at half maximum of the diffraction peaks. UV-Vis DRS in Figure 6.6 show that the reflectance of the microspheres is more than $80 \%$ in the range of $450-800 \mathrm{~nm}$, which is higher than that (around 70\%) of P25, confirming the enhanced light-scattering property of the microspheres.

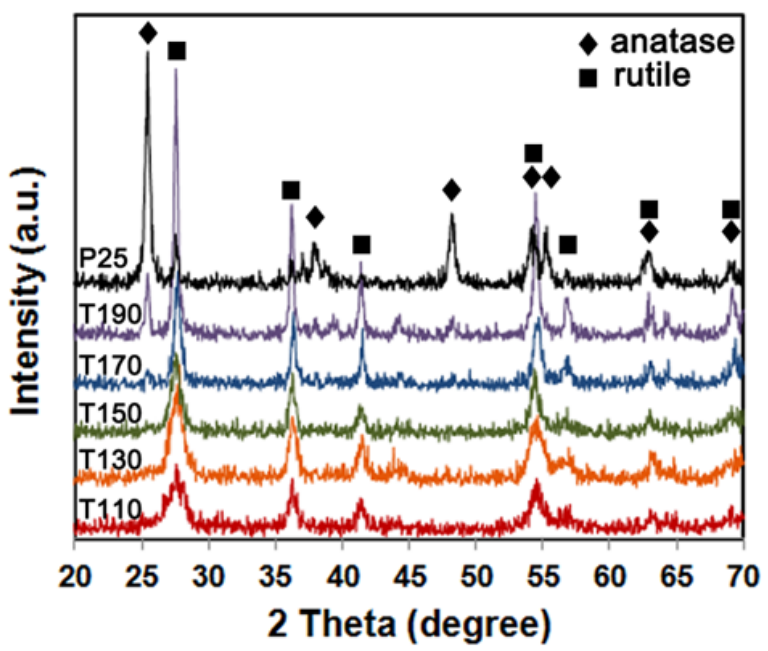

Figure 6.5 XRD patterns of the five microspheres and P25 powders. 


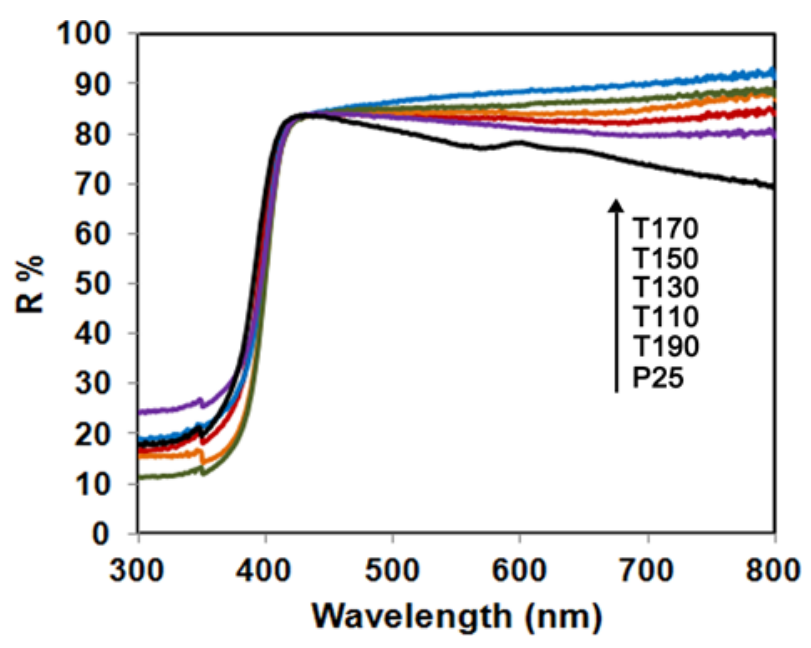

Figure 6.6 UV-Vis DRS of the five microspheres and P25 powders.

The five hierarchical $\mathrm{TiO}_{2}$ microspheres, as well as the P25 (as a reference), were utilized to prepare photoanodes using a doctor-blade technique. The active area and film thickness of the anodes were controlled to be $0.201 \mathrm{~cm}^{2}$ and $9 \mu \mathrm{m}$, respectively. Figure 6.7 shows the photocurrent density-voltage $(J-\mathrm{V})$ characteristics of the six devices, the performance parameters of which are summarized in Table 6.2 for comparison. For the hierarchical microspheres, the trend of short-circuit current density $\left(J_{\mathrm{sc}}\right)$ of the photoanodes corresponds to their specific surface areas, indicating that the $J_{\mathrm{sc}}$ is mainly determined by the dye loading. With the highest specific surface area, T130-based device gives the highest $J_{\mathrm{sc}}$ of $9.48 \mathrm{~mA} \mathrm{~cm}^{-2}$, while the $J_{\mathrm{sc}}$ of the device based on T110, T150, T170 and T190 is 8.89, 9.32, 7.91 and $7.36 \mathrm{~mA} \mathrm{~cm}^{-2}$, respectively. Although P25 is lower than T170 in specific surface area, its photoanode delivers a higher $J_{\mathrm{sc}}$ of $8.31 \mathrm{~mA} \mathrm{~cm}{ }^{-2}$, which may be due to the better dye adsorption property of the anatase $\mathrm{TiO}_{2}$ [91]. Open-circuit voltage $\left(V_{\text {oc }}\right)$ and fill factor (FF) of the microspheres-based devices are generally higher than that of P25 reference cell, which indicates efficient electron transfer in single-crystal rutile $\mathrm{TiO}_{2}$ nanorods with 
few-hundreds nanometer length. $V_{\text {oc }}$ and FF increase from T110 to T150 based photoanodes, which are attributed to the reduced internal resistance resulted from the effective electron transport in $\mathrm{TiO}_{2}$ nanorods with improved crystallinity at higher temperature. Compared to T150, the $V_{\text {oc }}$ and FF of T170 and T190 based devices decrease, which is ascribed to the formation of the anatase phase in these two samples, reducing the fast electron transport rate in single-crystal rutile $\mathrm{TiO}_{2}$. With a large surface area $\left(89.24 \mathrm{~m}^{2} \mathrm{~g}^{-1}\right)$, enhanced scattering effect $(\sim 18 \%$ reflectance improvement compared to P25), and efficient electron transport (highly crystalline rutile $\mathrm{TiO}_{2}$ single-crystal nanorods), T150-based device delivers the highest PCE of 4.90\%, more than 20\% higher than P25 reference cell (4.06\%).

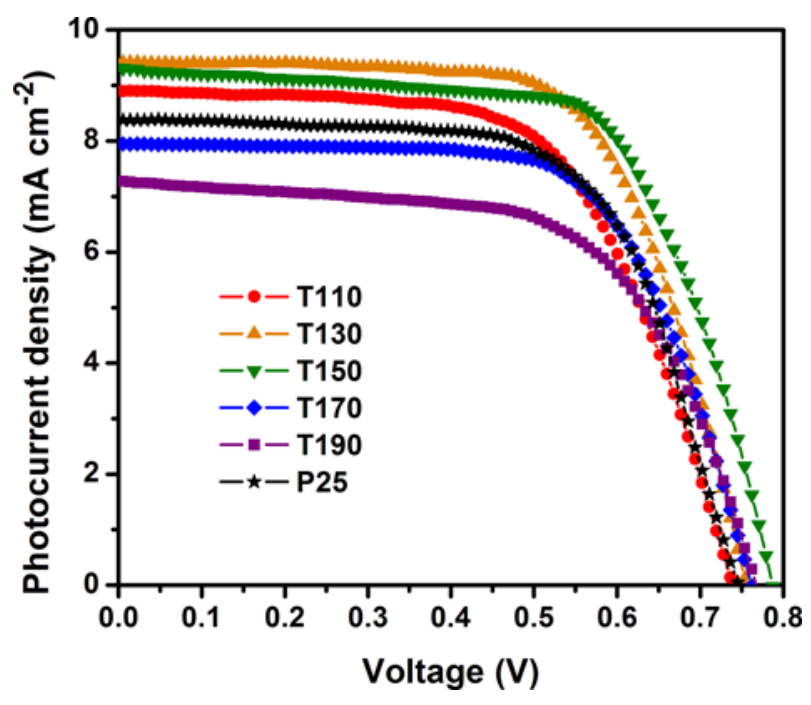

Figure 6.7 $\mathrm{J}$-V characteristics of the six devices with different anodes.

Table 6.2 Performance parameters of the microspheres and P25 based devices

\begin{tabular}{|c|c|c|c|c|}
\hline Sample & $\begin{array}{c}J_{\mathrm{sc}} \\
\left(\mathrm{mA} \mathrm{cm}^{-2}\right)\end{array}$ & $\begin{array}{l}V_{\text {oc }} \\
\text { (V) }\end{array}$ & $\begin{array}{l}\text { FF } \\
(\%)\end{array}$ & $\begin{array}{l}\text { PCE } \\
(\%)\end{array}$ \\
\hline T110 & 8.89 & 0.745 & 61.5 & 4.09 \\
\hline T130 & 9.48 & 0.762 & 65.9 & 4.74 \\
\hline T150 & 9.32 & 0.788 & 66.7 & 4.90 \\
\hline T170 & 7.91 & 0.771 & 66.1 & 4.05 \\
\hline T190 & 7.36 & 0.771 & 62.0 & 3.50 \\
\hline P25 & 8.31 & 0.753 & 64.9 & 4.06 \\
\hline
\end{tabular}



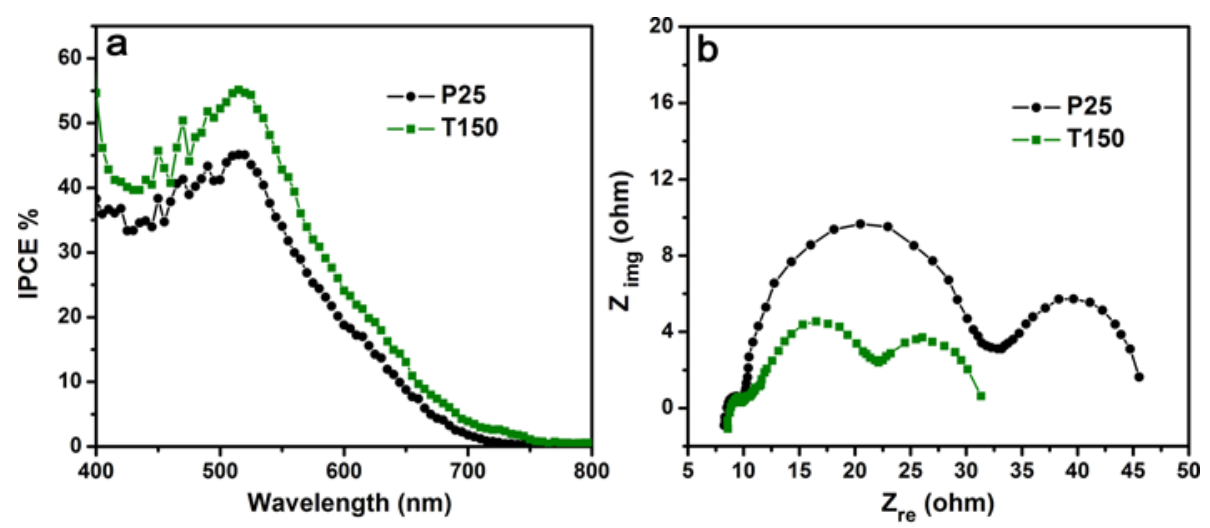

Figure 6.8 IPCE (a) and Nyquist plots (b) of the devices based on T150 and P25.

Incident photon-to-current conversion efficiency (IPCE) and electrochemical impedance spectra (EIS) of T150 and P25 based devices were measured to offer a physical insight into the effect of the $\mathrm{TiO}_{2}$ microspheres on DSSC performance enhancement. Figure 6.8a displays the IPCE curves as a function of wavelength. The enhanced IPCE of T150-based device over a wide range of 400-750 nm is attributed to the increased light harvesting efficiency from improved dye loading and light reflectance [173]. Nyquist plots of the two devices in Figure 6.8b illustrate three semicircles, the diameters of which represent the impedance of the corresponding processes. The first semicircles measured in the high-frequency $(\mathrm{kHz})$ range represent the Faraday resistance of the redox reaction of $\mathrm{I}^{-} / \mathrm{I}_{3}{ }^{-}$at the Pt/electrolyte interface. The second semicircles in medium-frequency $(1 \sim 100 \mathrm{~Hz})$ range reflect the electron transfer resistance at the $\mathrm{TiO}_{2} /$ dye/electrolyte interface, which is the most decisive factor in DSSCs. The third semicircles obtained in low-frequency $(\mathrm{mHz})$ range are related to the Warburg diffusion process of $\mathrm{I}_{3}^{-}$in the electrolyte [242, 271]. As the counter electrodes are exactly the same for both devices, the Faraday resistance of the two cells exhibit similar diameter values. An obvious decrease in the second 
semicircle diameter of the T150 device is observed, which is consistent to the fast electron transfer kinetics in more than $800 \mathrm{~nm}$ long single-crystal rutile $\mathrm{TiO}_{2}$ of $\mathrm{T} 150$ microsphere and the large specific surface area of the T150 based photoanode. The third semicircle of the device exhibits a slightly smaller diameter compared to that of P25 reference cell, which may be resultant from the bigger inter-particles pores that facilitate the diffusion of $\mathrm{I}_{3}^{-}$in the photoanode [34].

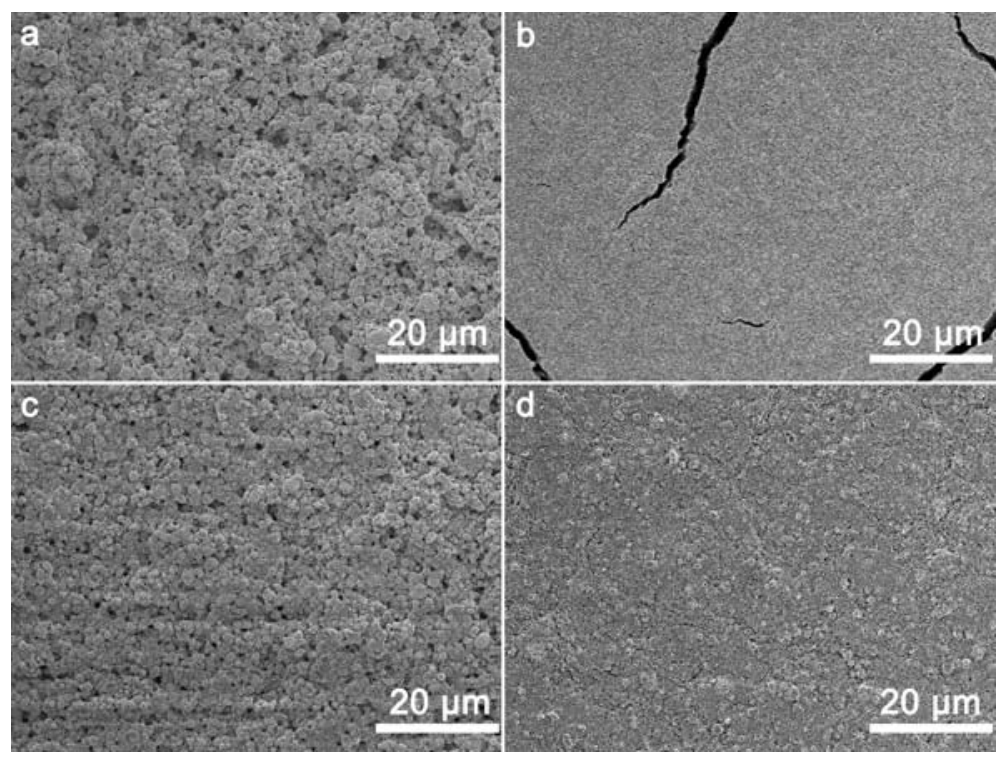

Figure 6.9 SEM images of the electrode films prepared using T150 (a), P25 (b) and a mixture of weight ratio of T150 and P25 at 80:20 (c) and 60:40 (d).

From the SEM images of the anode films (Figure 6.9), many voids can be observed among the microspheres in the T150-based photoanode. To make up for dye adsorption loss due to the presence of large voids, P25 was used as a void filler to improve dye loading and connectivity between the microspheres, the latter deemed essential for good electron transport. The weight ratio of T150 and P25 was adjusted to 60:40 to achieve a mesoporous electrode film of high void filling (Figure 6.9d). The devices prepared using this ratio were optimized by adjusting the anode film 
thickness and the photovoltaic performances of all the devices are summarized in Table 6.3. The $J_{\mathrm{sc}}$ increases while the $V_{\mathrm{oc}}$ and FF decrease with increasing film thickness. The composite photoanode with the thickness of $9.1 \mu \mathrm{m}$ gives a PCE of 5.69\%, 16\% and 40\% higher than T150 and P25 based solar cells with the same thickness. The optimal PCE (7.95\%) is obtained at an anode film thickness of 27.2 $\mu \mathrm{m}$, with the $J_{\text {sc }}$ of $18.8 \mathrm{~mA} \mathrm{~cm}^{-2}, V_{\text {oc }}$ of 0.745 and FF of $56.7 \%$. The optimal film thickness of the nanoparticle based photoanodes is generally 10-14 $\mu \mathrm{m}$ corresponding to the typical electron diffusion length of such films [16]. The increased optimal film thickness of the T150 based anode reflects the improved electron diffusion in anode film due to the incorporation of hierarchical $\mathrm{TiO}_{2}$ microspheres.

Table 6.3 Performance parameters of the T150:P25 (60:40 wt ratio) composite devices

\begin{tabular}{ccccc}
\hline $\begin{array}{c}\text { Thickness } \\
(\boldsymbol{\mu m})\end{array}$ & $\begin{array}{c}\boldsymbol{J}_{\mathbf{s c}} \\
\left(\mathbf{m A ~ c m} \mathbf{~ c m}^{-\mathbf{2}}\right)\end{array}$ & $\begin{array}{c}\boldsymbol{V}_{\mathbf{~ o c}} \\
\mathbf{( V )}\end{array}$ & $\begin{array}{c}\mathbf{F F} \\
\mathbf{( \% )}\end{array}$ & $\begin{array}{c}\text { PCE } \\
(\mathbf{\%})\end{array}$ \\
\hline $\mathbf{9 . 1}$ & 10.4 & 0.830 & 65.7 & 5.69 \\
$\mathbf{1 3 . 7}$ & 13.8 & 0.788 & 58.4 & 6.35 \\
$\mathbf{1 8 . 2}$ & 15.4 & 0.779 & 57.7 & 6.93 \\
$\mathbf{2 2 . 6}$ & 17.1 & 0.762 & 57.2 & 7.46 \\
$\mathbf{2 7 . 2}$ & 18.8 & 0.745 & 56.7 & 7.95 \\
$\mathbf{2 9 . 3}$ & 18.1 & 0.736 & 56.5 & 7.52 \\
\hline
\end{tabular}

\subsection{Summary}

We have developed a simple synthetic method to prepare complex hierarchical $\mathrm{TiO}_{2}$ microspheres constructed with radially assembled single-crystalline rutile $\mathrm{TiO}_{2}$ nanorods by combining an acid thermal crystallization process and a self-assembly process of the nanorods via a solvothermal amphiphile-water microreactor strategy. The morphology and crystallinity of the hierarchical microspheres are temperature dependent, which allows the control of the diameter and spacing of the nanorods by 
adjusting the reaction temperature to endow the microspheres with high specific surface area. A significant improvement (20\%) in the PCE of the T150 based device is achieved compared to that of the conventional P25 reference cell, which is attributed to the synergistic effects of the large specific surface area, enhanced scattering effect, and efficient electron transport properties of the T150 microspheres. Using P25 nanoparticles as void fillers, the T150 based photoanode exhibits a maximum PCE of $7.95 \%$ at an anode film thickness of $27.2 \mu \mathrm{m}$. The current one-pot solvothermal synthetic strategy may be extended for the preparation of other types of metal oxide microspheres with nano/micro hierarchical structure. 


\section{Chapter 7 General conclusions and recommendations for future research directions}

\subsection{General conclusions}

In this dissertation, novel $\mathrm{TiO}_{2}$ nanocomposites and nanostructures were successfully designed, synthesized, characterized and utilized as effective photoanode materials to improve the performance of DSSCs by enhancing the dye loading, electron transport property and scattering effect of the anode films. The working principles, device configuration and evaluation method of the DSSCs are thoroughly reviewed, and recent advances in $\mathrm{TiO}_{2}$-based photoanode optimization are also discussed.

The major contributions of this research project in DSSC development are summarized in the followings:

1. Graphene, as a 2D electron transport enhancer in the photoanode, is capable of effectively improve the PCE of DSSCs. Due to its high specific surface area and excellent electronic property, graphene can serve as support material and electron bridge in photoanode to enhance dye loading and electron transport.

2. The concentration of graphene in the photoanodes should be optimized, and the optimal concentration may vary from different graphene- $\mathrm{TiO}_{2}$ composites. Excess graphene can exacerbate the charge recombination or even result in short circuit, therefore increasing the internal resistance of DSSC devices or even destroying the devices. Inadequate graphene is not capable of forming 
the continuous electron transport network, limiting the effect of electron bridge and rendering electron transport in $\mathrm{TiO}_{2}$ matrix inefficient.

3. The nanostructure of $\mathrm{TiO}_{2}$ in graphene- $\mathrm{TiO}_{2}$ composite based photoanodes also plays an important role in DSSC performance improvement. Based on the results of this research project, smaller-sized $\mathrm{TiO}_{2}$ nanoparticles in graphene$\mathrm{TiO}_{2}$ composites deliver higher PCE, which is attributed to the synergistic effects of the high specific surface area produced from the ultra-small $\mathrm{TiO}_{2}-$ formed porous structure and fast electron transport in graphene nanosheets with compact $\mathrm{TiO}_{2}$ particles as electron leakage barriers.

4. Conducting atomic force microscopy (c-AFM) can be applied in DSSC photoanode characterization to obtain nanoscale electronic properties of the electrodes, which can be correlated with bulk device performance to reveal the fundamental mechanism of DSSC performance improvement.

5. The smaller-sized $\mathrm{TiO}_{2}$-graphene nanosheets are able to collapse intimately onto each other and form closer contact, which is capable of reducing the resistance at graphene- $\mathrm{TiO}_{2} / \mathrm{TiO}_{2}$-graphene interface and graphene- $\mathrm{TiO}_{2} / \mathrm{FTO}$ interface for efficient electron transport.

6. The utilization of hierarchical $\mathrm{TiO}_{2}$ microspheres consisting of single-crystal rutile nanorods as multi-functional photoanode materials is a simple and effective approach to improve the DSSC performance, by enhancing the dye loading, light scattering effect and electron transport.

7. The two simple solvothermal approaches in this dissertation both consist of 
multiple processes in the one-pot reactions. The crystallization of $\mathrm{TiO}_{2}$ and reduction of GO simultaneously occurred in the first solvothermal approach introduced in chapter 4, while the acid thermal crystallization and selfassembly process of the $\mathrm{TiO}_{2}$ nanorods were involved in the second approach introduced in chapter 6. Besides, both solvothermal approaches can be developed as universal methods to prepare graphene- $\mathrm{TiO}_{2}$ composites with various optimized $\mathrm{TiO}_{2}$ nanostructures for various applications and to prepare other metal oxide 3D nanostructures, respectively.

\subsection{Recommendations for future research directions}

DSSC has been tested in pilot-scale application, indicating that it is a highly promising low-cost sustainable energy generating technology. Sustainable Technologies International of Queanbeyan (Australia) constructed the first DSSC pilot plant in 2002 and G24 Innovations (G24i, Wales) established a pilot line of 5MW capacity in 2006 [32]. A $200 \mathrm{~m}^{2}$ of DSSC roof built at the CSIRO Energy Centre in Newcastle (NSW, Australia) further shows the perspective of DSSC commercialization [32, 283]. G24i is also the first to commercialize DSSC products. Its flexible modules are integrated into the items like bags, backpacks, and wireless keyboards for portable recharging of consumer electronics [44]. To further enhance the commercial attractiveness and safety of this technology, the following points are suggested for possible future research directions.

1. Nanomaterials with high conductivity can be employed as charge transport 
enhancer in DSSC photoanodes for PCE improvement. Examples of such nanomaterials include zero-dimensional fullerene, one-dimensional carbon nanotubes and two-dimensional graphene nanoflakes [119, 125, 141, 142, 284]. However, the effects of their morphologies, such as the size dimensions and shapes on charge transport properties of the photoanodes remain unclear. Systematic investigation on the effects using these semiconducting nanomaterials with different dimensional sizes should be carried out for further PCE improvement and understanding of DSSC energy harvesting mechanism.

2. Introducing other green energy conversion processes into the photoanodes may also be a promising approach to improve the DSSC performance. For instance, thermoelectric $\mathrm{Bi}_{2} \mathrm{Te}_{3}$ nanoplates has been recently incorporated into the $\mathrm{TiO}_{2}$ based photoanode to improve the PCE by $28 \%$, by converting the heat from charge recombination and infrared irradiation into the electrical energy, and meanwhile enhancing the electron transport in the photoanode [285]. Therefore, the incorporation of other novel semiconducting nanomaterials with high conductivity and beneficial properties, such as thermoelectric property, into the $\mathrm{TiO}_{2}$ based photoanodes allows the DSSCs to harvest both solar energy and resultant thermal energy for more efficient power conversion.

3. The costly platinum catalyst on the counter electrodes may be replaced by a 
dye-sensitized p-type semiconductor layer. For such tandem pn-DSSC consisting of both $n$ - and p-type photoelectrodes, the oxidation process of electrolyte still occurs at the conventional n-type photoelectrode/electrolyte interface, while its reduction process is accomplished at the p-type photoelectrode/electrolyte interface, instead of the Pt/electrolyte interface. Electrons are injected into the $\mathrm{I}^{-} / \mathrm{I}_{3}^{-}$redox couples from the dye molecules absorbed on the p-type semiconductor nanoparticles upon the excitation under irradiation, and subsequently the oxidized dyes are regenerated through the hole transport across the p-type semiconductor layer. However, the PCE of the tandem pn-DSSCs is very low, due to the poor performance of the p-type electrodes [286, 287]. Therefore, p-type photoelectrode optimization, such as incorporation of the nanomaterials with high conductivity (i.e. semiconducting single-walled carbon nanotubes) should be effective for PCE improvement of the tandem cells.

4. The liquid electrolyte used in the conventional DSSCs can cause sealant corrosion and cell leakage [288], which are major obstacles for large-scale fabrication of the DSSCs. These problems may be addressed by using ionic liquids- or polymer composites-based quasi-solid-state electrolyte to replace the conventional liquid electrolyte. The ionic liquids-based electrolyte has attracted much attention due to its negligible vapor pressure, nonvolatility, tunable viscosity, excellent thermal stability and high ionic conductivity. However, the PCE of DSSCs based on the ionic liquids electrolyte is relative 
low, due to low diffusion coefficients of the redox couples in this quasi-solidstate electrolyte. To realize the replacement of the liquid electrolyte without significant PCE loss, the modification of the ionic liquids-based electrolyte is needed in future research. Incorporation of polyaniline-loaded carbon black into the ionic liquids electrolyte has been reported to be capable of significantly improving the cell efficiency [289, 290], which indicates that incorporation of suitable carbon nanomaterials (i.e. carbon nanotubes and graphene nanoribbons) into the quasi-solid-state electrolytes can improve the diffusion of the redox couples and thus the performance of the solid-state DSSCs. 


\section{Reference}

1. Snaith, H.J. and L. Schmidt-Mende, Advances in liquid-electrolyte and solid-state dyesensitized solar cells. Advanced Materials, 2007. 19(20): p. 3187-3200.

2. $\quad$ Gong, J.W., J. Liang, and K. Sumathy, Review on dye-sensitized solar cells (DSSCs): Fundamental concepts and novel materials. Renewable \& Sustainable Energy Reviews, 2012. 16(8): p. 5848-5860.

3. Hamann, T.W., R.A. Jensen, A.B.F. Martinson, H. Van Ryswyk, and J.T. Hupp, Advancing beyond current generation dye-sensitized solar cells. Energy \& Environmental Science, 2008. 1(1): p. 66-78.

4. $\quad$ Press Release in 2011 by U.S. Energy Information Administration: International energy outlook 2011.

5. Hirsch, R.L., Mitigation of maximum world oil production: Shortage scenarios. Energy Policy, 2008. 36(2): p. 881-889.

6. Hughes, J.R., Peak-oil concems. Oil \& Gas Journal, 2008. 106(2): p. 12-12.

7. Witze, A., That's oil, folks. Nature, 2007. 445(7123): p. 14-17.

8. Kelly, N.A. and T.L. Gibson, Increasing the solar photovoltaic energy capture on sunny and cloudy days. Solar Energy, 2011. 85(1): p. 111-125.

9. Margeta, J. and Z. Glasnovic, Feasibility of the green energy production by hybrid solar plus hydro power system in Europe and similar climate areas. Renewable \& Sustainable Energy Reviews, 2010. 14(6): p. 1580-1590.

10. Islam, M.R., S. Mekhilef, and R. Saidur, Progress and recent trends of wind energy technology. Renewable \& Sustainable Energy Reviews, 2013. 21: p. 456-468.

11. Phillips, J., Evaluating the level and nature of sustainable development for a geothermal power plant. Renewable \& Sustainable Energy Reviews, 2010. 14(8): p. 2414-2425.

12. Kerckhoffs, H. and R. Renquist, Biofuel from plant biomass. Agronomy for Sustainable Development, 2013. 33(1): p. 1-19.

13. Goncalves, L.M., V.D. Bermudez, H.A. Ribeiro, and A.M. Mendes, Dye-sensitized solar cells: A safe bet for the future. Energy \& Environmental Science, 2008. 1(6): p. 655-667.

14. Hasan, M.A. and K. Sumathy, Photovoltaic thermal module concepts and their performance analysis: A review. Renewable \& Sustainable Energy Reviews, 2010. 14(7): p. 1845-1859.

15. Gratzel, M., Solar energy conversion by dye-sensitized photovoltaic cells. Inorganic Chemistry, 2005. 44(20): p. 6841-6851.

16. Zhang, Q.F. and G.Z. Cao, Nanostructured photoelectrodes for dye-sensitized solar cells. Nano Today, 2011. 6(1): p. 91-109.

17. Shah, A.V., H. Schade, M. Vanecek, J. Meier, E. Vallat-Sauvain, N. Wyrsch, U. Kroll, C. Droz, and J. Bailat, Thin-film silicon solar cell technology. Progress in Photovoltaics, 2004. 12(2-3): p. 113-142.

18. Chopra, K.L., P.D. Paulson, and V. Dutta, Thin-film solar cells: An overview. Progress in Photovoltaics, 2004. 12(2-3): p. 69-92. 
19. Palm, J., V. Probst, and F.H. Karg, Second generation CIS solar modules. Solar Energy, 2004. 77(6): p. 757-765.

20. Wohrle, D. and D. Meissner, ORGANIC SOLAR-CELLS. Advanced Materials, 1991. 3(3): p. 129-138.

21. Gratzel, M., Dye-sensitized solar cells. Journal of Photochemistry and Photobiology CPhotochemistry Reviews, 2003. 4(2): p. 145-153.

22. Green, M.A., K. Emery, Y. Hishikawa, and W. Warta, Solar Cell Efficiency Tables (Version 34). Progress in Photovoltaics, 2009. 17(5): p. 320-326.

23. Hardin, B.E., H.J. Snaith, and M.D. McGehee, The renaissance of dye-sensitized solar cells. Nature Photonics, 2012. 6(3): p. 162-169.

24. Green, M.A., Thin-film solar cells: review of materials, technologies and commercial status. Journal of Materials Science-Materials in Electronics, 2007. 18: p. S15-S19.

25. Romeo, A., A. Terheggen, D. Abou-Ras, D.L. Batzner, F.J. Haug, M. Kalin, D. Rudmann, and A.N. Tiwari, Development of thin-film Cu(In,Ga)Se-2 and CdTe solar cells. Progress in Photovoltaics, 2004. 12(2-3): p. 93-111.

26. Li, L.L. and E.W.G. Diau, Porphyrin-sensitized solar cells. Chemical Society Reviews, 2013. 42(1): p. 291-304.

27. Reddy, P.J., Solar power generation: technology, new concepts \& policy2012: Вoca Raton, FL : CRC Press.

28. Dai, S.Y., J. Weng, Y.F. Sui, S.H. Chen, S.F. Xiao, Y. Huang, F.T. Kong, X. Pan, L.H. Hu, C.N. Zhang, and K.J. Wang, The design and outdoor application of dye-sensitized solar cells. Inorganica Chimica Acta, 2008. 361(3): p. 786-791.

29. Oregan, B. and M. Gratzel, A LOW-COST, HIGH-EFFICIENCY SOLAR-CELL BASED ON DYE-SENSITIZED COLLOIDAL TIO2 FILMS. Nature, 1991. 353(6346): p. 737740.

30. Yella, A., H.W. Lee, H.N. Tsao, C.Y. Yi, A.K. Chandiran, M.K. Nazeeruddin, E.W.G. Diau, C.Y. Yeh, S.M. Zakeeruddin, and M. Gratzel, Porphyrin-Sensitized Solar Cells with Cobalt (II/III)-Based Redox Electrolyte Exceed 12 Percent Efficiency. Science, 2011. 334(6056): p. 629-634.

31. Green, M.A., K. Emery, Y. Hishikawa, W. Warta, and E.D. Dunlop, Solar cell efficiency tables (version 39). Progress in Photovoltaics, 2012. 20(1): p. 12-20.

32. Wang, L., X.M. Fang, and Z.G. Zhang, Design methods for large scale dye-sensitized solar modules and the progress of stability research. Renewable \& Sustainable Energy Reviews, 2010. 14(9): p. 3178-3184.

33. Han, L.Y., A. Fukui, N. Fuke, N. Koide, R. Yamanaka, and Ieee, High efficiency of dyesensitized solar cell and module. Conference Record of the 2006 IEEE 4th World Conference on Photovoltaic Energy Conversion, Vols 1 and 22006. 179-182.

34. Zhu, F., D.P. Wu, Q. Li, H. Dong, J.M. Li, K. Jiang, and D.S. Xu, Hierarchical TiO2 microspheres: synthesis, structural control and their applications in dye-sensitized solar cells. Rsc Advances, 2012. 2(31): p. 11629-11637.

35. Listorti, A., B. O'Regan, and J.R. Durrant, Electron Transfer Dynamics in DyeSensitized Solar Cells. Chemistry of Materials, 2011. 23(15): p. 3381-3399.

36. Hagfeldt, A., G. Boschloo, L.C. Sun, L. Kloo, and H. Pettersson, Dye-Sensitized Solar Cells. Chemical Reviews, 2010. 110(11): p. 6595-6663. 
37. Gregg, B.A., F. Pichot, S. Ferrere, and C.L. Fields, Interfacial Recombination Processes in Dye-Sensitized Solar Cells and Methods To Passivate the Interfaces. The Journal of Physical Chemistry B, 2001. 105(7): p. 1422-1429.

38. Jose, R., V. Thavasi, and S. Ramakrishna, Metal Oxides for Dye-Sensitized Solar Cells. Journal of the American Ceramic Society, 2009. 92(2): p. 289-301.

39. Gratzel, M., The advent of mesoscopic injection solar cells. Progress in Photovoltaics, 2006. 14(5): p. 429-442.

40. Markvart, T. and L. Castañer, Solar cells: Materials, manufacture and operation. Reprinted ed.2005: Elsevier, Oxford, UK.

41. Gratzel, M., Photoelectrochemical cells. Nature, 2001. 414(6861): p. 338-344.

42. Gratzel, M., Conversion of sunlight to electric power by nanocrystalline dye-sensitized solar cells (vol 164, pg 3, 2004). Journal of Photochemistry and Photobiology aChemistry, 2004. 168(3): p. 235-235.

43. Gratzel, M., Dye-sensitized solid-state heterojunction solar cells. Mrs Bulletin, 2005. 30(1): p. 23-27.

44. Baxter, J.B., Commercialization of dye sensitized solar cells: Present status and future research needs to improve efficiency, stability, and manufacturing. Journal of Vacuum Science \& Technology A, 2012. 30(2).

45. Asbury, J.B., R.J. Ellingson, H.N. Ghosh, S. Ferrere, A.J. Nozik, and T.Q. Lian, Femtosecond IR study of excited-state relaxation and electron-injection dynamics of $\mathrm{Ru}(d \mathrm{cbpy})(2)(\mathrm{NCS})(2)$ in solution and on nanocrystalline TiO2 and Al2O3 thin films. Journal of Physical Chemistry B, 1999. 103(16): p. 3110-3119.

46. Kuang, D.B., S. Ito, B. Wenger, C. Klein, J.E. Moser, R. Humphry-Baker, S.M. Zakeeruddin, and M. Gratzel, High molar extinction coefficient heteroleptic ruthenium complexes for thin film dye-sensitized solar cells. Journal of the American Chemical Society, 2006. 128(12): p. 4146-4154.

47. Listorti, A., C. Creager, P. Sommeling, J. Kroon, E. Palomares, A. Fornelli, B. Breen, P.R.F. Barnes, J.R. Durrant, C. Law, and B. O'Regan, The mechanism behind the beneficial effect of light soaking on injection efficiency and photocurrent in dye sensitized solar cells. Energy \& Environmental Science, 2011. 4(9): p. 3494-3501.

48. Bauer, C., G. Boschloo, E. Mukhtar, and A. Hagfeldt, Electron injection and recombination in $\mathrm{Ru}(d \mathrm{~d} b p y)(2)(N C S)(2)$ sensitized nanostructured $\mathrm{ZnO}$. Journal of Physical Chemistry B, 2001. 105(24): p. 5585-5588.

49. Ardo, S. and G.J. Meyer, Photodriven heterogeneous charge transfer with transitionmetal compounds anchored to $\mathrm{TiO} 2$ semiconductor surfaces. Chemical Society Reviews, 2009. 38(1): p. 115-164.

50. Hagfeldt, A. and M. Gratzel, Molecular photovoltaics. Accounts of Chemical Research, 2000. 33(5): p. 269-277.

51. Hagfeldt, A. and M. Gratzel, LIGHT-INDUCED REDOX REACTIONS IN NANOCRYSTALLINE SYSTEMS. Chemical Reviews, 1995. 95(1): p. 49-68.

52. Cao, F., G. Oskam, G.J. Meyer, and P.C. Searson, Electron transport in porous nanocrystalline TiO2 photoelectrochemical cells. Journal of Physical Chemistry, 1996. 100(42): p. 17021-17027.

53. Solbrand, A., H. Lindstrom, H. Rensmo, A. Hagfeldt, S.E. Lindquist, and S. Sodergren, 
Electron transport in the nanostructured TiO2-electrolyte system studied with timeresolved photocurrents. Journal of Physical Chemistry B, 1997. 101(14): p. 2514-2518.

54. Sodergren, S., A. Hagfeldt, J. Olsson, and S.E. Lindquist, THEORETICAL-MODELS FOR THE ACTION SPECTRUM AND THE CURRENT-VOLTAGE CHARACTERISTICS OF MICROPOROUS SEMICONDUCTOR-FILMS IN PHOTOELECTROCHEMICAL CELLS. Journal of Physical Chemistry, 1994. 98(21): p. 5552-5556.

55. Oregan, B., J. Moser, M. Anderson, and M. Gratzel, VECTORIAL ELECTRON INJECTION INTO TRANSPARENT SEMICONDUCTOR MEMBRANES AND ELECTRIC-FIELD EFFECTS ON THE DYNAMICS OF LIGHT-INDUCED CHARGE SEPARATION. Journal of Physical Chemistry, 1990. 94(24): p. 8720-8726.

56. Kopidakis, N., K.D. Benkstein, J. van de Lagemaat, and A.J. Frank, Transport-limited recombination of photocarriers in dye-sensitized nanocrystalline TiO2 solar cells. Journal of Physical Chemistry B, 2003. 107(41): p. 11307-11315.

57. Zhu, K., N. Kopidakis, N.R. Neale, J. van de Lagemaat, and A.J. Frank, Influence of surface area on charge transport and recombination in dye-sensitized $\mathrm{TiO} 2$ solar cells. Journal of Physical Chemistry B, 2006. 110(50): p. 25174-25180.

58. Kopidakis, N., N.R. Neale, K. Zhu, J. van de Lagemaat, and A.J. Frank, Spatial location of transport-limiting traps in TiO2 nanoparticle films in dye-sensitized solar cells. Applied Physics Letters, 2005. 87(20).

59. Chen, H., J.F. Lee, S. Tseng, M.S. Lin, and W.B. Liau, Photosensitized growth of $\mathrm{TiO} 2$ nanoparticles improved the charge transfer dynamics of a bichromophoric dye. Journal of Luminescence, 2012. 132(8): p. 2182-2187.

60. Barnes, P.R.F., A.Y. Anderson, J.R. Durrant, and B.C. O'Regan, Simulation and measurement of complete dye sensitised solar cells: including the influence of trapping, electrolyte, oxidised dyes and light intensity on steady state and transient device behaviour. Physical Chemistry Chemical Physics, 2011. 13(13): p. 5798-5816.

61. Dloczik, L., O. Ileperuma, I. Lauermann, L.M. Peter, E.A. Ponomarev, G. Redmond, N.J. Shaw, and I. Uhlendorf, Dynamic response of dye-sensitized nanocrystalline solar cells: Characterization by intensity-modulated photocurrent spectroscopy. Journal of Physical Chemistry B, 1997. 101(49): p. 10281-10289.

62. Kim, Y.J., Y.H. Lee, M.H. Lee, H.J. Kim, J.H. Pan, G.I. Lim, Y.S. Choi, K. Kim, N.G. Park, C. Lee, and W.I. Lee, Formation of Efficient Dye-Sensitized Solar Cells by Introducing an Interfacial Layer of Long-Range Ordered Mesoporous TiO2 Thin Film. Langmuir, 2008. 24(22): p. 13225-13230.

63. Kniprath, R., S. Duhm, H. Glowatzki, N. Koch, S. Rogaschewski, J.P. Rabe, and S. Kirstein, Internal structure of nanoporous TiO2/Polyion thin films prepared by layerby-layer deposition. Langmuir, 2007. 23(19): p. 9860-9865.

64. Benkstein, K.D., N. Kopidakis, J. van de Lagemaat, and A.J. Frank, Influence of the percolation network geometry on electron transport in dye-sensitized titanium dioxide solar cells. Journal of Physical Chemistry B, 2003. 107(31): p. 7759-7767.

65. Haque, S.A., Y. Tachibana, D.R. Klug, and J.R. Durrant, Charge recombination kinetics in dye-sensitized nanocrystalline titanium dioxide films under externally applied bias. Journal of Physical Chemistry B, 1998. 102(10): p. 1745-1749. 
66. Mori, S.N., W. Kubo, T. Kanzaki, N. Masaki, Y. Wada, and S. Yanagida, Investigation of the effect of alkyl chain length on charge transfer at TiO2/dye/electrolyte interface. Journal of Physical Chemistry C, 2007. 111(8): p. 3522-3527.

67. Clifford, J.N., E. Palomares, M.K. Nazeeruddin, M. Gratzel, and J.R. Durrant, Dye dependent regeneration dynamics in dye sensitized nanocrystalline solar cells: Evidence for the formation of a ruthenium bipyridyl cation/iodide intermediate. Journal of Physical Chemistry C, 2007. 111(17): p. 6561-6567.

68. Tefashe, U.M., K. Nonomura, N. Vlachopoulos, A. Hagfeldt, and G. Wittstock, Effect of Cation on Dye Regeneration Kinetics of N719-Sensitized TiO2 Films in AcetonitrileBased and Ionic-Liquid-Based Electrolytes Investigated by Scanning Electrochemical Microscopy. Journal of Physical Chemistry C, 2012. 116(6): p. 4316-4323.

69. Pelet, S., J.E. Moser, and M. Gratzel, Cooperative effect of adsorbed cations and iodide on the interception of back electron transfer in the dye sensitization of nanocrystalline TiO2. Journal of Physical Chemistry B, 2000. 104(8): p. 1791-1795.

70. Rowley, J.G., S. Ardo, Y.L. Sun, F.N. Castellano, and G.J. Meyer, Charge Recombination to Oxidized Iodide in Dye-Sensitized Solar Cells. Journal of Physical Chemistry C, 2011. 115(41): p. 20316-20325.

71. Liu, W.Q., L.H. Hu, S.Y. Dai, L. Guo, N.Q. Jiang, and D. Kou, The effect of the series resistance in dye-sensitized solar cells explored by electron transport and back reaction using electrical and optical modulation techniques. Electrochimica Acta, 2010. 55(7): p. 2338-2343.

72. Wang, M., P. Chen, R. Humphry-Baker, S.M. Zakeeruddin, and M. Gratzel, The Influence of Charge Transport and Recombination on the Performance of DyeSensitized Solar Cells. Chemphyschem, 2009. 10(1): p. 290-299.

73. Haque, S.A., Y. Tachibana, R.L. Willis, J.E. Moser, M. Gratzel, D.R. Klug, and J.R. Durrant, Parameters influencing charge recombination kinetics in dye-sensitized nanocrystalline titanium dioxide films. Journal of Physical Chemistry B, 2000. 104(3): p. 538-547.

74. Bisquert, J., A. Zaban, and P. Salvador, Analysis of the mechanisms of electron recombination in nanoporous $\mathrm{TiO} 2$ dye-sensitized solar cells. Nonequilibrium steadystate statistics and interfacial electron transfer via surface states. Journal of Physical Chemistry B, 2002. 106(34): p. 8774-8782.

75. Nakade, S., T. Kanzaki, W. Kubo, T. Kitamura, Y. Wada, and S. Yanagida, Role of electrolytes on charge recombination in dye-sensitized TiO2 solar cell (1): The case of solar cells using the I-/I3(-) redox couple. Journal of Physical Chemistry B, 2005. 109(8): p. 3480-3487.

76. Peter, L.M., Characterization and modeling of dye-sensitized solar cells. Journal of Physical Chemistry C, 2007. 111(18): p. 6601-6612.

77. O'Regan, B.C., K. Walley, M. Juozapavicius, A. Anderson, F. Matar, T. Ghaddar, S.M. Zakeeruddin, C. Klein, and J.R. Durrant, Structure/Function Relationships in Dyes for Solar Energy Conversion: A Two-Atom Change in Dye Structure and the Mechanism for Its Effect on Cell Voltage. Journal of the American Chemical Society, 2009. 131(10): p. 3541-3548.

78. Miyashita, M., K. Sunahara, T. Nishikawa, Y. Uemura, N. Koumura, K. Hara, A. Mori, 
T. Abe, E. Suzuki, and S. Mori, Interfacial Electron-Transfer Kinetics in Metal-Free Organic Dye-Sensitized Solar Cells: Combined Effects of Molecular Structure of Dyes and Electrolytes. Journal of the American Chemical Society, 2008. 130(52): p. 1787417881.

79. Gratzel, M., Recent Advances in Sensitized Mesoscopic Solar Cells. Accounts of Chemical Research, 2009. 42(11): p. 1788-1798.

80. Smestad, G.P., F.C. Krebs, C.M. Lampert, C.G. Granqvist, K.L. Chopra, X. Mathew, and $\mathrm{H}$. Takakura, Reporting solar cell efficiencies in solar energy materials and solar cells. Solar Energy Materials and Solar Cells, 2008. 92(4): p. 371-373.

81. Jose, R., A. Kumar, V. Thavasi, K. Fujihara, S. Uchida, and S. Ramakrishna, Relationship between the molecular orbital structure of the dyes and photocurrent density in the dye-sensitized solar cells. Applied Physics Letters, 2008. 93(2).

82. De Angelis, F., S. Fantacci, A. Selloni, M. Gratzel, and M.K. Nazeeruddin, Influence of the sensitizer adsorption mode on the open-circuit potential of dye-sensitized solar cells. Nano Letters, 2007. 7(10): p. 3189-3195.

83. Fabregat-Santiago, F., J. Bisquert, G. Garcia-Belmonte, G. Boschloo, and A. Hagfeldt, Influence of electrolyte in transport and recombination in dye-sensitized solar cells studied by impedance spectroscopy. Solar Energy Materials and Solar Cells, 2005. 87(1-4): p. 117-131.

84. Nazeeruddin, M.K., P. Pechy, T. Renouard, S.M. Zakeeruddin, R. Humphry-Baker, P. Comte, P. Liska, L. Cevey, E. Costa, V. Shklover, L. Spiccia, G.B. Deacon, C.A. Bignozzi, and M. Gratzel, Engineering of efficient panchromatic sensitizers for nanocrystalline TiO2-based solar cells. Journal of the American Chemical Society, 2001. 123(8): p. 1613-1624.

85. Hashimoto, K., H. Irie, and A. Fujishima, TiO2 photocatalysis: A historical overview and future prospects. Japanese Journal of Applied Physics Part 1-Regular Papers Brief Communications \& Review Papers, 2005. 44(12): p. 8269-8285.

86. Kwon, S., M. Fan, A.T. Cooper, and H.Q. Yang, Photocatalytic applications of microand Nano-TiO2 in environmental engineering. Critical Reviews in Environmental Science and Technology, 2008. 38(3): p. 197-226.

87. Zhao, H., L. Liu, J.M. Andino, and Y. Li, Bicrystalline TiO2 with controllable anatasebrookite phase content for enhanced CO2 photoreduction to fuels. Journal of Materials Chemistry A, 2013. 1(28): p. 8209-8216.

88. Na-Phattalung, S., M.F. Smith, K. Kim, M.H. Du, S.H. Wei, S.B. Zhang, and S. Limpijumnong, First-principles study of native defects in anatase $\mathrm{TiO}$. Physical Review B, 2006. 73(12).

89. Park, N.G., J. van de Lagemaat, and A.J. Frank, Comparison of dye-sensitized rutileand anatase-based TiO2 solar cells. Journal of Physical Chemistry B, 2000. 104(38): p. 8989-8994.

90. Wold, A., PHOTOCATALYTIC PROPERTIES OF TIO2. Chemistry of Materials, 1993. 5(3): p. 280-283.

91. Takahashi, J., H. Itoh, S. Motai, and S. Shimada, Dye adsorption behavior of anataseand rutile-type TiO2 nanoparticles modified by various heat-treatments. Journal of Materials Science, 2003. 38(8): p. 1695-1702. 
92. Feng, X.J., K. Zhu, A.J. Frank, C.A. Grimes, and T.E. Mallouk, Rapid Charge Transport in Dye-Sensitized Solar Cells Made from Vertically Aligned Single-Crystal Rutile TiO2 Nanowires. Angewandte Chemie-International Edition, 2012. 51(11): p. 2727-2730.

93. Hao, F., H. Lin, C. Zhou, Y. Liu, and J. Li, Bifunctional single-crystalline rutile nanorod decorated heterostructural photoanodes for efficient dye-sensitized solar cells. Physical Chemistry Chemical Physics, 2011. 13(35): p. 15918-15924.

94. Jena, A., S.P. Mohanty, P. Kumar, J. Naduvath, V. Gondane, P. Lekha, J. Das, H.K. Narula, S. Mallick, and P. Bhargava, Dye Sensitized Solar Cells: A Review. Transactions of the Indian Ceramic Society, 2012. 71(1): p. 1-16.

95. Ito, S., P. Liska, P. Comte, R.L. Charvet, P. Pechy, U. Bach, L. Schmidt-Mende, S.M. Zakeeruddin, A. Kay, M.K. Nazeeruddin, and M. Gratzel, Control of dark current in photoelectrochemical (TiO2/I--I-3(-)) and dye-sensitized solar cells. Chemical Communications, 2005(34): p. 4351-4353.

96. Zhang, Z., S. Ito, B. O'Regan, D. Kuang, S.M. Zakeeruddin, P. Liska, R. Charvet, P. Comte, M.K. Nazeeruddin, P. Pechy, R. Humphry-Baker, T. Koyanagi, T. Mizuno, and M. Graetzel, The electronic role of the TiO2 light-scattering layer in dye-sensitized solar cells. Zeitschrift Fur Physikalische Chemie-International Journal of Research in Physical Chemistry \& Chemical Physics, 2007. 221(3): p. 319-327.

97. Keis, K., C. Bauer, G. Boschloo, A. Hagfeldt, K. Westermark, H. Rensmo, and H. Siegbahn, Nanostructured $\mathrm{ZnO}$ electrodes for dye-sensitized solar cell applications. Journal of Photochemistry and Photobiology a-Chemistry, 2002. 148(1-3): p. 57-64.

98. Keis, K., E. Magnusson, H. Lindstrom, S.E. Lindquist, and A. Hagfeldt, A 5\% efficient photo electrochemical solar cell based on nanostructured ZnO electrodes. Solar Energy Materials and Solar Cells, 2002. 73(1): p. 51-58.

99. Redmond, G., D. Fitzmaurice, and M. Graetzel, VISIBLE-LIGHT SENSITIZATION BY CIS-BIS(THIOCYANATO)BIS(2,2'-BIPYRIDYL-4,4'DICARBOXYLATO)RUTHENIUM(II) OF A TRANSPARENT NANOCRYSTALLINE ZNO FILM PREPARED BY SOL-GEL TECHNIQUES. Chemistry of Materials, 1994. 6(5): p. 686-691.

100. Saito, M. and S. Fujihara, Large photocurrent generation in dye-sensitized ZnO solar cells. Energy \& Environmental Science, 2008. 1(2): p. 280-283.

101. Breckenridge, R.G. and W.R. Hosler, ELECTRICAL PROPERTIES OF TITANIUM DIOXIDE SEMICONDUCTORS. Physical Review, 1953. 91(4): p. 793-802.

102. Ramasamy, E. and J. Lee, Ordered Mesoporous SnO2-Based Photoanodes for HighPerformance Dye-Sensitized Solar Cells. Journal of Physical Chemistry C, 2010. 114(50): p. 22032-22037.

103. Green, A.N.M., E. Palomares, S.A. Haque, J.M. Kroon, and J.R. Durrant, Charge transport versus recombination in dye-sensitized solar cells employing nanocrystalline TiO2 and SnO2 films. Journal of Physical Chemistry B, 2005. 109(25): p. 12525-12533.

104. Fukai, Y., Y. Kondo, S. Mori, and E. Suzuki, Highly efficient dye-sensitized SnO2 solar cells having sufficient electron diffusion length. Electrochemistry Communications, 2007. 9(7): p. 1439-1443.

105. Parks, G.A., ISOELECTRIC POINTS OF SOLID OXIDES SOLID HYDROXIDES AND 
AQUEOUS HYDROXO COMPLEX SYSTEMS. Chemical Reviews, 1965. 65(2): p. 177-\&.

106. Eguchi, K., H. Koga, K. Sekizawa, and K. Sasaki, Nb2O5-based composite electrodes for dye-sensitized solar cells. Journal of the Ceramic Society of Japan, 2000. 108(12): p. 1067-1071.

107. Hoshikawa, T., R. Kikuchi, K. Sasaki, and K. Eguchi, Impedance analysis of electronic transport in dye-sensitized solar cells. Electrochemistry, 2002. 70(9): p. 675-680.

108. Lenzmann, F., J. Krueger, S. Burnside, K. Brooks, M. Gratzel, D. Gal, S. Ruhle, and D. Cahen, Surface photovoltage spectroscopy of dye-sensitized solar cells with TiO2, $\mathrm{Nb2O5}$, and SrTiO3 nanocrystalline photoanodes: Indication for electron injection from higher excited dye states. Journal of Physical Chemistry B, 2001. 105(27): p. 6347-6352.

109. Guo, P. and M.A. Aegerter, RU(II) sensitized Nb2O5 solar cell made by the sol-gel process. Thin Solid Films, 1999. 351(1-2): p. 290-294.

110. Sancho-Parramon, J., V. Janicki, and H. Zorc, Compositional dependence of absorption coefficient and band-gap for Nb2O5-SiO2 mixture thin films. Thin Solid Films, 2008. 516(16): p. 5478-5482.

111. Sayama, K., H. Sugihara, and H. Arakawa, Photoelectrochemical properties of a porous Nb2O5 electrode sensitized by a ruthenium dye. Chemistry of Materials, 1998. 10(12): p. 3825-3832.

112. Aegerter, M.A., Sol-gel niobium pentoxide: A promising material for electrochromic coatings, batteries, nanocrystalline solar cells and catalysis. Solar Energy Materials and Solar Cells, 2001. 68(3-4): p. 401-422.

113. Burnside, S., J.E. Moser, K. Brooks, M. Gratzel, and D. Cahen, Nanocrystalline mesoporous strontium titanate as photoelectrode material for photosensitized solar devices: Increasing photovoltage through flatband potential engineering. Journal of Physical Chemistry B, 1999. 103(43): p. 9328-9332.

114. Tan, B., E. Toman, Y. Li, and Y. Wu, Zinc stannate (Zn2SnO4) dye-sensitized solar cells. Journal of the American Chemical Society, 2007. 129(14): p. 4162-+.

115. Lana-Villarreal, T., G. Boschloo, and A. Hagfeldt, Nanostructured zinc stannate as semiconductor working electrodes for dye-sensitized solar cells. Journal of Physical Chemistry C, 2007. 111(14): p. 5549-5556.

116. Balaya, P., J. Jamnik, J. Fleig, and J. Maier, Mesoscopic electrical conduction in nanocrystalline SrTiO3. Applied Physics Letters, 2006. 88(6).

117. Tennakone, K., G. Kumara, I.R.M. Kottegoda, and V.P.S. Perera, An efficient dyesensitized photoelectrochemical solar cell made from oxides of tin and zinc. Chemical Communications, 1999(1): p. 15-16.

118. Jang, S.R., R. Vittal, and K.J. Kim, Incorporation of functionalized single-wall carbon nanotubes in dye-sensitized TiO2 solar cells. Langmuir, 2004. 20(22): p. 9807-9810.

119. Kongkanand, A., R.M. Dominguez, and P.V. Kamat, Single wall carbon nanotube scaffolds for photoelectrochemical solar cells. Capture and transport of photogenerated electrons. Nano Letters, 2007. 7(3): p. 676-680.

120. Kim, S.L., S.R. Jang, R. Vittal, J. Lee, and K.J. Kim, Rutile TiO2-modified multi-wall carbon nanotubes in $\mathrm{TiO} 2$ film electrodes for dye-sensitized solar cells. Journal of 
Applied Electrochemistry, 2006. 36(12): p. 1433-1439.

121. Zhang, S.W., H.H. Niu, Y. Lan, C. Cheng, J.Z. Xu, and X.K. Wang, Synthesis of TiO2 Nanoparticles on Plasma-Treated Carbon Nanotubes and Its Application in Photoanodes of Dye-Sensitized Solar Cells. Journal of Physical Chemistry C, 2011. 115(44): p. 22025-22034.

122. Chan, Y.F., C.C. Wang, B.H. Chen, and C.Y. Chen, Incorporation of plasmafunctionalized carbon nanocapsules into a nanocrystalline TiO2 photoanode for use in dye-sensitized solar cells. Carbon, 2011. 49(14): p. 4898-4910.

123. Chen, T., L.B. Qiu, Z.B. Cai, F. Gong, Z.B. Yang, Z.S. Wang, and H.S. Peng, Intertwined Aligned Carbon Nanotube Fiber Based Dye-Sensitized Solar Cells. Nano Letters, 2012. 12(5): p. 2568-2572.

124. Kamat, P.V., K. Tvrdy, D.R. Baker, and J.G. Radich, Beyond Photovoltaics: Semiconductor Nanoarchitectures for Liquid-Junction Solar Cells. Chemical Reviews, 2010. 110(11): p. 6664-6688.

125. Chen, J.Z., B. Li, J.F. Zheng, J.H. Zhao, and Z.P. Zhu, Role of Carbon Nanotubes in Dye-Sensitized TiO2-Based Solar Cells. Journal of Physical Chemistry C, 2012. 116(28): p. 14848-14856.

126. Lee, K.M., C.W. Hu, H.W. Chen, and K.C. Ho, Incorporating carbon nanotube in a low-temperature fabrication process for dye-sensitized TiO2 solar cells. Solar Energy Materials and Solar Cells, 2008. 92(12): p. 1628-1633.

127. Chan, Y.F., C.C. Wang, B.H. Chen, and C.Y. Chen, Dye-sensitized TiO2 solar cells based on nanocomposite photoanode containing plasma-modified multi-walled carbon nanotubes. Progress in Photovoltaics, 2013. 21(1): p. 47-57.

128. Brown, P., K. Takechi, and P.V. Kamat, Single-walled carbon nanotube scaffolds for dye-sensitized solar cells. Journal of Physical Chemistry C, 2008. 112(12): p. 47764782.

129. Guai, G.H., Y. Li, C.M. Ng, C.M. Li, and M.B. Chan-Park, TiO2 Composing with Pristine, Metallic or Semiconducting Single-Walled Carbon Nanotubes: Which Gives the Best Performance for a Dye-Sensitized Solar Cell. Chemphyschem, 2012. 13(10): p. 2566-2572.

130. Liu, J.W., Y.T. Kuo, K.J. Klabunde, C. Rochford, J. Wu, and J. Li, Novel Dye-Sensitized Solar Cell Architecture Using TiO2-Coated Vertically Aligned Carbon Nanofiber Arrays. Acs Applied Materials \& Interfaces, 2009. 1(8): p. 1645-1649.

131. Rochford, C., Z.Z. Li, J. Baca, J.W. Liu, J. Li, and J. Wu, The effect of annealing on the photoconductivity of carbon nanofiber/TiO2 core-shell nanowires for use in dyesensitized solar cells. Applied Physics Letters, 2010. 97(4).

132. Geim, A.K. and K.S. Novoselov, The rise of graphene. Nature Materials, 2007. 6(3): p. 183-191.

133. Balandin, A.A., S. Ghosh, W.Z. Bao, I. Calizo, D. Teweldebrhan, F. Miao, and C.N. Lau, Superior thermal conductivity of single-layer graphene. Nano Letters, 2008. 8(3): p. 902-907.

134. Bolotin, K.I., K.J. Sikes, Z. Jiang, M. Klima, G. Fudenberg, J. Hone, P. Kim, and H.L. Stormer, Ultrahigh electron mobility in suspended graphene. Solid State Communications, 2008. 146(9-10): p. 351-355. 
135. Stoller, M.D., S.J. Park, Y.W. Zhu, J.H. An, and R.S. Ruoff, Graphene-Based Ultracapacitors. Nano Letters, 2008. 8(10): p. 3498-3502.

136. Lee, C., X.D. Wei, J.W. Kysar, and J. Hone, Measurement of the elastic properties and intrinsic strength of monolayer graphene. Science, 2008. 321(5887): p. 385-388.

137. Novoselov, K.S., D. Jiang, F. Schedin, T.J. Booth, V.V. Khotkevich, S.V. Morozov, and A.K. Geim, Two-dimensional atomic crystals. Proceedings of the National Academy of Sciences of the United States of America, 2005. 102(30): p. 10451-10453.

138. Schniepp, H.C., J.L. Li, M.J. McAllister, H. Sai, M. Herrera-Alonso, D.H. Adamson, R.K. Prud'homme, R. Car, D.A. Saville, and I.A. Aksay, Functionalized single graphene sheets derived from splitting graphite oxide. Journal of Physical Chemistry B, 2006. 110(17): p. 8535-8539.

139. Hummers, W.S. and R.E. Offeman, PREPARATION OF GRAPHITIC OXIDE. Journal of the American Chemical Society, 1958. 80(6): p. 1339-1339.

140. Li, D., M.B. Muller, S. Gilje, R.B. Kaner, and G.G. Wallace, Processable aqueous dispersions of graphene nanosheets. Nature Nanotechnology, 2008. 3(2): p. 101-105.

141. Sun, S.R., L. Gao, and Y.Q. Liu, Enhanced dye-sensitized solar cell using grapheneTiO2 photoanode prepared by heterogeneous coagulation. Applied Physics Letters, 2010. 96(8).

142. Yang, N.L., J. Zhai, D. Wang, Y.S. Chen, and L. Jiang, Two-Dimensional Graphene Bridges Enhanced Photoinduced Charge Transport in Dye-Sensitized Solar Cells. Acs Nano, 2010. 4(2): p. 887-894.

143. Zhu, C.Z., S.J. Guo, P. Wang, L. Xing, Y.X. Fang, Y.M. Zhai, and S.J. Dong, One-pot, water-phase approach to high-quality graphene/TiO2 composite nanosheets. Chemical Communications, 2010. 46(38): p. 7148-7150.

144. Tang, Y.B., C.S. Lee, J. Xu, Z.T. Liu, Z.H. Chen, Z.B. He, Y.L. Cao, G.D. Yuan, H.S. Song, L.M. Chen, L.B. Luo, H.M. Cheng, W.J. Zhang, I. Bello, and S.T. Lee, Incorporation of Graphenes in Nanostructured TiO2 Films via Molecular Grafting for Dye-Sensitized Solar Cell Application. Acs Nano, 2010. 4(6): p. 3482-3488.

145. Nelson, J. and R.E. Chandler, Random walk models of charge transfer and transport in dye sensitized systems. Coordination Chemistry Reviews, 2004. 248(13-14): p. 11811194.

146. van de Lagemaat, J., N.G. Park, and A.J. Frank, Influence of electrical potential distribution, charge transport, and recombination on the photopotential and photocurrent conversion efficiency of dye-sensitized nanocrystalline TiO2 solar cells: A study by electrical impedance and optical modulation techniques. Journal of Physical Chemistry B, 2000. 104(9): p. 2044-2052.

147. Peter, L.M., Dye-sensitized nanocrystalline solar cells. Physical Chemistry Chemical Physics, 2007. 9(21): p. 2630-2642.

148. Fisher, A.C., L.M. Peter, E.A. Ponomarev, A.B. Walker, and K.G.U. Wijayantha, Intensity dependence of the back reaction and transport of electrons in dye-sensitized nanacrystalline TiO2 solar cells. Journal of Physical Chemistry B, 2000. 104(5): p. 949-958.

149. Forro, L., O. Chauvet, D. Emin, L. Zuppiroli, H. Berger, and F. Levy, HIGHMOBILITY N-TYPE CHARGE-CARRIERS IN LARGE SINGLE-CRYSTALS OF 
ANATASE (TIO2). Journal of Applied Physics, 1994. 75(1): p. 633-635.

150. Law, M., L.E. Greene, J.C. Johnson, R. Saykally, and P.D. Yang, Nanowire dyesensitized solar cells. Nature Materials, 2005. 4(6): p. 455-459.

151. Feng, X.J., K. Shankar, O.K. Varghese, M. Paulose, T.J. Latempa, and C.A. Grimes, Vertically Aligned Single Crystal TiO2 Nanowire Arrays Grown Directly on Transparent Conducting Oxide Coated Glass: Synthesis Details and Applications. Nano Letters, 2008. 8(11): p. 3781-3786.

152. Liu, B. and E.S. Aydil, Growth of Oriented Single-Crystalline Rutile TiO2 Nanorods on Transparent Conducting Substrates for Dye-Sensitized Solar Cells. Journal of the American Chemical Society, 2009. 131(11): p. 3985-3990.

153. Mor, G.K., O.K. Varghese, M. Paulose, K. Shankar, and C.A. Grimes, A review on highly ordered, vertically oriented TiO2 nanotube arrays: Fabrication, material properties, and solar energy applications. Solar Energy Materials and Solar Cells, 2006. 90(14): p. 2011-2075.

154. Roy, P., D. Kim, K. Lee, E. Spiecker, and P. Schmuki, TiO2 nanotubes and their application in dye-sensitized solar cells. Nanoscale, 2010. 2(1): p. 45-59.

155. Zhu, K., N.R. Neale, A. Miedaner, and A.J. Frank, Enhanced charge-collection efficiencies and light scattering in dye-sensitized solar cells using oriented $\mathrm{TiO} 2$ nanotubes arrays. Nano Letters, 2007. 7(1): p. 69-74.

156. Paulose, M., K. Shankar, S. Yoriya, H.E. Prakasam, O.K. Varghese, G.K. Mor, T.A. Latempa, A. Fitzgerald, and C.A. Grimes, Anodic growth of highly ordered $\mathrm{TiO}_{2}$ nanotube arrays to $134 \mathrm{mu} \mathrm{m}$ in length. Journal of Physical Chemistry B, 2006. 110(33): p. 16179-16184.

157. Prakasam, H.E., K. Shankar, M. Paulose, O.K. Varghese, and C.A. Grimes, A new benchmark for $\mathrm{TiO} 2$ nanotube array growth by anodization. Journal of Physical Chemistry C, 2007. 111(20): p. 7235-7241.

158. Ruan, C.M., M. Paulose, O.K. Varghese, G.K. Mor, and C.A. Grimes, Fabrication of highly ordered TiO2 nanotube arrays using an organic electrolyte. Journal of Physical Chemistry B, 2005. 109(33): p. 15754-15759.

159. Paulose, M., H.E. Prakasam, O.K. Varghese, L. Peng, K.C. Popat, G.K. Mor, T.A. Desai, and C.A. Grimes, TiO2 nanotube arrays of $1000 \mathrm{mu}$ m length by anodization of titanium foil: Phenol red diffusion. Journal of Physical Chemistry C, 2007. 111(41): p. 14992-14997.

160. Stergiopoulos, T., A. Ghicov, V. Likodimos, D.S. Tsoukleris, J. Kunze, P. Schmuki, and P. Falaras, Dye-sensitized solar cells based on thick highly ordered $\mathrm{TiO}(2)$ nanotubes produced by controlled anodic oxidation in non-aqueous electrolytic media. Nanotechnology, 2008. 19(23).

161. Macak, J.M., H. Tsuchiya, A. Ghicov, and P. Schmuki, Dye-sensitized anodic TiO2 nanotubes. Electrochemistry Communications, 2005. 7(11): p. 1133-1137.

162. Paulose, M., K. Shankar, O.K. Varghese, G.K. Mor, B. Hardin, and C.A. Grimes, Backside illuminated dye-sensitized solar cells based on titania nanotube array electrodes. Nanotechnology, 2006. 17(5): p. 1446-1448.

163. Jennings, J.R., A. Ghicov, L.M. Peter, P. Schmuki, and A.B. Walker, Dye-sensitized solar cells based on oriented $\mathrm{TiO} 2$ nanotube arrays: Transport, trapping, and transfer 
of electrons. Journal of the American Chemical Society, 2008. 130(40): p. 13364-13372.

164. Ghicov, A., S.P. Albu, R. Hahn, D. Kim, T. Stergiopoulos, J. Kunze, C.A. Schiller, P. Falaras, and P. Schmuki, TiO2 Nanotubes in Dye-Sensitized Solar Cells: Critical Factors for the Conversion Efficiency. Chemistry-an Asian Journal, 2009. 4(4): p. 520525.

165. Stergiopoulos, T., A. Valota, V. Likodimos, T. Speliotis, D. Niarchos, P. Skeldon, G.E. Thompson, and P. Falaras, Dye-sensitization of self-assembled titania nanotubes prepared by galvanostatic anodization of $\mathrm{Ti}$ sputtered on conductive glass. Nanotechnology, 2009. 20(36).

166. Grimes, C.A., Synthesis and application of highly ordered arrays of $\mathrm{TiO} 2$ nanotubes. Journal of Materials Chemistry, 2007. 17(15): p. 1451-1457.

167. Mor, G.K., K. Shankar, M. Paulose, O.K. Varghese, and C.A. Grimes, Use of highlyordered TiO2 nanotube arrays in dye-sensitized solar cells. Nano Letters, 2006. 6(2): p. 215-218.

168. Park, J.H., T.W. Lee, and M.G. Kang, Growth, detachment and transfer of highlyordered $\mathrm{TiO}(2)$ nanotube arrays: use in dye-sensitized solar cells. Chemical Communications, 2008(25): p. 2867-2869.

169. Li, J.G., T. Ishigaki, and X.D. Sun, Anatase, brookite, and rutile nanocrystals via redox reactions under mild hydrothermal conditions: Phase-selective synthesis and physicochemical properties. Journal of Physical Chemistry C, 2007. 111(13): p. 49694976.

170. Chou, C.S., M.G. Guo, K.H. Liu, and Y.S. Chen, Preparation of TiO2 particles and their applications in the light scattering layer of a dye-sensitized solar cell. Applied Energy, 2012. 92: p. 224-233.

171. Fang, W.Q., X.H. Yang, H.J. Zhu, Z. Li, H.J. Zhao, X.D. Yao, and H.G. Yang, Yolk@shell anatase TiO2 hierarchical microspheres with exposed $\{001\}$ facets for highperformance dye sensitized solar cells. Journal of Materials Chemistry, 2012. 22(41): p. 22082-22089.

172. Lan, C.M., S.E. Liu, J.W. Shiu, J.Y. Hu, M.H. Lin, and E.W.G. Diau, Formation of sizetunable dandelion-like hierarchical rutile titania nanospheres for dye-sensitized solar cells. Rsc Advances, 2013. 3(2): p. 559-565.

173. Liao, J.Y., B.X. Lei, D.B. Kuang, and C.Y. Su, Tri-functional hierarchical TiO2 spheres consisting of anatase nanorods and nanoparticles for high efficiency dye-sensitized solar cells. Energy \& Environmental Science, 2011. 4(10): p. 4079-4085.

174. Liao, J.Y., H.P. Lin, H.Y. Chen, D.B. Kuang, and C.Y. Su, High-performance dyesensitized solar cells based on hierarchical yolk-shell anatase TiO2 beads. Journal of Materials Chemistry, 2012. 22(4): p. 1627-1633.

175. Sheng, J., L.H. Hu, W.X. Li, L.E. Mo, H.J. Tian, and S.Y. Dai, Formation of singlecrystalline rutile $\mathrm{TiO} 2$ splitting microspheres for dye-sensitized solar cells. Solar Energy, 2011. 85(11): p. 2697-2703.

176. Sun, Z.Q., J.H. Kim, Y. Zhao, D. Attard, and S.X. Dou, Morphology-controllable 1D3D nanostructured $\mathrm{TiO} 2$ bilayer photoanodes for dye-sensitized solar cells. Chemical Communications, 2013. 49(10): p. 966-968.

177. Wu, D.P., F. Zhu, J.M. Li, H. Dong, Q. Li, K. Jiang, and D.S. Xu, Monodisperse TiO2 
hierarchical hollow spheres assembled by nanospindles for dye-sensitized solar cells. Journal of Materials Chemistry, 2012. 22(23): p. 11665-11671.

178. Yang, W.G., J.M. Li, Y.L. Wang, F. Zhu, W.M. Shi, F.R. Wan, and D.S. Xu, A facile synthesis of anatase $\mathrm{TiO} 2$ nanosheets-based hierarchical spheres with over $90 \%\{001\}$ facets for dye-sensitized solar cells. Chemical Communications, 2011. 47(6): p. 18091811.

179. Ye, M.D., H.Y. Liu, C.J. Lin, and Z.Q. Lin, Hierarchical Rutile TiO2 Flower ClusterBased High Efficiency Dye-Sensitized Solar Cells via Direct Hydrothermal Growth on Conducting Substrates. Small, 2013. 9(2): p. 312-321.

180. Kim, Y.J., M.H. Lee, H.J. Kim, G. Lim, Y.S. Choi, N.G. Park, K. Kim, and W.I. Lee, Formation of Highly Efficient Dye-Sensitized Solar Cells by Hierarchical Pore Generation with Nanoporous TiO2 Spheres. Advanced Materials, 2009. 21(36): p. 3668-+.

181. Chen, D.H., F.Z. Huang, Y.B. Cheng, and R.A. Caruso, Mesoporous Anatase TiO2 Beads with High Surface Areas and Controllable Pore Sizes: A Superior Candidate for High-Performance Dye-Sensitized Solar Cells. Advanced Materials, 2009. 21(21): p. 2206-+.

182. Li, J.M., K. Cao, Q. Li, and D.S. Xu, Tetragonal faceted-nanorods of anatase TiO2 with a large percentage of active $\{100\}$ facets and their hierarchical structure. Crystengcomm, 2012. 14(1): p. 83-85.

183. Sommeling, P.M., B.C. O'Regan, R.R. Haswell, H.J.P. Smit, N.J. Bakker, J.J.T. Smits, J.M. Kroon, and J.A.M. van Roosmalen, Influence of a TiCl4 post-treatment on nanocrystalline TiO2 films in dye-sensitized solar cells. Journal of Physical Chemistry B, 2006. 110(39): p. 19191-19197.

184. Zeng, L.Y., S.Y. Dai, K.J. Wang, X. Pan, C.W. Shi, and L. Guo, Mechanism of enhanced performance of dye-sensitized solar cell based TiO2 films treated by titanium tetrachloride. Chinese Physics Letters, 2004. 21(9): p. 1835-1837.

185. Ito, S., K. Ishikawa, C.J. Wen, S. Yoshida, and T. Watanabe, Dye-sensitized photocells with meso-macroporous $\mathrm{TiO} 2$ film electrodes. Bulletin of the Chemical Society of Japan, 2000. 73(11): p. 2609-2614.

186. Kambe, S., S. Nakade, Y. Wada, T. Kitamura, and S. Yanagida, Effects of crystal structure, size, shape and surface structural differences on photo-induced electron transport in $\mathrm{TiO} 2$ mesoporous electrodes. Journal of Materials Chemistry, 2002. 12(3): p. $723-728$.

187. Diamant, Y., S. Chappel, S.G. Chen, O. Melamed, and A. Zaban, Core-shell nanoporous electrode for dye sensitized solar cells: the effect of shell characteristics on the electronic properties of the electrode. Coordination Chemistry Reviews, 2004. 248(13-14): p. 1271-1276.

188. Huang, S.Y., G. Schlichthorl, A.J. Nozik, M. Gratzel, and A.J. Frank, Charge recombination in dye-sensitized nanocrystalline TiO2 solar cells. Journal of Physical Chemistry B, 1997. 101(14): p. 2576-2582.

189. Nazeeruddin, M.K., A. Kay, I. Rodicio, R. Humphrybaker, E. Muller, P. Liska, N. Vlachopoulos, and M. Gratzel, CONVERSION OF LIGHT TO ELECTRICITY BY CISX2BIS(2,2'-BIPYRIDYL-4,4'-DICARBOXYLATE)RUTHENIUM(II)

CHARGE- 
TRANSFER SENSITIZERS ( $X=C L-, \quad B R-, \quad I-, \quad C N-$, AND SCN-) ON NANOCRYSTALLINE TIO2 ELECTRODES. Journal of the American Chemical Society, 1993. 115(14): p. 6382-6390.

190. Cahen, D., G. Hodes, M. Gratzel, J.F. Guillemoles, and I. Riess, Nature of photovoltaic action in dye-sensitized solar cells. Journal of Physical Chemistry B, 2000. 104(9): p. 2053-2059.

191. Diamant, Y., S.G. Chen, O. Melamed, and A. Zaban, Core-shell nanoporous electrode for dye sensitized solar cells: the effect of the SrTiO3 shell on the electronic properties of the TiO2 core. Journal of Physical Chemistry B, 2003. 107(9): p. 1977-1981.

192. Chen, S.G., S. Chappel, Y. Diamant, and A. Zaban, Preparation of Nb2O5 coated $\mathrm{TiO} 2$ nanoporous electrodes and their application in dye-sensitized solar cells. Chemistry of Materials, 2001. 13(12): p. 4629-4634.

193. Palomares, E., J.N. Clifford, S.A. Haque, T. Lutz, and J.R. Durrant, Control of charge recombination dynamics in dye sensitized solar cells by the use of conformally deposited metal oxide blocking layers. Journal of the American Chemical Society, 2003. 125(2): p. 475-482.

194. Wang, Z.S., T. Yamaguchi, H. Sugihara, and H. Arakawa, Significant efficiency improvement of the black dye-sensitized solar cell through protonation of TiO2 films. Langmuir, 2005. 21(10): p. 4272-4276.

195. Jung, H.S., J.-K. Lee, S. Lee, K.S. Hong, and H. Shin, Acid adsorption on $\mathrm{TiO} 2$ nanoparticles - An electrochemical properties study. Journal of Physical Chemistry C, 2008. 112(22): p. 8476-8480.

196. Feng, X., K. Shankar, M. Paulose, and C.A. Grimes, Tantalum-Doped Titanium Dioxide Nanowire Arrays for Dye-Sensitized Solar Cells with High Open-Circuit Voltage. Angewandte Chemie-International Edition, 2009. 48(43): p. 8095-8098.

197. Ko, K.H., Y.C. Lee, and Y.J. Jung, Enhanced efficiency of dye-sensitized TiO2 solar cells (DSSC) by doping of metal ions. Journal of Colloid and Interface Science, 2005. 283(2): p. 482-487.

198. Duan, Y., N. Fu, Q. Liu, Y. Fang, X. Zhou, J. Zhang, and Y. Lin, Sn-Doped TiO2 Photoanode for Dye-Sensitized Solar Cells. Journal of Physical Chemistry C, 2012. 116(16): p. 8888-8893.

199. Liu, J., H. Yang, W. Tan, X. Zhou, and Y. Lin, Photovoltaic performance improvement of dye-sensitized solar cells based on tantalum-doped $\mathrm{TiO} 2$ thin films. Electrochimica Acta, 2010. 56(1): p. 396-400.

200. Wang, M., S. Bai, A. Chen, Y. Duan, Q. Liu, D. Li, and Y. Lin, Improved photovoltaic performance of dye-sensitized solar cells by Sb-doped TiO2 photoanode. Electrochimica Acta, 2012. 77: p. 54-59.

201. Li, J.-Z., F.-T. Kong, G.-H. Wu, Y. Huang, W.-C. Chen, and S.-Y. Dai, TiO2/Dye/Electrolyte Interface Modification for Dye-Sensitized Solar Cells. Acta Physico-Chimica Sinica, 2013. 29(9): p. 1851-1864.

202. Archana, P.S., R. Jose, T.M. Jin, C. Vijila, M.M. Yusoff, and S. Ramakrishna, Structural and Electrical Properties of Nb-Doped Anatase TiO2 Nanowires by Electrospinning. Journal of the American Ceramic Society, 2010. 93(12): p. 4096-4102.

203. Chandiran, A.K., F. Sauvage, M. Casas-Cabanas, P. Comte, S.M. Zakeeruddin, and M. 
Graetzel, Doping a TiO2 Photoanode with Nb5+ to Enhance Transparency and Charge Collection Efficiency in Dye-Sensitized Solar Cells. Journal of Physical Chemistry C, 2010. 114(37): p. 15849-15856.

204. Lue, X., X. Mou, J. Wu, D. Zhang, L. Zhang, F. Huang, F. Xu, and S. Huang, Improved-Performance Dye-Sensitized Solar Cells Using Nb-Doped TiO2 Electrodes: Efficient Electron Injection and Transfer. Advanced Functional Materials, 2010. 20(3): p. 509-515.

205. Lee, J.-K. and M. Yang, Progress in light harvesting and charge injection of dyesensitized solar cells. Materials Science and Engineering: B, 2011. 176(15): p. 11421160.

206. Asahi, R., T. Morikawa, T. Ohwaki, K. Aoki, and Y. Taga, Visible-light photocatalysis in nitrogen-doped titanium oxides. Science, 2001. 293(5528): p. 269-271.

207. Burda, C., Y.B. Lou, X.B. Chen, A.C.S. Samia, J. Stout, and J.L. Gole, Enhanced nitrogen doping in TiO2 nanoparticles. Nano Letters, 2003. 3(8): p. 1049-1051.

208. Gole, J.L., J.D. Stout, C. Burda, Y.B. Lou, and X.B. Chen, Highly efficient formation of visible light tunable TiO2-xNx photocatalysts and their transformation at the nanoscale. Journal of Physical Chemistry B, 2004. 108(4): p. 1230-1240.

209. Ohno, T., T. Mitsui, and M. Matsumura, Photocatalytic activity of S-doped TiO2 photocatalyst under visible light. Chemistry Letters, 2003. 32(4): p. 364-365.

210. Sakthivel, S. and H. Kisch, Daylight photocatalysis by carbon-modified titanium dioxide. Angewandte Chemie-International Edition, 2003. 42(40): p. 4908-4911.

211. Yu, J.C., J.G. Yu, W.K. Ho, Z.T. Jiang, and L.Z. Zhang, Effects of F- doping on the photocatalytic activity and microstructures of nanocrystalline TiO2 powders. Chemistry of Materials, 2002. 14(9): p. 3808-3816.

212. Zhou, J.K., L. Lv, J. Yu, H.L. Li, P.-Z. Guo, H. Sun, and X.S. Zhao, Synthesis of selforganized polycrystalline F-doped $\mathrm{TiO} 2$ hollow microspheres and their photocatalytic activity under visible light. Journal of Physical Chemistry C, 2008. 112(14): p. 53165321.

213. Di Valentin, C., G. Pacchioni, A. Selloni, S. Livraghi, and E. Giamello, Characterization of paramagnetic species in $N$-doped TiO2 powders by EPR spectroscopy and DFT calculations. Journal of Physical Chemistry B, 2005. 109(23): p. 11414-11419.

214. Cao, A.N., Z. Liu, S.S. Chu, M.H. Wu, Z.M. Ye, Z.W. Cai, Y.L. Chang, S.F. Wang, Q.H. Gong, and Y.F. Liu, A Facile One-step Method to Produce Graphene-CdS Quantum Dot Nanocomposites as Promising Optoelectronic Materials. Advanced Materials, 2010. 22(1): p. 103-+.

215. Ding, S.J., J.S. Chen, D.Y. Luan, F.Y.C. Boey, S. Madhavi, and X.W. Lou, Graphenesupported anatase $\mathrm{TiO} 2$ nanosheets for fast lithium storage. Chemical Communications, 2011. 47(20): p. 5780-5782.

216. Chen, S., J.W. Zhu, X.D. Wu, Q.F. Han, and X. Wang, Graphene Oxide-MnO2 Nanocomposites for Supercapacitors. Acs Nano, 2010. 4(5): p. 2822-2830.

217. Guo, C.X., H.B. Yang, Z.M. Sheng, Z.S. Lu, Q.L. Song, and C.M. Li, Layered Graphene/Quantum Dots for Photovoltaic Devices. Angewandte Chemie-International Edition, 2010. 49(17): p. 3014-3017. 
218. Guo, S.J., S.J. Dong, and E.W. Wang, Three-Dimensional Pt-on-Pd Bimetallic Nanodendrites Supported on Graphene Nanosheet: Facile Synthesis and Used as an Advanced Nanoelectrocatalyst for Methanol Oxidation. Acs Nano, 2010. 4(1): p. 547555.

219. Pumera, M., Graphene-based nanomaterials for energy storage. Energy \& Environmental Science, 2011. 4(3): p. 668-674.

220. Sun, Y., Q. Wu, and G. Shi, Graphene based new energy materials. Energy \& Environmental Science, 2011. 4(4): p. 1113-1132.

221. Wang, Y., C.X. Guo, X. Wang, C. Guan, H.B. Yang, K.A. Wang, and C.M. Li, Hydrogen storage in a Ni-B nanoalloy-doped three-dimensional graphene material. Energy \& Environmental Science, 2011. 4(1): p. 195-200.

222. Zhang, X.Y., H.P. Li, X.L. Cui, and Y.H. Lin, Graphene/TiO2 nanocomposites: synthesis, characterization and application in hydrogen evolution from water photocatalytic splitting. Journal of Materials Chemistry, 2010. 20(14): p. 2801-2806.

223. Yen, M.Y., M.C. Hsiao, S.H. Liao, P.I. Liu, H.M. Tsai, C.C.M. Ma, N.W. Pu, and M.D. Ger, Preparation of graphene/multi-walled carbon nanotube hybrid and its use as photoanodes of dye-sensitized solar cells. Carbon, 2011. 49(11): p. 3597-3606.

224. Kim, S.R., M.K. Parvez, and M. Chhowalla, UV-reduction of graphene oxide and its application as an interfacial layer to reduce the back-transport reactions in dyesensitized solar cells. Chemical Physics Letters, 2009. 483(1-3): p. 124-127.

225. Zhou, K.F., Y.H. Zhu, X.L. Yang, X. Jiang, and C.Z. Li, Preparation of graphene-TiO2 composites with enhanced photocatalytic activity. New Journal of Chemistry, 2011. 35(2): p. 353-359.

226. De Marco, L., M. Manca, R. Giannuzzi, F. Malara, G. Melcarne, G. Ciccarella, I. Zama, R. Cingolani, and G. Gigli, Novel Preparation Method of TiO2-Nanorod-Based Photoelectrodes for Dye-Sensitized Solar Cells with Improved Light-Harvesting Efficiency. Journal of Physical Chemistry C, 2010. 114(9): p. 4228-4236.

227. Lin, H., C.P. Huang, W. Li, C. Ni, S.I. Shah, and Y.-H. Tseng, Size dependency of nanocrystalline $\mathrm{TiO} 2$ on its optical property and photocatalytic reactivity exemplified by 2-chlorophenol. Applied Catalysis B-Environmental, 2006. 68(1-2): p. 1-11.

228. Chae, S.Y., M.K. Park, S.K. Lee, T.Y. Kim, S.K. Kim, and W.I. Lee, Preparation of size-controlled $\mathrm{TiO} 2$ nanoparticles and derivation of optically transparent photocatalytic films. Chemistry of Materials, 2003. 15(17): p. 3326-3331.

229. Xu, N.P., Z.F. Shi, Y.Q. Fan, J.H. Dong, J. Shi, and M.Z.C. Hu, Effects of particle size of $\mathrm{TiO} 2$ on photocatalytic degradation of methylene blue in aqueous suspensions. Industrial \& Engineering Chemistry Research, 1999. 38(2): p. 373-379.

230. Chou, T.P., Q.F. Zhang, B. Russo, G.E. Fryxell, and G.Z. Cao, Titania particle size effect on the overall performance of dye-sensitized solar cells. Journal of Physical Chemistry C, 2007. 111(17): p. 6296-6302.

231. Bian, Z., J. Zhu, F. Cao, Y. Huo, Y. Lu, and H. Li, Solvothermal synthesis of welldefined TiO2 mesoporous nanotubes with enhanced photocatalytic activity. Chemical Communications, 2010. 46(44): p. 8451-8453.

232. Ferrari, A.C., J.C. Meyer, V. Scardaci, C. Casiraghi, M. Lazzeri, F. Mauri, S. Piscanec, D. Jiang, K.S. Novoselov, S. Roth, and A.K. Geim, Raman spectrum of graphene and 
graphene layers. Physical Review Letters, 2006. 97(18).

233. Lambert, T.N., C.A. Chavez, B. Hernandez-Sanchez, P. Lu, N.S. Bell, A. Ambrosini, T. Friedman, T.J. Boyle, D.R. Wheeler, and D.L. Huber, Synthesis and Characterization of Titania-Graphene Nanocomposites. Journal of Physical Chemistry C, 2009. 113(46): p. 19812-19823.

234. Stankovich, S., D.A. Dikin, R.D. Piner, K.A. Kohlhaas, A. Kleinhammes, Y. Jia, Y. Wu, S.T. Nguyen, and R.S. Ruoff, Synthesis of graphene-based nanosheets via chemical reduction of exfoliated graphite oxide. Carbon, 2007. 45(7): p. 1558-1565.

235. Lim, J., K. Choi, J.R. Rani, J.-S. Kim, C. Lee, J. Hoon Kim, and S. Chan Jun, Terahertz, optical, and Raman signatures of monolayer graphene behavior in thermally reduced graphene oxide films. Journal of Applied Physics, 2013. 113(18): p. --

236. Kudin, K.N., B. Ozbas, H.C. Schniepp, R.K. Prud'homme, I.A. Aksay, and R. Car, Raman Spectra of Graphite Oxide and Functionalized Graphene Sheets. Nano Letters, 2007. 8(1): p. 36-41.

237. Khai, T.V., D.S. Kwak, Y.J. Kwon, H.Y. Cho, T.N. Huan, H. Chung, H. Ham, C. Lee, N.V. Dan, N.T. Tung, and H.W. Kim, Direct production of highly conductive graphene with a low oxygen content by a microwave-assisted solvothermal method. Chemical Engineering Journal, 2013. 232(0): p. 346-355.

238. Lu, B., X. Ke, Z. Zhang, J. Hao, B. Zhang, and J. Tang, Amine-assisted solvothermal approach for the in situ synthesis of metal telluride/reduced graphene oxide. Carbon, 2013. 63(0): p. 157-164.

239. Tu, X., S. Luo, G. Chen, and J. Li, One-Pot Synthesis, Characterization, and Enhanced Photocatalytic Activity of a BiOBr-Graphene Composite. Chemistry - A European Journal, 2012. 18(45): p. 14359-14366.

240. Koo, B.K., D.Y. Lee, H.J. Kim, W.J. Lee, and J.S. Song, Seasoning effect of dyesensitized solar cells with different counter electrodes. Journal of Electroceramics, 2006. 17(1): p. 79-82.

241. Qian, J.F., P. Liu, Y. Xiao, Y. Jiang, Y.L. Cao, X.P. Ai, and H.X. Yang, TiO2-Coated Multilayered SnO2 Hollow Microspheres for Dye-Sensitized Solar Cells. Advanced Materials, 2009. 21(36): p. 3663-+.

242. Wang, Q., J.E. Moser, and M. Gratzel, Electrochemical impedance spectroscopic analysis of dye-sensitized solar cells. Journal of Physical Chemistry B, 2005. 109(31): p. 14945-14953.

243. Yan, K., Y. Qiu, W. Chen, M. Zhang, and S. Yang, A double layered photoanode made of highly crystalline $\mathrm{TiO} 2$ nanooctahedra and agglutinated mesoporous $\mathrm{TiO} 2$ microspheres for high efficiency dye sensitized solar cells. Energy \& Environmental Science, 2011. 4(6): p. 2168-2176.

244. Yang, H., G.H. Guai, C. Guo, Q. Song, S.P. Jiang, Y. Wang, W. Zhang, and C.M. Li, NiO/Graphene Composite for Enhanced Charge Separation and Collection in p-Type Dye Sensitized Solar Cell. Journal of Physical Chemistry C, 2011. 115(24): p. 1220912215.

245. Kern, R., R. Sastrawan, J. Ferber, R. Stangl, and J. Luther, Modeling and interpretation of electrical impedance spectra of dye solar cells operated under open-circuit conditions. Electrochimica Acta, 2002. 47(26): p. 4213-4225. 
246. Kuang, D., J. Brillet, P. Chen, M. Takata, S. Uchida, H. Miura, K. Sumioka, S.M. Zakeeruddin, and M. Gratzel, Application of highly ordered TiO2 nanotube arrays in flexible dye-sensitized solar cells. Acs nano, 2008. 2(6): p. 1113-1116.

247. Fan, J.J., S.W. Liu, and J.G. Yu, Enhanced photovoltaic performance of dye-sensitized solar cells based on TiO2 nanosheets/graphene composite films. Journal of Materials Chemistry, 2012. 22(33): p. 17027-17036.

248. Madhavan, A.A., S. Kalluri, D.K. Chacko, T.A. Arun, S. Nagarajan, K.R.V. Subramanian, A.S. Nair, S.V. Nair, and A. Balakrishnan, Electrical and optical properties of electrospun TiO2-graphene composite nanofibers and its application as DSSC photo-anodes. Rsc Advances, 2012. 2(33): p. 13032-13037.

249. Song, J.L., Z.Y. Yin, Z.J. Yang, P. Amaladass, S.X. Wu, J. Ye, Y. Zhao, W.Q. Deng, H. Zhang, and X.W. Liu, Enhancement of Photogenerated Electron Transport in DyeSensitized Solar Cells with Introduction of a Reduced Graphene Oxide-TiO2 Junction. Chemistry-a European Journal, 2011. 17(39): p. 10832-10837.

250. Zhu, P.N., A.S. Nair, S.J. Peng, S.Y. Yang, and S. Ramakrishna, Facile Fabrication of TiO2-Graphene Composite with Enhanced Photovoltaic and Photocatalytic Properties by Electrospinning. Acs Applied Materials \& Interfaces, 2012. 4(2): p. 581-585.

251. Bell, N.J., H.N. Yun, A.J. Du, H. Coster, S.C. Smith, and R. Amal, Understanding the Enhancement in Photoelectrochemical Properties of Photocatalytically Prepared TiO2Reduced Graphene Oxide Composite. Journal of Physical Chemistry C, 2011. 115(13): p. 6004-6009.

252. He, Z.M., J. Liu, Y. Qiao, C.M. Li, and T.T.Y. Tan, Architecture Engineering of Hierarchically Porous Chitosan/Vacuum-Stripped Graphene Scaffold as Bioanode for High Performance Microbial Fuel Cell. Nano Letters, 2012. 12(9): p. 4738-4741.

253. Dang, X.D., A.B. Tamayo, J. Seo, C.V. Hoven, B. Walker, and T.Q. Nguyen, Nanostructure and Optoelectronic Characterization of Small Molecule Bulk Heterojunction Solar Cells by Photoconductive Atomic Force Microscopy. Advanced Functional Materials, 2010. 20(19): p. 3314-3321.

254. Dante, M., J. Peet, and T.Q. Nguyen, Nanoscale charge transport and internal structure of bulk heterojunction conjugated polymer/fullerene solar cells by scanning probe microscopy. Journal of Physical Chemistry C, 2008. 112(18): p. 7241-7249.

255. Guide, M., X.D. Dang, and T.Q. Nguyen, Nanoscale Characterization of Tetrabenzoporphyrin and Fullerene-Based Solar Cells by Photoconductive Atomic Force Microscopy. Advanced Materials, 2011. 23(20): p. 2313-+.

256. Bolsée, J.-C., W.D. Oosterbaan, L. Lutsen, D. Vanderzande, and J. Manca, The Importance of Bridging Points for Charge Transport in Webs of Conjugated Polymer Nanofibers. Advanced Functional Materials, 2013. 23(7): p. 862-869.

257. Dang, X.D., M. Dante, and T.Q. Nguyen, Morphology and conductivity modification of poly(3,4-ethylenedioxythiophene):poly(styrene sulfonate) films induced by conductive atomic force microscopy measurements. Applied Physics Letters, 2008. 93(24).

258. Hunter, S. and T.D. Anthopoulos, Observation of Unusual, Highly Conductive Grain Boundaries in High-Mobility Phase Separated Organic Semiconducting Blend Films Probed by Lateral-Transport Conductive-AFM. Advanced Materials, 2013: p. n/a-n/a.

259. Kelley, T.W., E. Granstrom, and C.D. Frisbie, Conducting Probe Atomic Force 
Microscopy: A Characterization Tool for Molecular Electronics. Advanced Materials, 1999. 11(3): p. 261-264.

260. Yang, M., B. Ding, and J.-K. Lee, Surface Electrochemical Properties of Niobiumdoped Titanium Dioxide Nanorods and Their Effect on Carrier Collection Efficiency of Dye Sensitized Solar Cells. Journal of Power Sources, (0).

261. Alexeev, A. and J. Loos, Conductive atomic force microscopy (C-AFM) analysis of photoactive layers in inert atmosphere. Organic Electronics, 2008. 9(1): p. 149-154.

262. Dante, M., C. Yang, B. Walker, F. Wudl, and T.Q. Nguyen, Self-Assembly and ChargeTransport Properties of a Polythiophene-Fullerene Triblock Copolymer. Advanced Materials, 2010. 22(16): p. 1835-+.

263. Douheret, O., L. Lutsen, A. Swinnen, M. Breselge, K. Vandewal, L. Goris, and J. Manca, Nanoscale electrical characterization of organic photovoltaic blends by conductive atomic force microscopy. Applied Physics Letters, 2006. 89(3).

264. MacDonald, G.A., R.A. Veneman, D. Placencia, and N.R. Armstrong, Electrical Property Heterogeneity at Transparent Conductive Oxide/Organic Semiconductor Interfaces: Mapping Contact Ohmicity Using Conducting-Tip Atomic Force Microscopy. Acs nano, 2012. 6(11): p. 9623-9636.

265. Reid, O.G., K. Munechika, and D.S. Ginger, Space charge limited current measurements on conjugated polymer films using conductive atomic force microscopy. Nano Letters, 2008. 8(6): p. 1602-1609.

266. Coffey, D.C., O.G. Reid, D.B. Rodovsky, G.P. Bartholomew, and D.S. Ginger, Mapping Local Photocurrents in Polymer/Fullerene Solar Cells with Photoconductive Atomic Force Microscopy. Nano Letters, 2007. 7(3): p. 738-744.

267. Rice, A.H., R. Giridharagopal, S.X. Zheng, F.S. Ohuchi, D.S. Ginger, and C.K. Luscombe, Controlling Vertical Morphology within the Active Layer of Organic Photovoltaics Using Poly(3-hexylthiophene) Nanowires and Phenyl-C61-butyric Acid Methyl Ester. Acs nano, 2011. 5(4): p. 3132-3140.

268. Tsoi, W.C., P.G. Nicholson, J.S. Kim, D. Roy, T.L. Burnett, C.E. Murphy, J. Nelson, D.D.C. Bradley, J.-S. Kim, and F.A. Castro, Surface and subsurface morphology of operating nanowire:fullerene solar cells revealed by photoconductive-AFM. Energy \& Environmental Science, 2011. 4(9): p. 3646-3651.

269. Huang, Y., S.Y. Dai, S.H. Chen, C.N. Zhang, Y.F. Sui, S.F. Xiao, and L.H. Hu, Theoretical modeling of the series resistance effect on dye-sensitized solar cell performance. Applied Physics Letters, 2009. 95(24).

270. Chang, W.C., Y.Y. Cheng, W.C. Yu, Y.C. Yao, C.H. Lee, and H.H. Ko, Enhancing performance of $\mathrm{ZnO}$ dye-sensitized solar cells by incorporation of multiwalled carbon nanotubes. Nanoscale Research Letters, 2012. 7: p. 1-7.

271. Zhu, G., L.K. Pan, J. Yang, X.J. Liu, H.C. Sun, and Z. Sun, Electrospun nest-shaped TiO2 structures as a scattering layer for dye sensitized solar cells. Journal of Materials Chemistry, 2012. 22(46): p. 24326-24329.

272. Hoshikawa, T., M. Yamada, R. Kikuchi, and K. Eguchi, Impedance analysis of internal resistance affecting the photoelectrochemical performance of dye-sensitized solar cells. Journal of the Electrochemical Society, 2005. 152(2): p. E68-E73.

273. Wold, D.J. and C.D. Frisbie, Fabrication and characterization of metal-molecule-metal 
junctions by conducting probe atomic force microscopy. Journal of the American Chemical Society, 2001. 123(23): p. 5549-5556.

274. Woellner, C.F., J.A. Freire, M. Guide, and T.Q. Nguyen, The theoretical current-voltage dependence of a non-degenerate disordered organic material obtained with conductive atomic force microscopy. Journal of Chemical Physics, 2011. 135(8).

275. Bessergenev, V., High-temperature anomalies of dielectric constant in TiO2 thin films. Materials Research Bulletin, 2009. 44(8): p. 1722-1728.

276. Fan, K., T.Y. Peng, J.N. Chen, X.H. Zhang, and R.J. Li, A simple preparation method for quasi-solid-state flexible dye-sensitized solar cells by using sea urchin-like anatase TiO2 microspheres. Journal of Power Sources, 2013. 222: p. 38-44.

277. Wu, X., G.Q. Lu, and L.Z. Wang, Effect of sodium on photovoltaic properties of dyesensitized solar cells assembled with anatase $\mathrm{TiO} 2$ nanosheets with exposed $\{001\}$ facets. Journal of Colloid and Interface Science, 2013. 391: p. 70-73.

278. Xue, B., T. Sun, F. Mao, L.C. Sun, W. Yang, Z.D. Xu, and X. Zhang, Facile synthesis of mesoporous core-shell $\mathrm{TiO} 2$ nanostructures from TiCl3. Materials Research Bulletin, 2011. 46(9): p. 1524-1529.

279. Zhou, J., G.L. Zhao, B. Song, and G.R. Han, Solvent-controlled synthesis of threedimensional TiO2 nanostructures via a one-step solvothermal route. Crystengcomm, 2011. 13(7): p. 2294-2302.

280. Wang, C.C. and J.Y. Ying, Sol-gel synthesis and hydrothermal processing of anatase and rutile titania nanocrystals. Chemistry of Materials, 1999. 11(11): p. 3113-3120.

281. Penn, R.L. and J.F. Banfield, Morphology development and crystal growth in nanocrystalline aggregates under hydrothermal conditions: Insights from titania. Geochimica Et Cosmochimica Acta, 1999. 63(10): p. 1549-1557.

282. Lu, G.W., C. Li, and G.Q. Shi, Synthesis and characterization of 3D dendritic gold nanostructures and their use as substrates for surface-enhanced raman scattering. Chemistry of Materials, 2007. 19(14): p. 3433-3440.

283. Service, R.F., Solar cells - Tricks for beating the heat help panels see the light. Science, 2003. 300(5623): p. 1219-1219.

284. Park, H., W.R. Kim, C. Yang, H.G. Kim, and W.Y. Choi, Effect of a Fullerene Derivative on the Performance of TiO2-Nanotube-Based Dye-Sensitized Solar Cells. Journal of Nanoscience and Nanotechnology, 2012. 12(2): p. 1535-1538.

285. Chen, T., G.H. Guai, C. Gong, W.H. Hu, J.X. Zhu, H.B. Yang, Q.Y. Yan, and C.M. Li, Thermoelectric Bi2Te3-improved charge collection for high-performance dye-sensitized solar cells. Energy \& Environmental Science, 2012. 5(4): p. 6294-6298.

286. Nattestad, A., M. Ferguson, R. Kerr, Y.B. Cheng, and U. Bach, Dye-sensitized nickel(II) oxide photocathodes for tandem solar cell applications. Nanotechnology, 2008. 19(29).

287. Nattestad, A., A.J. Mozer, M.K.R. Fischer, Y.B. Cheng, A. Mishra, P. Bauerle, and U. Bach, Highly efficient photocathodes for dye-sensitized tandem solar cells. Nature Materials, 2010. 9(1): p. 31-35.

288. Brennan, L.J., M.T. Byrne, M. Bari, and Y.K. Gun'ko, Carbon Nanomaterials for DyeSensitized Solar Cell Applications: A Bright Future. Advanced Energy Materials, 2011. 1(4): p. 472-485.

289. Chen, P.Y., C.P. Lee, R. Vittal, and K.C. Ho, A quasi solid-state dye-sensitized solar 
cell containing binary ionic liquid and polyaniline-loaded carbon black. Journal of Power Sources, 2010. 195(12): p. 3933-3938.

290. Lee, C.P., P.Y. Chen, R. Vittal, and K.C. Ho, Iodine-free high efficient quasi solid-state dye-sensitized solar cell containing ionic liquid and polyaniline-loaded carbon black. Journal of Materials Chemistry, 2010. 20(12): p. 2356-2361. 